Florida International University FIU Digital Commons

6-21-2018

\title{
Public Service Values and Disparate Performance: The Case of Section 8 Housing Choice Voucher (HCV) Program
}

Melissa Gomez Hernandez

mgome255@fiu.edu

DOI: 10.25148 /etd.FIDC006849

Follow this and additional works at: https://digitalcommons.fiu.edu/etd

Part of the Other Public Affairs, Public Policy and Public Administration Commons, Policy Design, Analysis, and Evaluation Commons, Public Administration Commons, and the Public Affairs Commons

\section{Recommended Citation}

Hernandez, Melissa Gomez, "Public Service Values and Disparate Performance: The Case of Section 8 Housing Choice Voucher (HCV) Program" (2018). FIU Electronic Theses and Dissertations. 3785.

https://digitalcommons.fiu.edu/etd/3785 


\section{FLORIDA INTERNATIONAL UNIVERSITY}

Miami, Florida

PUBLIC SERVICE VALUES AND DISPARATE PERFORMANCE: THE CASE OF SECTION 8 HOUSING CHOICE VOUCHER (HCV) PROGRAM

A dissertation submitted in partial fulfillment of the

Requirements for the degree of

DOCTOR OF PHILOSOPHY

in

PUBLIC AFFAIRS

by

Melissa Gomez Hernandez

2018 
To: Dean John F. Stack, Jr.

Steven J. Green School of International and Public Affairs

This dissertation, written by Melissa Gomez Hernandez, and entitled Public Service Values and Disparate Performance: The Case of Section 8 Housing Choice Voucher (HCV) Program, having been approved in respect to style and intellectual content, is referred to you for judgment.

We have read this dissertation and recommend that it be approved.

$\begin{array}{r}\hline \text { Shaoming Cheng } \\ \hline \text { Susannah B. Ali } \\ \hline \text { Matthew D. Marr } \\ \hline \text { Mohamad G. Alkadry, Major Professor }\end{array}$

Date of Defense: June 21, 2018

The dissertation of Melissa Gomez Hernandez is approved.

Dean John F. Stack, Jr.

School of International and Public Affairs

Andrés G. Gil

Vice President for Research and Economic Development and Dean of the University Graduate School

Florida International University, 2018 


\section{DEDICATION}

I dedicate this dissertation to my sister, Susan Gomez Hernandez, and my friend, Teresa. To my nuclear families, Gomez Hernandez and Romero. To my numerous chosen

family members, spread across the United States and Colombia. I am forever grateful for your support, patience, love, and admiration for my academic path. 


\section{ACKNOWLEDGMENTS}

To my dissertation committee members, Dr. Shaoming Cheng, Dr. Matthew D. Marr, and Dr. Susannah Ali thank you for your permanent support and assistance along the way. Your presence and prompt responses helped me overcome every obstacle of the way. To Dr. Mohamad G. Alkadry, my dissertation advisor, I am forever grateful, not only for your guidance but for giving me the freedom to explore and remain intellectually curious. There was never an unanswered question, but better than that, there was never an unasked one.

To the Department of Public Policy and Administration staff and faculty, my fellow Ph.D. Students at FIU, thank you for enriching my academic life and caring for me during my doctoral quest. To Dr. Paavo Monkkonen, at the Department of Urban Planning at the Luskin School of Public Affairs, and my Fall 2016 classmates at the University of California, Los Angeles, thank you for making me a better scholar.

To Public Housing Authorities and Section $8 \mathrm{HCV}$ Program administrators that participated in this study, you have my most profound gratitude forever. To the Fulbright Scholarships Program for opening a world of beautiful and challenging experiences, and providing opportunities for both, individuals like me, and their home countries.

Finally, I want to salute the logistic support of Ms. Gladis Betancourt in Los Angeles, California. Fieldwork obstacles turned more amicable and pleasant surrounded by family. 


\title{
ABSTRACT OF THE DISSERTATION \\ PUBLIC SERVICE VALUES AND DISPARATE PERFORMANCE: THE CASE OF SECTION 8 HOUSING CHOICE VOUCHER (HCV) PROGRAM
}

\author{
by \\ Melissa Gomez Hernandez \\ Florida International University, 2018 \\ Miami, Florida \\ Professor Mohamad G. Alkadry, Major Professor \\ Public administration scholars accept that public service values guide \\ administrators' behavior. This guidance also derives from social and cultural values that \\ motivate administrators' individual attitudes. A part of the field recognizes that public \\ servants play an active role during the implementation process through their daily use of \\ discretion. Nevertheless, public administrators' values and attitudes are rarely linked to \\ policy implementation and organizational performance. In consequence, public policy \\ evaluation seldom considers the role of values and attitudes of those implementing policy. \\ This study examines how public administrators' values and attitudes towards \\ citizens shape policy implementation and influence organizational and program \\ performance. The implementation and results of Section $8 \mathrm{HCV}$ Program serve as case \\ study to address the linkage between public service values and performance. The Section \\ $8 \mathrm{HCV}$ is the federal government's major program that assists low-income families, elderly \\ and disabled people to afford decent, safe, and sanitary housing in the private market. The \\ Program allows participants to choose any housing that meets its requirements.
}


This research hypothesizes that environmental and organizational factors impose a toll on organizational and policy performance, and that public administrators' values and attitudes towards recipients buffer some of these effects. The study employs a quantitative methods approach to examine and combine demographic characteristics of the communities that surround Public Housing Authorities -where the Section 8 Housing Choice Voucher Program is implemented-, statistic indicators of the local housing market, Section $8 \mathrm{HCV}$ structural factors of operation, levels of poverty and race desegregation in vouchers recipient, and the quality of their neighborhoods, to establish a correlation between Public Housing Authorities' poor performance and less advantageous environmental factors, and vice versa.

I conducted semi-structured interviews among Section $8 \mathrm{HCV}$ Program's case managers, directors and front-line practitioners in Public Housing Authorities in the states of Florida and California to identify the Public Service Values-based strategies that influence program's implementation, and both, organizational and program's performance.

The quantitative evidence collected and analyzed in this dissertation indicates that environmental and organizational factors impose a toll on Public Housing Authorities and Section $8 \mathrm{HCV}$ program's performance. Meanwhile, the qualitative portion of the study suggests that public administrators' values and attitudes towards recipients permeate the implementation process and influence Section $8 \mathrm{HCV}$ program's results. 


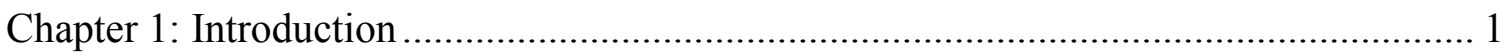

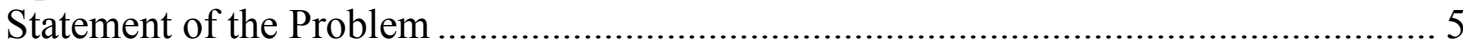

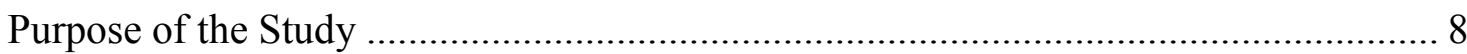

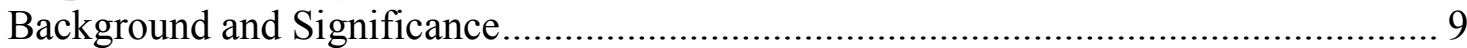

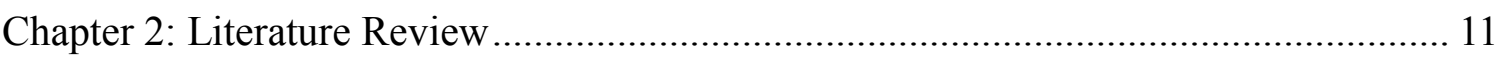

Public Administrators' Values and Attitudes in the Policy Implementation Process:

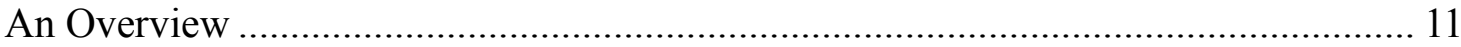

Public Service Values and Organizational Performance.............................................. 12

The Principle of Political Neutrality as Technical Expertise ....................................... 14

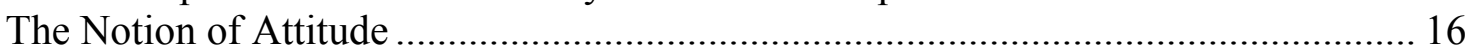

The Section 8 Housing Choice Voucher Program: Public Administrators' values and attitudes Influencing Performance and Policy Outcomes ............................................ 17

Chapter 3: Research Questions, Hypotheses, and Theoretical Framework ....................... 20

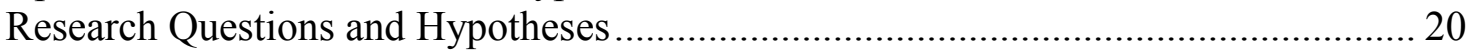

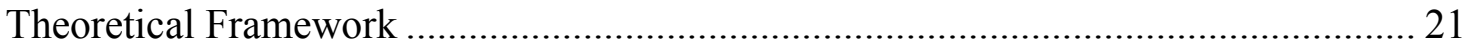

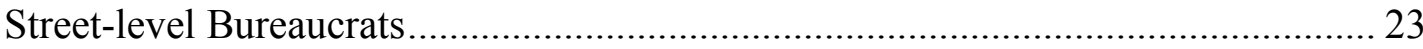

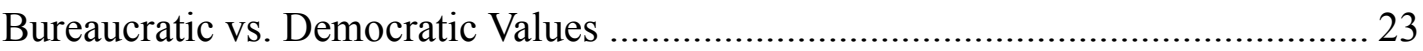

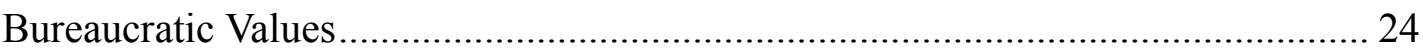

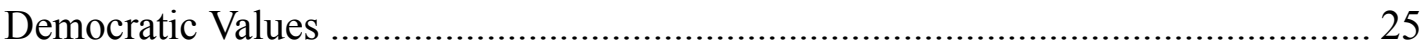

The Managerial Perspective and the 'Customer' Type ............................................ 26

Critical Theory, the Inquiry on the Notion of Neutrality, and the Category of

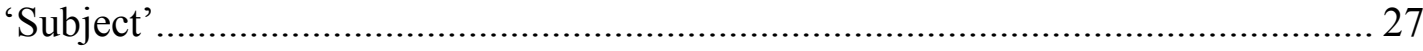

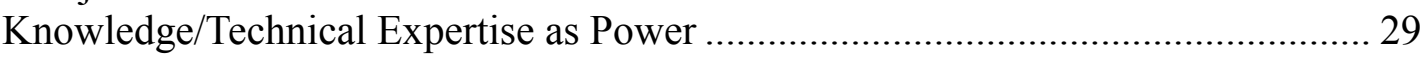

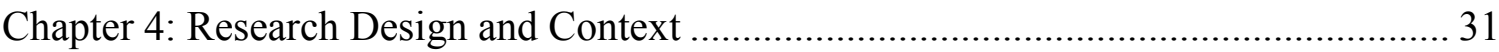

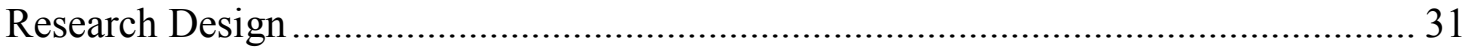

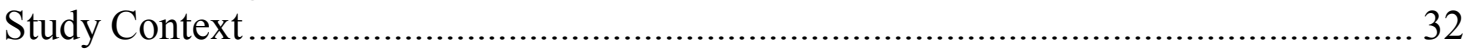

Housing Policy Trends in the Recent U.S. History ……........................................ 32

Public Housing Authorities and Section 8 HCV Program: Origin, Nature and

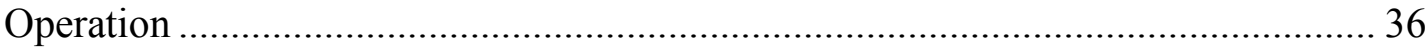

Methodological Stages of the Research ..................................................................... 41

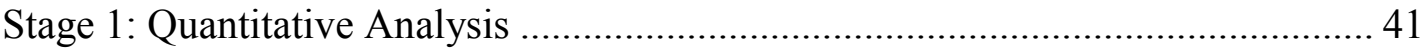

Unit of Analysis and Study Sample.................................................................. 42

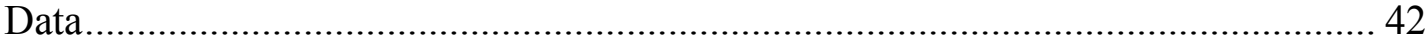

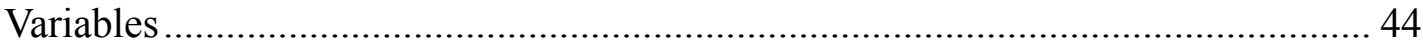

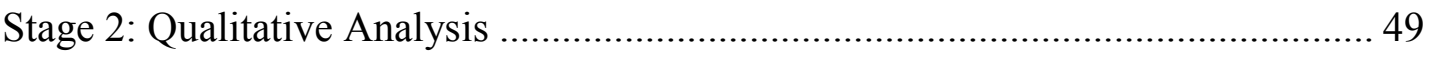

Unit of Analysis and Study Sample....................................................................... 49

Qualitative Research Strategy \& Data ........................................................................ 50

Rationale behind the Selection of the States of California and Florida....................... 51 
Chapter 5: Environmental and Organizational Influencers of Performance at PHAs and

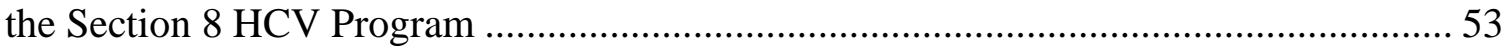

Descriptive Statistics .......................................................................................... 54

Independent Variables: Environmental and Organizational Influencers of

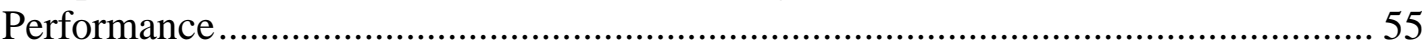

Dependent Variable 1: County Seat Public Housing Authority Score ....................... 56

Dependent Variable 2: The Section $8 \mathrm{HCV}$ program's Hardly-Controllable

Structural Factors (as predictor of performance) ......................................................5 59

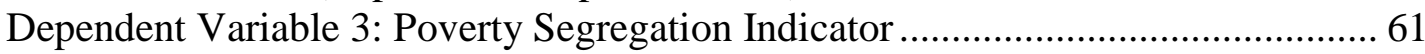

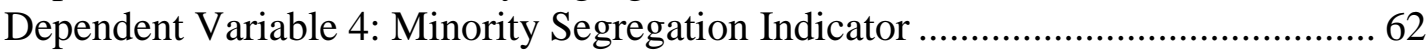

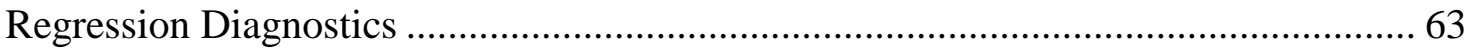

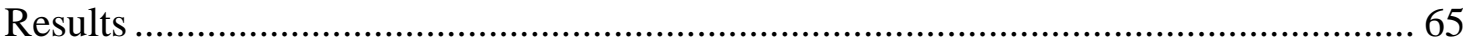

Model 1: Environmental and Organizational Influencers of PHAs' Performance.... 65 Model 1A: Environmental and Organizational Influencers of PHAs' Management

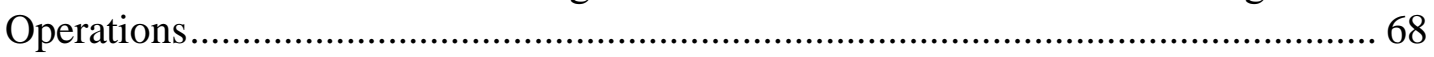

Model 1B: Environmental and Organizational Influencers of PHAs' Financial

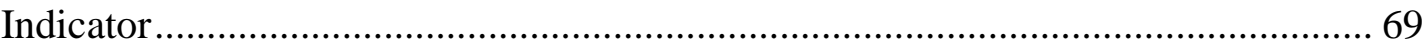

Model 1C: Environmental and Organizational Influencers of PHAs' Physical

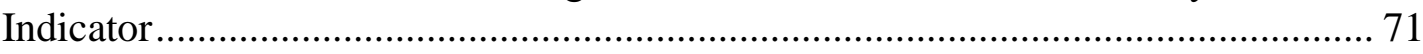

Model 2: Compounded Effect of Environmental and Organizational Influencers on the Section $8 \mathrm{HCV}$ program's hardly-controllable structural factors (as predictor of

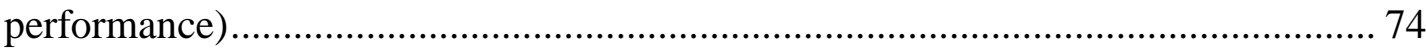

Model 3: Environmental and Organizational Influencers of Poverty Segregation Levels on Section 8 HCV Recipients ..................................................................... 76

Model 4: Environmental and Organizational Influencers of Racial Segregation Levels on Section 8 HCV Recipients …………………................................... 78

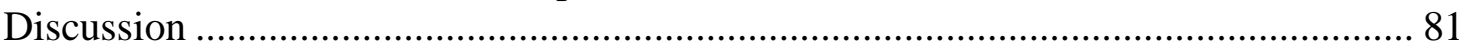

Influencers of Organizational Performance: Public Housing Authorities in the U.S.81 Predictors of Policy Performance: The Case of Section 8 HCV Program ................. 83 Influencers of Policy Outcomes: Addressing Poverty and Minority Segregation among Section 8 HCV Program's Recipients .......................................................... 84

Chapter 6: Public Administrators' Values and Attitudes towards Citizens during Section 8 HCV Program's Implementation Process ......................................................... 89

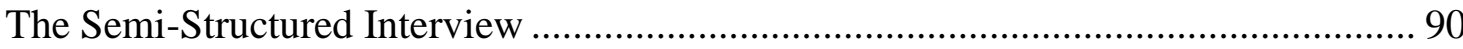

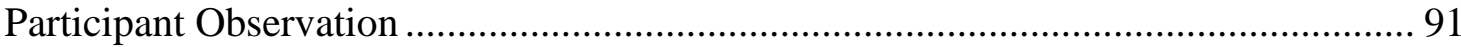

Selection and Depiction of the Study Participants ................................................... 92

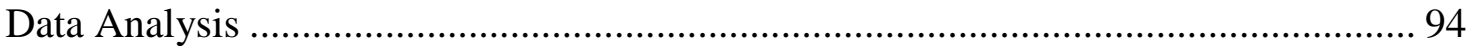

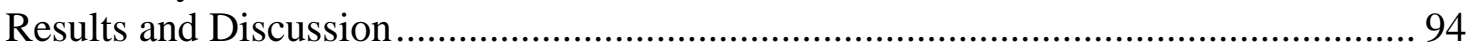

Reporting on Silence: An Archeology of Rejection ................................................. 94

High-Performance PHAs Administrators' Values and Attitudes towards Citizens during the Implementation Process of Section 8 HCV Program................................ 100

Analyzing Administrators' Interpretation of the Notion of Public Service Values 100 The "Balancing Act," or the Complexities of Selecting a Unique Set of Values ....... 104 Addressing the Importance of Bureaucratic and Managerial Values ....................... 104 
Navigating Between Bureaucratic and Democratic Values ................................... 108

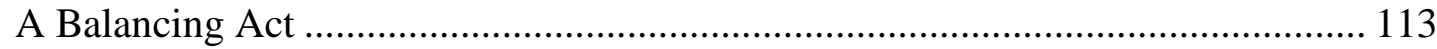

Where Are These Values Coming From?........................................................... 117

Political Neutrality and Technical Expertise as Source of Administrative Discretion 118

Notion and Scope of Political Neutrality According to Section 8 HCV Program's

Implementers

Technical Expertise as a Tool for Achieving Political Neutrality ............................ 121

The Parallel Avenue of Administrative Discretion ................................................. 123

The Demeanors that Challenge Neutrality ………………...................................... 127

Public Administrators' Attitudes towards Section 8 HCV Program's Recipients ..... 130

Life Happens.................................................................................................. 130

Representative Bureaucracy, or a Hypothesis on the Compassionate Rationale .... 133

Devolution, Democratic Values and Regulations: The Multiple Levels of

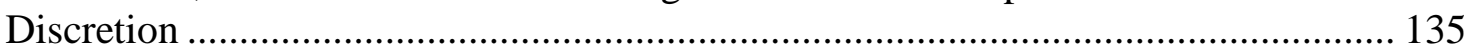

High Levels of Administrative Discretion............................................................ 137

Medium Levels of Administrative Discretion ....................................................... 139

Low Levels of Administrative Discretion ............................................................. 141

The Limits of the Administrative Discretion and the Signature Outcomes of the

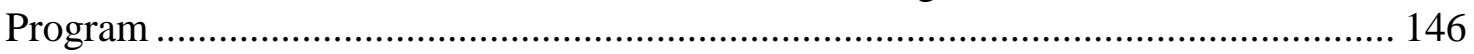

Neighborhood and Unit Quality .................................................................... 149

Race and Poverty Desegregation ..................................................................... 150

Obstacles to Section 8 HCV Program ................................................................. 152

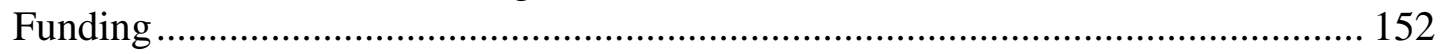

Tightness of Local Housing Markets.................................................................... 154

Limits to Recipients' Services Delivery ............................................................... 155

Landlords' Attitudes towards the Program and Voucher Holders ........................... 156

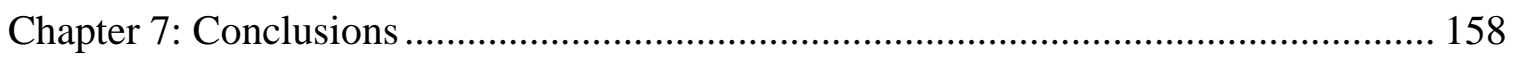

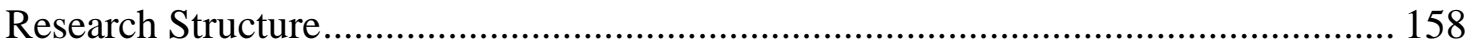

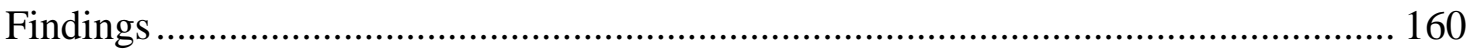

Contribution, Limitations and Future Research ....................................................... 164

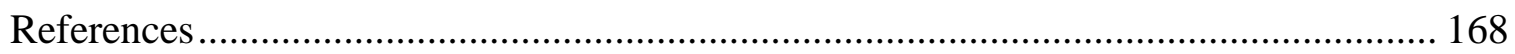

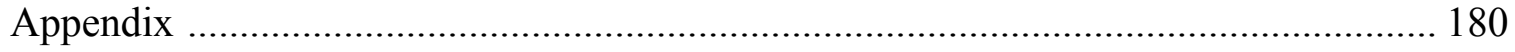

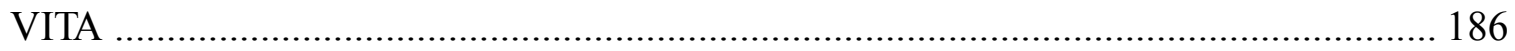


Table 1. Research Questions and Hypotheses ............................................................. 20

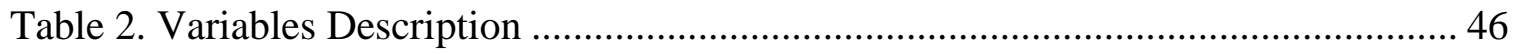

Table 3. Independent Variables: Environmental and Organizational Influencers of

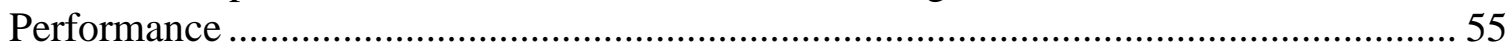

Table 4. Dependent Variable: County Seat Public Housing Authorities Performance

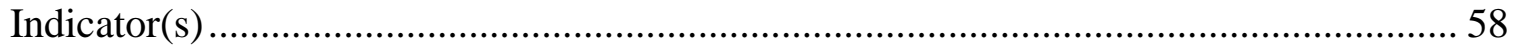

Table 5. Demographic Analysis of CS_PHAScore - Comparison of Mean Results........ 59

Table 6. Dependent Variable: Hardly Controllable Section 8 HCV Program's

Structural Factors (as predictor of performance) ........................................................... 60

Table 7. Constructing S8_StFactors using Principal Component Factoring (PCF).......... 61

Table 8. Dependent Variable: The Section 8 HCV Program's Hardly-Controllable

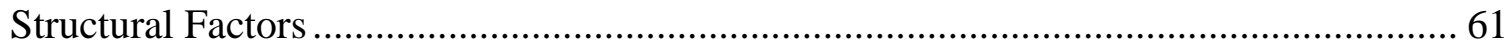

Table 9. Dependent Variable: Poverty Segregation Indicator .......................................... 62

Table 10. Dependent Variable: Minority Segregation Indicator ……................................ 63

Table 11. Environmental and Organizational Influencers of PHAs' Performance .......... 66

Table 12. Environmental and Organizational Influencers of PHAs' Management

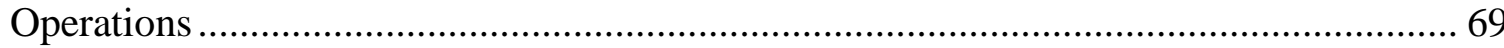

Table 13. Environmental and Organizational Influencers of PHAs' Financial Indicator. 71

Table 14. Environmental and Organizational Influencers of PHAs' Physical Indicator.. 73

Table 15. Compounded Effect of Environmental and Organizational Influencers on the Section $8 \mathrm{HCV}$ program's hardly-controllable structural factors (as predictor of performance).

Table 16. Environmental and Organizational Influencers of Poverty Segregation

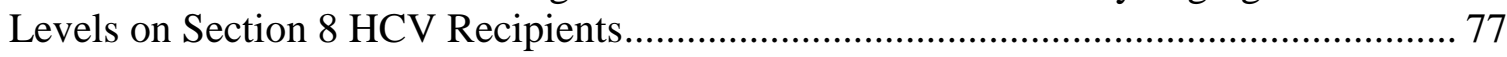

Table 17. Environmental and Organizational Influencers of Racial Segregation Levels on Section 8 HCV Recipients 
Table 18 - Depiction of Participants of the Study

Table 19. Section 8 HCV Program Levels of Administrative Discretion and Actions .. 136 


\section{LIST OF FIGURES}

FIGURE

PAGE

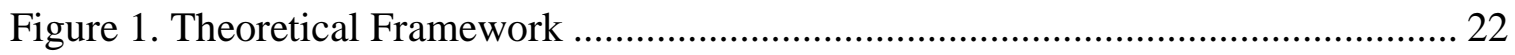

Figure 2. A Public Housing Authority's Structure ................................................... 37

Figure 3. Section 8 HCV Program Process................................................................ 40

Figure 4. Qualitative Research Strategy ............................................................. 51

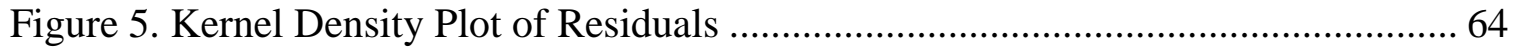

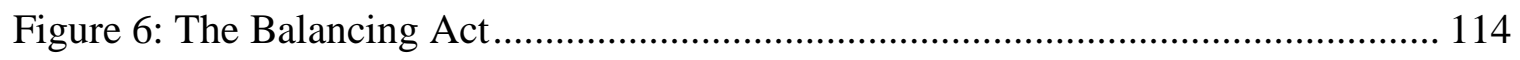




\section{LIST OF ABBREVIATIONS AND ACRONYMS}

\begin{tabular}{|c|c|}
\hline AMP & Asset Management Project \\
\hline CalWORKS & California Work Opportunity and Responsibility to Kids \\
\hline CFP & Capital Fund Program \\
\hline CFR & Code of Federal Regulations \\
\hline DCI & Distressed Community Index \\
\hline DPSS & Department of Public Social Services \\
\hline FASS & Financial Indicator Score \\
\hline FIU & Florida International University \\
\hline FMR & Fair Market Rents \\
\hline FSSP & Family Self-Sufficiency Program \\
\hline GR & General Relief \\
\hline HAP & Housing Assistance Payments Contract \\
\hline $\mathrm{HCV}$ & Housing Choice Voucher \\
\hline HPI & House Price Index \\
\hline HQS & Housing Quality Standards \\
\hline HUD & US Department of Housing and Urban Development \\
\hline HUD-VASH & Veterans Affairs Supportive Housing \\
\hline IMS & Inventory Management System \\
\hline IRB & Institutional Review Board \\
\hline MASS & Management Operations Indicator \\
\hline NHA & National Housing Act of 1934 \\
\hline NPA & New Public Administration \\
\hline
\end{tabular}




$\begin{array}{ll}\text { NPM } & \text { New Public Management } \\ \text { NPS } & \text { New Public Service } \\ \text { OLS } & \text { Ordinary Least Squared } \\ \text { PASS } & \text { Physical Indicator Score } \\ \text { PCF } & \text { Principal Component Factor Analysis } \\ \text { PHA } & \text { Public Housing Authority } \\ \text { PHAS } & \text { Public Housing Assessment System } \\ \text { QHWR } & \text { Quality Housing and Work Responsibility Act } \\ \text { R/ECAP } & \text { Racially or Ethnically Concentrated Areas of Poverty } \\ \text { RTA } & \text { Request for Tenancy Approval } \\ \text { SS } & \text { Social Security } \\ \text { VIF } & \text { Variance Inflation Factor }\end{array}$




\section{Chapter 1: Introduction}

In 1997, Sandra J. Newman and Ann B. Schnare determined that housing programs in the U.S. had failed to deliver on the promise of neighborhood quality to vulnerable citizens (Newman \& Schnare, 1997: 726). Nowadays, public housing programs continue to be affected by concentrated poverty and disproportionate rates of racial segregation of minority recipients (Austin Turner, 2003; Carlson, Haveman, Kaplan \& Wolfe, 2009; Deng 2007). The outcome disparities within housing programs in the United States are so notorious that even the most well regarded and successful housing policy initiative, the Section 8 Housing Choice Voucher Program, specifically created to tackle problems of poverty and minority concentration, also faces these difficulties (Deng, 2007: 22; Devine et al. 2003; Galvez, 2010: 6; Hartung and Henig 1997; Newman \& Schnare, 1997: 726; Pendall 2000; Varady \& Walker, 2000; Varady, 2010: 402).

In the midst of this policy failure (Deng, 2007: 22; Newman \& Schnare, 1997: 726), housing scholars explain Section 8 HCV program's unaccomplished goals, going from the existence of markets with serious housing shortages (Deng, 2007: 21), to racial discrimination in society (Pendall, 2000: 892), to program's internal inadequacies (Grigsby \& Bourassa, 2003: 982). Yet, a core question remains unasked and unanswered: Do public administrators' values and attitudes play a role in this policy failure?

Some indicators focus the attention on "administrative inefficiency at the local level" (Basolo \& Hastings, 2003; Katz \& Turner, 2001, Popkin \& Cunningham, 1999, in Marr, 2005: 86), the presence of a "troublesome bureaucracy" (Marr, 2005: 92), red tape (Grigsby \& Bourassa, 2003: 988), and evidence of landlords' complaints of the 'Bureaucratic System' in section 8 vouchers (Grigsby \& Bourassa, 2003: 988). 
Nevertheless, public administrators' part in policy implementation and organizational performance remains unexplored.

Public administration scholars accept that public values guide administrators' behavior (Andersen et al., 2012: 294). Such guidance also derives from "social and cultural values" (Molina, 2015: 49) that motivate administrators' individual attitudes. Public administrators' attitudes towards citizens accrue an affective component, the "emotional basis for serving others" (Knoke \& Wright-Isak, 1982 in Andersen et al. 2012: 295). For instance, apparently unimportant emotional and physical factors, such as mealtimes, are a significant predictor of ruling outcomes among judges, as important as inmates' past recidivism and participation in rehabilitation programs (The Economist, 2011). Public administrators' values also perform an important role during the implementation process (Elmore, 1979: 604; Matland, 2015: 49), where street level bureaucrats "shape public policy through their daily use of discretion" (Bastien, 2009: 665). In the same vein, public servants reflect their "values or interests in the goals being pursued more or less effectively by public organizations", resulting in administrators influencing performance as well (Fried, 1976: 15 in Talbot, 2010, 137).

Despite the evidence, policy implementation and organizational performance have been less frequently linked to public administrators' values and attitudes (Bastien, 2009). In consequence, the evaluation of any public policy seldom passes by the consideration of the role of public service values and attitudes of its implementers. Thus, the main research question of this study is: Do values and attitudes applied by public administrators to the implementation process of Section 8 HCV program influence recipients' access to high quality, affordable, non-racially segregated and non-poverty concentrated homes? 
In this dissertation, I analyze how public administrators' values and attitudes shape a given policy, overcoming the influence of environmental and organizational factors that impact both, organizational and program's performance. The unsatisfactory results of the American housing policy serve as case study. The case study examines the linkage between the Section 8 HCV Program staff's values and attitudes towards citizens -applied during the implementation process-, and three specific outcomes of the program: 1. the ability to provide decent and affordable housing; 2. the incidence of housing desegregation in terms of poverty and race, and 3. housing and neighborhood quality among program recipients.

The study has two stages that respond to two different operative questions. In the first stage, I use quantitative techniques to answer: If, and to what extent, do organizational and environmental conditions, such as demographics and political preferences of communities, economic factors, and racial disparities affect public organizations' performance and policy? Through the use of secondary data, I test how environmental factors (from political preferences, to geographic location, to housing market conditions), and some structural organizational conditions, impose a toll on PHAs and Section 8 HCV's performance. In the study, I also analyze how environmental and organizational factors affect the distinctive goal of poverty and race desegregation that first inspired the creation of the Section $8 \mathrm{HCV}$ program (Austin Turner, 2003: 1). The second stage takes advantage of the information collected in the first stage.

In the second stage, and after mapping and analyzing the influencing factors of PHAs and Section $8 \mathrm{HCV}$ program performance disparity, I analyze the predominant sets of public values and attitudes utilized by Section $8 \mathrm{HCV}$ program's directors, front-line staff and case managers to implement policy and overcome adverse environmental factors 
surrounding their organization and program. I conduct interviews with Section $8 \mathrm{HCV}$ program's staff at PHAs, along with ethnographic observation of public administrators' quotidian rapport with program recipients in the states of Florida and California. This stage responds to the second operative question: how do public administrators' preferred set of values and attitudes coincide with either positive or negative organizational and policy performance at the Section 8 HCV Program?

I expected to find matches between public administrators' individual responses to in-depth interviews about public service values and attitudes used by them when addressing citizens, and the results of the general quantitative analysis. I also expected to find that a more democratic set of values and 'holistic' attitudes (Marr, 2016) towards recipients would coincide with PHAs and Section $8 \mathrm{HCV}$ program's higher levels of performance. Conversely, more bureaucratic/managerial oriented set of values carried by public administrators would coincide with less positive or even negative results of the program.

The study fills several gaps in the Public Administration literature. Other authors previously addressed the importance of public service values and attitudes in public administrators' actions towards elected officials (Golden, 1998; Lindblom, 1977: 141; Ringquist, 1995; Yackee \& Yackee, 2006). This study incorporates the effects of administrators' actions on citizens/program recipients, adding citizenship to the politicsadministration dichotomy equation. In the same vein, public service values are seldom addressed throughout a practical policy case study (Bastien, 2009; Watkins-Hayes, 2009). Instead, values are approached as self-contained entities, with no surrounding policy context (Molina, 2015: 53). This research utilizes a policy case -the Section $8 \mathrm{HCV}$ program- and analyzes administrators' public service values and attitudes in actual 
implementation actions towards citizens and their influence on organizational and policy performance. Finally, this dissertation attempts to move the discussion about political neutrality of public administrators from a theoretical venue to a practical one.

\section{Statement of the Problem}

Public housing programs are affected by concentrated poverty and disproportionate rates of racial segregation of minority recipients (Austin Turner, 2003; Carlson, Haveman, Kaplan \& Wolfe, 2009; Deng 2007). Section 8 Housing Choice Voucher Program gives recipients the freedom to select the particular housing location and unit's characteristics that best suit their demands (Austin Turner, 2003: 1). Created to tackle poverty and minority concentration problems of public housing, Section $8 \mathrm{HCV}$ faces the same difficulties as its unit-based housing assistance counterparts (Deng, 2007: 22; Newman \& Schnare, 1997: 726; Varady \& Walker, 2000; Varady, 2010: 402). "Nearly 10 percent of voucher recipients in the 50 largest Metropolitan Statistical Areas lived in neighborhoods with poverty rates above 40 percent, and approximately 22 percent lived in tracts with poverty rates above 30 percent" (Galvez, 2010: 5).

These adverse outcomes have been attributed to market tightness (Austin Turner, 2003: 1; Deng, 2007: 22; Ross, Shlay \& Picon, 2012: 39; Williamson, Smith \& StrambiKramer, 2009: 121), budgeting causes (Austin Turner, 2003: 1), recipient households' preferences (Deng, 2007: 22), and landlords' racial and ethnic discrimination (Beck, 1996: 159). Nonetheless, the question of the role of individual policy implementers, i.e., frontline staff officials and case managers, has been largely overlooked.

The main research question of this study is: Do values and attitudes applied by public administrators' to the implementation process of Section 8 Housing Choice Voucher 
program influence recipients' access to high quality, affordable, non-racially and nonpoverty concentrated homes?

To answer this question, I test four hypotheses. First, I hypothesize that Public Housing Authorities and Section 8 Housing Choice Voucher Program nationwide display dissimilar performance that results in recipients' differentiated access to quality, affordable, non-racially, and non-poverty concentrated homes. Second, I hypothesize that such performance disparities are correlated to environmental, organizational, and policy factors, and that these factors impact both, PHAs and Section $8 \mathrm{HCV}$ performance. Third, I claim that an implementers' democratic-centered set of public values (those that address program recipients as citizens) and attitudes will coincide with positive policy outcomes regarding poverty/race desegregation and higher levels of housing and neighborhood quality. Conversely, I hypothesize that an orthodox/managerial/domination-oriented set of public values (those that address recipients as Client/Customer/subject) will coincide with negative policy outcomes in terms of the factors mentioned above.

To test these four hypotheses I employ a mixed methods approach. A direct causal relation between public administrators' values and attitudes, and organizational and policy performance does not apply in this study. The subjective condition of public servants' values and the existence of other factors that influence organizational and policy performance impedes this task. Nevertheless, this study hypothesizes that public administrators' implementation motivated by certain values and attitudes could coincide with a given organizational and policy outcome and vice versa.

I develop two consecutive and interdependent stages of the study. In the first stage I use quantitative techniques to identify the performance disparities in Section $8 \mathrm{HCV}$ 
Program. This stage of the study addresses the first research question: if, and to what extent, do organizational and environmental conditions, such as demographics and political preferences of communities, economic factors, and racial disparities affect public organizations' performance and policy? The fundamental aim is to determine and map the variations and discrepancies in PHAs and Section $8 \mathrm{HCV}$ programs results across the United States and to determine how environmental and organizational factors impact both, organizational and program's performance. The factors analyzed encompass five fundamental dimensions. The first three indicate historical program's success: 1. Poverty and race desegregation; 2. Neighborhood quality; and 3. Housing quality. While the other two dimensions speak for: 4. Section 8 Housing Choice Voucher Program structural factors, and 5. Demographic characteristics of surrounding communities. Ordinary Least Square method is utilized to address this operative question.

The second stage is a case study and takes advantage of the information collected in the first stage. I address the second research question: How do public administrators' preferred set of values and attitudes coincide with either positive or negative organizational and policy performance at the Section 8 HCV Program?

After mapping PHAs and Section $8 \mathrm{HCV}$ Program performance disparity nationwide, along with the environmental factors that cause such disparity at the county and county seat level, I determine the most predominant sets of public values and attitudes among Section $8 \mathrm{HCV}$ program officials (either more democratic or Orthodox/managerial/domination oriented). Through a qualitative approach, I find matches between public servants' individual responses to in-depth interviews, and the results of the quantitative analysis. This stage attempts to identify: 1. Public administrators' discursive 
devices towards citizens in terms of values and attitudes, specially their capitalization of technical expertise as source of discretion (Foucault, 1980), the rationales behind their attitudes (Alexander \& Stivers, 2010; Alkadry \& Blessett, 2010; Marr, 2016) and their utilized set of values, 2 . The perceived scope of public administrators' actions during the implementation process, including those possible constrictions posed by structural factors (Marr, 2016: 225), and, 3. Their perceived impact on policy outcomes and organizational performance.

Due to reasons of demographic diversity, environmental heterogeneities, housing market variabilities, and population, I selected the states of California and Florida for the case study.

\section{Purpose of the Study}

The goal of this study is to understand how public administrators apply values and attitudes towards citizens during the implementation process, overcoming difficult organizational and environmental conditions while influencing both, organizational and policy performance. To analyze this research problem, I address the correlation between environmental characteristics of communities surrounding public housing authorities that implement the Section 8 Housing Choice Voucher Program, and PHA's organizational performance. I also identify a number of Section $8 \mathrm{HCV}$ Program Structural Factors and their influence on PHAs and program's performance. My hypothesis is that such factors impose a toll on Public Housing Authorities and Section 8 HCV program's performance. Consequently, I identify which of these environmental and organizational factors influence the most, both, organizational and policy performance and provide feasible explanations from literature and observation. Finally, I use a qualitative approach to address public 
administrators' values and attitudes towards citizens, identifying coincidences between public administrators' behavior and the results of the quantitate analysis.

\section{Background and Significance}

The fundamental aim of any housing policy is the sustained provision of "decent and safe housing for eligible low-Income families, the elderly, and persons with disabilities" (US Department of Housing and Urban Development). This major objective lies in the pursuit of social equity (Austin Turner \& Kingsley, 2008: 13; Grigsby \& Bourassa, 2003: 976; King, 2000: 116), understanding social equity as "the basic underpinning principle for welfare provision" (King, 2000: 115). Housing programs are also meant to guarantee a proper and fair allocation of goods in society (Rawls, 1973), and the assurance of a sustainable growth by the mitigation of social inequalities (Berg \& Ostry, 2011).

The Section 8 Housing Choice Voucher Program attempts to solve previous public housing issues by "avoid[ing] concentrations of poverty typical of some public housing projects, and to permit assisted households to gain access to a wider range of higher-quality neighborhoods than they would have reached without the voucher, or if they have been offered a place-based housing unit." (Galvez, 2010: 1).

Despite these remarkable policy aims, the objective has not been fully accomplished. Voucher holders experience high levels of socio-economic and racial clustering (Newman \& Schnare, 1997: 714; Ross, Shlay \& Picon, 2012: 36; Wang, Varady \& Wang, 2008: 65), with white recipients being more prone to gain access to housing in a wider range of metropolitan neighborhoods than African American and Hispanic households (Austin Turner, 2003: 2). 
This study is relevant to a policy audience. It addresses public administrators' part in policy implementation, performance and outcomes, which has been the most neglected factor when considering Section 8, or any other program deficiencies. While examining environmental and structural factors such as budget and market tightness, scholars largely overlooked public administrators' values and attitudes towards citizens during the implementation process.

The research is equally significant to the field of public administration, since updates a number of theoretical discussions that impact organizational practices: The inclusion of citizenship into the politics-administration dichotomy. The approach to public service values as shaping elements of policy and performance, and the translation of the principle of political neutrality debate from a traditionally conceptual setting to a pragmatic one. 


\section{Chapter 2: Literature Review}

Public Administrators' Values and Attitudes in the Policy Implementation Process: An Overview

The notion of public service values in public administration is predominantly normative. It is presented as "the ideals, coined as principles to be followed when producing a public service or regulating citizens behavior, thus providing direction to the behavior of public servants" (Andersen et al., 2012: 293). In this tradition, values in public administration have been widely studied in two ways. Firstly, as the development of thoughtful lists of relevant and frequently used public service values such as neutrality, efficiency, and accountability (Box, 2015; Demir, Reddick \& Nank, 2013: 83). These lists emphasize an idealistic depiction of these values and the servants that incarnate them. Secondly, public service values are grouped into public administrators' categories, organized according to the prevalent set of values utilized during their administrative activities. This categorization goes from Alasdair MacIntyre's (1984) ideal types of administrative roles of public servants as Mediator, Steward, Magistrate, and Advocate (Molina, 2015: 50), to Kernaghan's categories of public service values (Box, 2015: 27) classified as ethical, professional, democratic, and human (Molina, 2015: 57).

Scholars are aware of the existence of a broad variety of public service values and the competition among them (Andersen et.al. 2012: 293). Values are also definitive motivators of public servants' behavior (Demir, Reddick \& Nank, 2013: 79). Accordingly, Molina (2015: 49) states that "public administrators are broadly influenced by a wide range of social and cultural values, and will tend to accept organizational values as long as they are perceived as being consistent with those wider values". Despite recognizing the impact 
of public administrators' attitudes and values on their administrative activities, very few scholars contextualize the discussion of public servants' values preferences in a political and ideological perspective (Molina, 2015: 49). Conversely, most public administration scholars affirm that public values can coexist despite tensions, rejecting that values can be mutually exclusive. Following Van Wart (1998), public servants come to reach a "workable gestalt" that provides them with a feasible resolution in a particular competing values dispute scenario. This normative approach poses a difficulty when linking public service values to quotidian administrators' behaviors, and when connecting both -values and behaviors- to the realities of policy implementation and outcomes.

\section{Public Service Values and Organizational Performance}

Public Administration scholars approach the notion of performance as "the achievements of public programs and organizations in terms of the outputs and outcomes that they produce" (O’Toole Jr. \& Meier, 2011: 2). Efficiency, effectiveness, equity, and public satisfaction (Boyne, 2003 in O’Toole Jr. \& Meier, 2011: 2) are fundamental dimensions of such a notion. Performance measurement of public organization and policy leads to the improvement of delivered services, transparency, organizational innovation and the "quality of policymaking" (De Bruijn, 2001: 5).

The most recurrent interest within the field is the way performance measurement is developed for management and accountability purposes, and their link to budgetary processes (Fawcett \& Kleiner, 1994, in Van der Waldt, 2004: 49). Following Van der Waldt (2004: 49), "Measurement is the yardstick by which the value of productivity improvements can be quantified and assessed." In this vein, scholars conduct their research efforts towards the "determinants of performance in public organizations" (Boyne, Meier, 
O’Toole Jr., \& Walker, 2006: 1), focusing on management (O’Toole Jr. \& Meier, 2011: 4; Walker, Boyne, \& Brewer, 2010: 8), and less frequently addressing environmental factors, regarded by some scholars as the "most poorly understood and poorly measured aspect of the production process" (Smith, in Boyne, Meier, O’Toole \& Walker, 2006: 87).

In identifying "management practices and external constraints" (Walker, Boyne \& Brewer, 2010: 8) that impact organizational and policy performance, a number of dimensions account as components of performance indicators: "quantity of outputs, quality of outputs, efficiency, equity outcomes, value for money, and consumer satisfaction" (Boyne, 2003 in Brewer, in Boyne, Meier, O’Toole Jr., \& Walker, 2006: 36). In this, apparently straightforward, measurement process, several perspectives emerge to question certain aspects of performance, as both, concept and measurement indicator.

A significant number of scholars have come to agree that, far from being objective, organizational performance is "a socially-constructed concept; thus, all measures of performance are subjective" (Brewer, in Boyne, Meier, O’Toole Jr., \& Walker, 2006: 35). This subjectivity extends itself to the difficulties associated with measuring government's outcomes, a given policy or organization's ultimate effect that is not always easily determined (Smith, 1993 in Van der Waldt, 2004: 48). More interestingly, a few specialists interrogate the construction of public value through performance measurement (Talbot, 2010: 130), pointing out the challenges of measuring notions such as "equity, democracy, participation, and citizenship" (Talbot, 2010: 49).

This study focuses on the following unexplored questions of the performance literature, formulated by Fried (in Talbot, 2010: 137): "We take administrative performance to be measurable not only by effectiveness but by the question of effectiveness 
for whom, by what measure or indicator? Whose values or interests are reflected in the goals being pursued more or less effectively by public organizations?" These set of questions identify a gap in the literature, where a competition among public service values is revealed, and values such as effectiveness express themselves as "inherently paradoxical (...) as organizations have to satisfy contradictory demands and values simultaneously to be really effective" (Quinn \& Cameron, 1988; Cameron, 2006 in Talbot, 2010: 151).

In pursuing and measuring performance, it may happen that "improvements on a given criterion (efficiency, for instance) might result in declines on another (equity, say)" (O’Toole \& Meier, 2011: 2). Such a value-conflict environment extends questions to public administrators as implementers of policy to be measured and evaluated, above all, on "how individual behavior relates to organizational or institutional arrangements" (Talbot, 2010: 190).

The Principle of Political Neutrality as Technical Expertise

Researchers address the principle of political neutrality in public administration almost exclusively from the perspective of the hierarchical separation between elected officials and public administrators. Described as "the impartiality of administrators in political issues" (Overeem, 2005: 313), political neutrality lies at the center of the orthodoxy paradigm (Denhardt \& Denhardt, 2011: 9) where public administrators behave as obedient and unbiased executors of public policy.

Two main approaches dominate the theoretical construction of the principle of political neutrality. On the one hand lies "the orthodoxy heritage" (Waldo, 1998), the predominant and almost naturalized position of public administrators as value-neutral (Overeem, 2005: 313). On the other hand, there is a critical elaboration against political 
neutrality as a fundamental component of the 'efficiency' or 'orthodox' paradigm. This posture condemns the negligence of the linkage between public administrators and citizens (Denhardt \& Denhardt, 2000: 555), attacks the fixation with efficiency and rationalism, along with the prevalence of market-driven and mechanistic models of management, privileging more 'democratic' and participative schemes of administration (Dahl, 1947: 1; Frederickson, 1997: 35). In the interstices of these two opposite approaches lie the historical critiques (Friedrich, 1940; Svara, 2006) of the principle of political neutrality that reject the ideal of public administrators as value-neutral, while reaffirming the impossibility of a dichotomist relationship between politics and administration.

The claims of Friedrich's (1940) and Svara's (2006) theoretical contenders, Herman Finer (1941), and the more contemporary Patrick Overeem (2005), introduce the principle of political neutrality in public administration as an unreachable ideal. Despite their vehement defense of the political impartiality of administrators, both authors, Finer and Overeem (2005: 322), concede the existence of an imperishable 'grey zone' of discretion on public administrators' behavior.

This study addresses seven theoretical hypotheses on the political neutrality of public administrators: 1 . the principle of political neutrality is an ideal, impossible to accomplish in the reality of public administrators (Friedrich, 1940: 3). 2. Public administrators do exert administrative discretion in their daily decision-making and implementation processes (Friedrich, 1940; Lipsky, 1980; Svara, 2006). 3. Due to the impossible applicability of the principle of political neutrality in real scenarios, administrators replace neutrality with a more reachable value. 4. Public servants use technical expertise as the proxy for political neutrality (Dahl, 1947: 1). 5. Administrative 
discretion is justified by administrators' technical expertise (Dahl, 1947; Foucault, 1980). 6. Public Administrators' 'expertise' is founded not exclusively in technical knowledge but in political (citizenship), social, and cultural constructions of identities (socio-economic status, race, gender, background) (Forester, 1984: 26). 7. Such identities' construction impacts policy outputs (Habermas, 1973, in Fischer, 1993: 166).

\section{The Notion of Attitude}

The Merriam-Webster dictionary defines the word 'attitude' as 'the way you think and feel about someone or something." The dictionary also explains that an attitude is "a feeling or way of thinking that affects a person's behavior." While public service values are self-contained entities, specifically described and listed, for instance, the value of efficiency is "to act in a manner that achieves the desired results using minimal resources" (Molina, 2015: 53), public servants' attitudes towards citizens possess a more elusive content.

Alexander and Stivers $(2010,583)$ explain that “(..$)$ administrators themselves are embedded within a political and cultural context, and their reasons for actions are drawn from it." In this vein, public administrators' actions of policy-making and implementation are imbued by the "way they think and feel" about the citizens they serve, which include "predominant understandings of causes of poverty and appropriate interventions." (Marr, 2016: 217). Administrators guide themselves not only by administrative values but also by “society's customs and conventions" (Alexander \& Stivers, 2010: 582).

One of the most salient examples of public administrators' attitudes towards citizens is the reproduction of cultural patterns regarding race. Race and ethnicity manifest themselves "in patterns of policy interpretation and discretionary judgments of individual 
administrators" (Alexander \& Stivers, 2010: 578). In consequence, public administrators often act under their "racial patterns" (Alexander \& Stivers, 2010: 578; Marr, 2016: 217), which frequently results in negative outcomes for particular groups (Alkadry \& Blessett, 2010: 549).

The Section 8 Housing Choice Voucher Program: Public Administrators' values and attitudes Influencing Performance and Policy Outcomes

The Housing Choice Voucher Program allows the recipient to select the housing location and unit's characteristics that best suit his/her demands (Austin Turner, 2003: 1). In theory, recipients "choose better neighborhoods than they might otherwise be able to afford" (Pendall, 2000: 881). There is a deliberate and thoughtful policy aim behind this program's mobility characteristic, the idea that the freedom to select quality housing and neighborhood will facilitate racial and economic desegregation (Schwartz, 2010 in Ross, Shlay \& Picon, 2012: 36). Despite this policy objective, Section 8 HCV program results are unsatisfactory at the very least (Austin Turner, 2003: 2; Galvez, 2010: 5; Pendall, 2000: 882).

Scholars concur on a number of causes that account for the unaccomplished goal of poverty and racial desegregation, and the absence of housing betterment for Section 8 Voucher program recipients. First, there are "market causes." Authors who advocate for these arguments (Austin Turner, 2003: 1; Deng, 2007: 22; Ross, Shlay \& Picon, 2012: 39; Williamson, Smith \& Strambi-Kramer, 2009: 121) blame the shortages of moderately priced rental housing and the tightness of local housing markets for the voucher recipients' difficulties in finding a proper, non-segregated home. Frequently, rental housing is 
concentrated in distressed neighborhoods (Pendall, 2000: 882), an intrinsic market situation over which neither the Program nor the recipients have control.

Secondly, there are the "budgeting causes" (Austin Turner, 2003: 1). According to Turner and Kingsley (2008: 3), "Only 5.5 million (31 percent) of the total 18.0 million eligible households with housing needs receive assistance. That number represents just 23 percent of the 23.6 million that are eligible". These figures express the inadequacy of federal spending in affordable housing, where only one in approximate three eligible households get assistance (Austin Turner, 2003: 1).

Thirdly, there are "family preferences" or "individual needs" (Deng, 2007: 22). Sometimes, despite the availability of rental housing in socio-economic and racially deconcentrated neighborhoods, many voucher holders face the dilemma of improving their quality of life by renouncing their support systems formed by family, friends, churches, and services (Deng, 2007: 22). A substantial number of these households make the decision to live in economically distressed and racially concentrated neighborhoods that are at the same time familiar and supportive ones.

The fourth factor that prevents Section $8 \mathrm{HCV}$ Program to reach the goal of poverty and racial desegregation among its recipients is landlords' racial and ethnic discrimination. Following Beck (1996: 159), “The Section 8 program's minimal success in promoting integration is attributable to the widespread discrimination against prospective section 8 tenants by private landlords, especially in largely white, middle-class communities". The U.S. Department of Housing and Urban Development (2013: 39) has evidence of systemic discrimination against black, Hispanic and Asian home seekers in rental and sales market. 
Finally, there are the obstacles inherent to the program. Tegeler et al. (1995) subdivide these intrinsic limitations of the Housing Choice Voucher Program into four categories: “(...) disproportionate allocations; residency preferences; multiple admissions requirements; and discretionary administrative practices that impede eligible families from obtaining subsidies.” (Tegeler, Hanley \& Liben, 1995: 467).

Tegeler et.al. Rationalize the influence of public administrators' values and attitudes towards program recipients and their impact on policy outcomes by introducing "discretionary administrative practices" as a possible cause for Section 8 HCV Program shortcomings. Through this term, Tegeler et al. explain situations such as "AfricanAmerican city residents waited over ten years for subsidies they would never receive, [while] white suburban applicants received subsidies within eighteen to twenty-four months." (Tegeler, Hanley \& Liben, 1995: 472). Other scholars incidentally allude to public administrators' responsibility in policy outcomes by qualifying the "program's portability feature" as a "bureaucratic nightmare" (Austin Turner, 2003: 1). These authors also mention administrative malfeasance in Section $8 \mathrm{HCV}$ program, consisting in "delays in conducting inspections and approving leases, unreliability in making subsidy payments, and lack of responsiveness to landlord inquiries or complaints" (Turner, Popkin, and Cunningham in Austin Turner, 2003: 3). Despite these efforts to include public administrators in the policy outcomes discussion, and the existence of an 'intuitive knowledge' about how public servants' values and attitudes affect the implementation process, the authors above fall short exploring the subject. 


\section{Chapter 3: Research Questions, Hypotheses, and Theoretical Framework}

\section{Research Questions and Hypotheses}

Chapter 3 comprises the research questions, hypotheses, and theoretical framework. Table 1 below encompasses research questions and their corresponding hypotheses, design, and methods.

Table 1. Research Questions and Hypotheses

\begin{tabular}{|c|c|c|c|}
\hline Research Questions & Hypotheses & Design & Methods \\
\hline $\begin{array}{l}\text { Q1. If, and to what extent, } \\
\text { do organizational and } \\
\text { environmental conditions, } \\
\text { such as demographics and } \\
\text { political preferences of } \\
\text { communities, economic } \\
\text { factors, and racial disparities } \\
\text { affect public organizations' } \\
\text { performance? }\end{array}$ & $\begin{array}{l}\text { H1. Environmental and } \\
\text { organizational factors pose } \\
\text { a toll on organizational } \\
\text { performance. }\end{array}$ & $\begin{array}{l}\text { Quantitative } \\
\text { Secondary } \\
\text { Data }\end{array}$ & OLS \\
\hline $\begin{array}{l}\text { Q2. Do environmental and } \\
\text { organizational conditions } \\
\text { compound the effect of } \\
\text { Section } 8 \text { HCV Program's } \\
\text { Hardly-Controllable } \\
\text { Structural Factors (as } \\
\text { predictor of performance)? }\end{array}$ & $\begin{array}{l}\text { H2. Environmental and } \\
\text { organizational conditions } \\
\text { compound the effect of } \\
\text { Section } 8 \text { HCV Program's } \\
\text { Hardly-Controllable } \\
\text { Structural Factors (as } \\
\text { predictor of policy } \\
\text { performance). }\end{array}$ & $\begin{array}{l}\text { Quantitative } \\
\text { Secondary } \\
\text { Data }\end{array}$ & OLS \\
\hline $\begin{array}{l}\text { Q3. Do environmental, } \\
\text { organizational and Section } 8 \\
\text { HCV program structural } \\
\text { factors affect poverty } \\
\text { segregation levels on } \\
\text { Section } 8 \text { HCV recipients? }\end{array}$ & $\begin{array}{l}\text { H3. Environmental, } \\
\text { organizational, and Section } \\
8 \mathrm{HCV} \text { Program structural } \\
\text { factors affect poverty } \\
\text { segregation levels on } \\
\text { Section } 8 \mathrm{HCV} \text { recipients. }\end{array}$ & $\begin{array}{l}\text { Quantitative } \\
\text { Secondary } \\
\text { Data }\end{array}$ & OLS \\
\hline $\begin{array}{l}\text { Q4. Do environmental, } \\
\text { organizational and Section } 8 \\
\text { HCV program structural } \\
\text { factors affect racial } \\
\text { segregation levels on } \\
\text { Section } 8 \text { HCV recipients? }\end{array}$ & $\begin{array}{l}\text { H4. Environmental, } \\
\text { organizational and Section } \\
8 \mathrm{HCV} \text { Program structural } \\
\text { factors affect racial } \\
\text { segregation levels on } \\
\text { Section } 8 \mathrm{HCV} \text { recipients. }\end{array}$ & $\begin{array}{l}\text { Quantitative } \\
\text { Secondary } \\
\text { Data }\end{array}$ & OLS \\
\hline & $\begin{array}{l}\text { H5.1. There are four } \\
\text { possible sets of public }\end{array}$ & Qualitative & $\begin{array}{l}\text { Participant } \\
\text { observation }\end{array}$ \\
\hline
\end{tabular}


Q5. If, and to what extent, do public administrators' preferred set of values and attitudes coincide with either positive or negative organizational and policy performance of PHAs and Section 8 HCV Program? values and attitudes that define the behavior of public administrators towards citizens:

Client (Orthodoxy); Customer (NPM); Citizen (NPA - NPS); Subject (Critical Theory).

H5.2. A more democraticcentered set of public values and attitudes will coincide with positive policy performance in terms of poverty/race desegregation and higher levels of housing and neighborhood quality. H5.3. An orthodox/NPM/dominationoriented set of public values (Client/Customer/subject types) will coincide with negative policy performance in terms of poverty/race desegregation and lower levels of housing and neighborhood quality. and semistructured interviews

\section{Theoretical Framework}

Theories of bureaucratic politics and the Principal-Agent Model inform this research (see Figure 1 below). Both theoretical approaches to bureaucracy admit that public administration is neither a "technical and value-neutral activity, separable from politics" (Frederickson \& Smith, 2003: 41), nor a unitary and single rational exercise of planning and execution (Allison \& Halperin, 1972: 43). 
Figure 1. Theoretical Framework

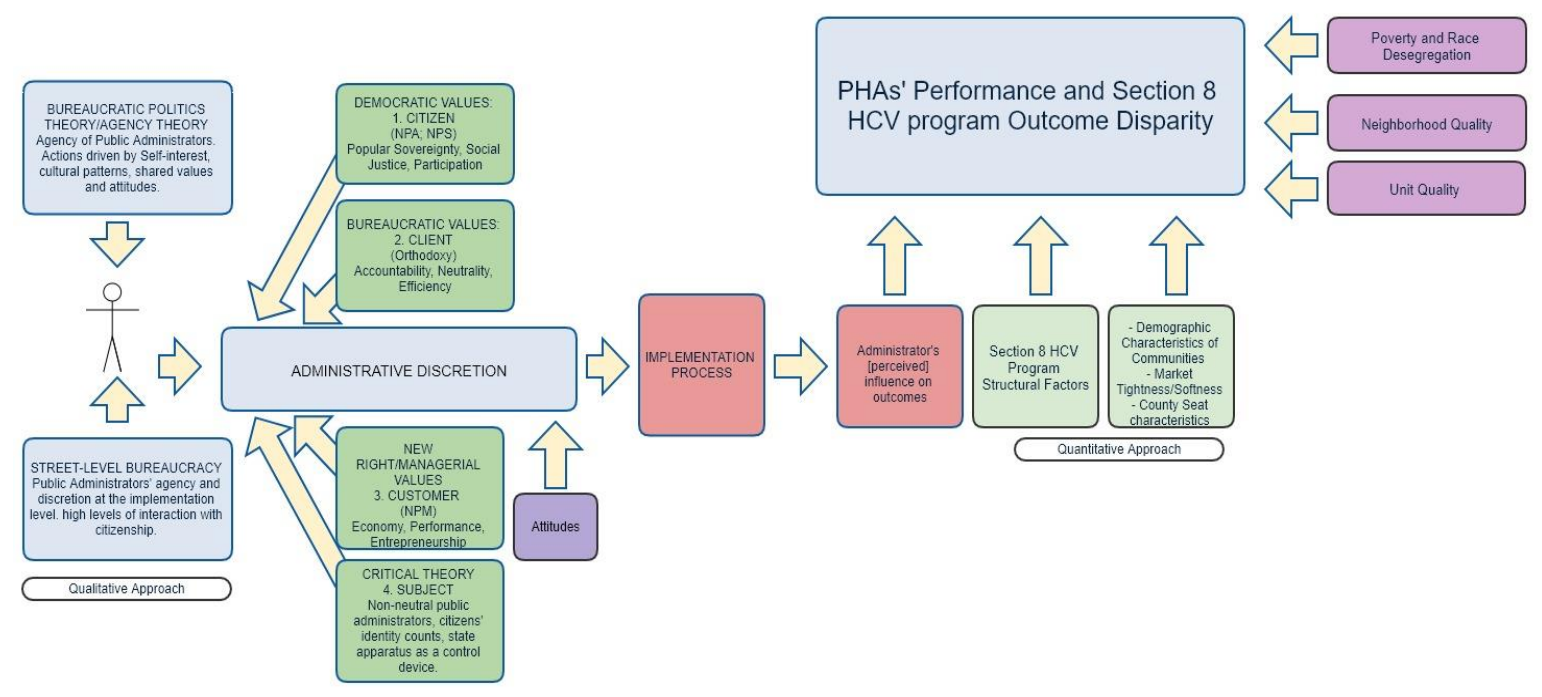

These theoretical perspectives make three foundational conceptual contributions to the present study. The first one lies in the defense of the notion of public administrator's agency, by depicting him/her as a carrier of a significant level of autonomy and discretion (Allison \& Halperin, 1972: 43; Waterman \& Meier, 1998: 175). Second, the idea of the implementation process of any policy as highly vulnerable to public servants' agency, autonomy, and discretion. Scholars from the Bureaucratic Politics and the Principal-Agent model theories claim that during the implementation process, bureaucrats and their actions are often distant from the policy initially formulated. Public servants can also detach themselves from the formal decisions of what Allison and Halperin called the "senior players" (Mazmanian \& Sabatier, 1983 in Waterman \& Meier, 1998: 181; Allison \& Halperin, 1972: 46). In this vein, Clifford states that “(...) once a decision is made, considerable slippage can occur in implementing it" (Clifford, 1990: 162). The third and final contribution from these theoretical views has to do with the agreement on the 
existence of an accepted set of values among public administrators. A shared corpus of attitudes, images, and assumptions that "provide common answers" to practitioners' frequent questions (Allison \& Halperin, 1972: 56).

\section{Street-level Bureaucrats}

The notion of street-level bureaucrats allows public administrators to exercise "substantial discretion" in the execution of their work when dealing directly with the public (Lipsky, 1980: 3). Administrative discretion of public servants is presented as unescapable, where public servants such as social services employees, law enforcement officers, and teachers, conduct professional activities that demand direct contact with citizens. According to Lipsky (1980), the quotidian actions of these street-level administrators and not their agencies' mandates are what, in fact, determine the public policy direction.

This notion is important for this study due to two arguments. The first one has to do with the ability of the street-level bureaucracy theory to place administrators in a position of claiming a certain legitimacy and discretional power, based on their expertise (Matland, 1995: 155). Secondly, this expertise-founded legitimacy allows public administrators to develop their own “'coping devices' for simplifying, and often distorting, the aims of policymakers" (Elmore, 1979: 609-10). In the case of the Section 8 Voucher Program, housing specialists participate in both "discretionary administrative practices" (Tegeler, Hanley \& Liben, 1995: 467), and high levels of interaction with the citizenship during the different phases of the implementation process.

\section{Bureaucratic vs. Democratic Values}

The predominant academic position of public administrators' vis-à-vis public service values builds this interaction as "an ongoing dialectic to resolve "legitimate 
competition of values and inevitable shifts in priority"' (Van Wart, 1998: xviii, in Molina, 2015: 49). Despite admitting that public service values can be mutually exclusive, compete from time to time, or attempt to find a desirable balance (Molina, 2015: 50), a limited number of scholars delve into the possibility that the selection of an exclusive set of values could turn into a permanent preference for public servants. This study follows H. George Frederickson (1997: 31) and his claim that "At any point in time, one set of values may be dominant and have a lock on the practice of public administration." In this study, I propose four possible set of values for public administrators to utilize in policy implementation and rapports with citizens:

\section{Bureaucratic Values}

The origins of the requirement of political neutrality on public administrators' behavior along with the dominance of the classic and neo-bureaucratic models (Frederickson, 1997: 31) lie in the early foundation of the administrative state. There were two different and equivalent preoccupations regarding the tensioning relationship between politics and bureaucrats. On one hand, there was the American concern about the strength and influence of politicians upon the structure of the administrative state. Scholars of this thought attempted to take "politics out of administration" (Fry, 1989, pp. 1036-1037, in Overeem, 2005: 316). On the other hand, Max Weber shared the "American founders" preoccupation, but from a contrasting path. Weber's concern lied in the fear that "politics was rather too weak to curb administrative power, and that the danger of Beamtenherrschaft (government by functionaries) was imminent" (Weber, 1919/1968, p. 28, in Overeem, 2005: 316). 
A particular typology of public administrator-citizen' rapport emanates from the predominance of the previously explained set of values and attitudes within the field. The category of "client" gathers the most fundamental formulations of modern American public administration's birth. During this stage, Woodrow Wilson and Frank J. Goodnow fought the effects of an unorganized, unprofessional corps of public servants, whose decisions and actions were mediated by the political sphere and the actions of its elected officials (Kernaghan, 1976: 435; Overeem, 2005: 317; Stivers, 1995: 523). To confront these behaviors and turn public administrators into mere executors of policy, the values installed at that time were -and still are- efficiency, accountability, and of course, political neutrality of public administrators.

\section{Democratic Values}

By the 1960s, public administrators were criticized due to their apparent lack of self-consciousness, insensibility and blind conformity towards the most urgent matters of society (Frederickson, 1989: 95-96). The very content of the notion of political neutrality was severely questioned, including its moral and ethical validity (Jackson, 1987: 280). The Weberian definition of the principle as "obey 'exactly as if the order agreed with his own conviction'" (Weber, in Jackson, 1987: 286) appeared diluted in the midst of the decade. The "Minnowbrook Perspective", later known as "The New Public Administration" (NPA), was a movement developed in the field with the support of Dwight Waldo (Frederickson, 1989:96). This movement advocated for the contestation of those values historically established from the orthodoxy of Woodrow Wilson and Frank J. Goodnow and the paradigmatic place of the technical efficiency postulated by Luther Gulick, Herbert

Simon and Frederick Taylor. The members of this group (Marini, 1971, in Overeem, 2005: 
318) committed themselves to attack the traditional standards of "input-output ratio as token of technical efficiency" (Rutgers \& Van der Meer, 2010: 758). Replacing them with 'democratic values' such as "equality, freedom, social responsibility, and the general welfare, as an end to be promoted when necessary by public action, regulating property and restricting profit" (McClosky \& Zoller, 1984, in Frederickson, 1989: 96).

This more normative approach of the New Public Administration (Marini, 1971), and the New Public Service (Denhardt \& Denhardt, 2015) perspectives allows the construction of the category of "citizen" to address the relationship between public servants and policy recipients. Under this theoretical light, social equity (Frederickson, 1997: 31), popular sovereignty (Waldo, 1998), and participation (Denhardt \& Denhardt, 2011) are regarded as the fundamental values of public servants' practice.

\section{The Managerial Perspective and the 'Customer' Type}

The 1980s welcomed the movement that attempted to revolutionize public administration. Many names were assigned to such movement: New Public Management (Denhardt, 2011: 141), the New Right, New Conservatism (Peters \& Savoie, 1994: 419), and Managerialism (Kettl, 2005: 9), among others. This transformation was driven by two fundamental assumptions. First, the conception of the bureaucracy as profoundly ill (Peters \& Savoie, 1994: 418; Savoie, 1995: 112; Kettl, 2005: 41). Among the pathological conditions developed by the orthodox modern bureaucracies are the inherent excesses of the traditional hierarchy and its authority-driven practices (Kettl, 2005: 41). The traditional Weberian bureaucracy was also conceived as "lethargic, cautious, bloated, expensive, unresponsive, a creature of routine, $[\ldots]$ incapable of accepting new challenges" (Savoie, 1995: 2014). These critiques favored the general perception of a "broken" classic 
bureaucracy, needing to be "fixed" (Savoie, 1995: 112) and assessed through the creation of a "system of performance accountability" (Moynihan, 2008; Pollitt \& Bouckaert, 2000 in O’Toole \& Meier, 2014: 244).

The second fundamental conception of the managerial theories alludes to the source of the solutions to these bureaucracy's pathologies. Such solutions would appeal to the private sector, under the conviction that "private sector management is superior to public administration" (Savoie, 1995: 113). The application of the private sector's measures demanded a new and different type of public servant.

The NPM administrators are considered "public entrepreneurs" (Osborne \& Gaebler, 1992 in Denhardt, 2011: 142), "doers rather than thinkers" (Peters \& Savoie, 1994: 420), empowered and autonomous, and evaluate themselves by their rapport with clients and their capacity of "earning" instead of "spending" (Savoie, 1995: 113). The "Customer" type is the relationship established between public servants and citizens in the light of the New Public Management's precepts (Dewitt, Kettl, Dyer \& Lovan, 1994; Kamensky, 1996; Kettl, 2005). This relation is mediated by values and attitudes such as economy (Kettl, 2005: 1), performance (Kettl, 2005: 24), and entrepreneurship (Osborne \& Gaebler, 1992 in Denhardt, 2011: 142).

Critical Theory, the Inquiry on the Notion of Neutrality, and the Category of 'Subject'

The allocation of services and goods by public administrators is expected to be efficient, neutral, democratic, and professional. Nevertheless, a suspicion emerges over the behavior of officials in front of vulnerable citizens, and the nature of their expertisefounded administrative discretion starts to be more intensely interrogated (Alkadry \& Blessett, 2010: 532). 
This inquiry comes from the very origin of the principle of neutrality, that emerges as part of the liberal tradition of addressing the public sphere as neutral and rational. The Rawlsian assumption of a neutral public sphere, in which "Each person possesses an inviolability founded on justice that even the welfare of society as a whole cannot override" (Rawls, 1973: 3). This idea includes the ideal of citizenship's impartiality (Young, 1990: 97), along with the equally neutral condition of their interactions with public administrators. This assumption of neutrality of public administration legitimizes the practitioners' status of "blindness" towards citizens in policy matters (Eagan, 2006: 386).

The fundamental problem with the acceptance of the principle of political neutrality of public servants lies in the existence of a defective liberal notion of citizenship whose apparently 'neutral' content keeps the assumption that all citizens are equally treated by public organizations and their members. In reality, the construction of individuals' fixed identities, like being classified as a woman, or a man, or black, or poor, etc., “(...) theoretically frees bodies from their contingencies such as race and gender" [but in reality] "creates those seeming contingencies as natural, and marks some as ineligible to be citizens subjects in the fullest sense" (Eagan, 2006: 386). The rationale behind Eagan's claim is that identity cannot be hidden because it is body-portable. Public agents -as well as the public policy that they design and implement- are clearly able to identify who is who in the public game. Therefore, non-full citizens -those whose identities are not hegemonic- are subject to exclusion and discrimination (Eagan, 2006: 390; Gomez, 2004).

The development of this sense of political neutrality among citizens and public administrators is deliberate and serves "ideological functions" (Young, 1990: 97). In the relationship between officials and citizens, the ideal of impartiality covers the unequal 
allocation of goods and services through public policy, hiding “ (...) the ways in which the particular perspectives of dominant groups claim universality, and helps justify hierarchical decision-making structures" (Young, 1990: 97). Many times, those claims of universality lie right behind the technical efficiency's discourse. The construction of the "subject" type of rapport between public servants and citizens contributes to a more critical approach to administrators' attitudes and values, when introducing power and domination as determinant variables (Alkadry \& Blessett, 2010; Eagan, 2006; Foucault, 1980; Mouffe, 1993).

Knowledge/Technical Expertise as Power

The doctrine of public administrators' political neutrality is historically supported by a disciplinary aspiration of scientism (Dahl, 1947: 1). One that implements the precepts and techniques of a positivist, rational method. Its major attempt lies in the accomplishment of the objective of "secure the maximal beneficial result contemplated by the law with the minimum expenditure of the social resources" (Walker, in Dahl, 1947: 2).

Demonstrated inconveniences of this efficiency/scientific path have been amply discussed (Dahl, 1947; Waldo, 1998). On one hand, there is the problem of the competition between 'democratic values' -liberty and equality (Waldo, 1998: 91)-, and those considered non-democratic ones -"national security, personal safety, productivity and efficiency" (Waldo, 1998: 91). On the other hand, lies the menace of the endangering of public administration's normative principles by inhibiting itself to demonstrate moral values, since "(...) science cannot construct a bridge across the great gap between 'is' to 'ought"' (Dahl, 1947: 1). 
Despite these established disadvantages, public administration insists on its scientific purity and efficiency-driven actions (Dahl, 1947: 4). The discipline refuses to resign a "power which the West since Medieval times has attributed to science and has reserved for those engaged in scientific discourse" (Foucault, 1980: 85).

Scientific neutrality discourse within public administration is guaranteed by administrators' expert posture. According to John Forester's typology (1989: 29), “the technician supposes that the political context at hand can be ignored. Adopting a benign view of politics, the technician believes that sound technical work will prevail on its own merits". Nevertheless, the literature stresses the public sphere as a well-defined field of power where non-neutral public administrators make decisions according to determined interests (Young, 1990: 112). Following Habermas, “(...) technocratic decisions strategies have been introduced to confer scientific legitimation on decisions that would otherwise have failed to generate consent in the more open process of public deliberation" (in Fischer, 1993: 166). 


\section{Chapter 4: Research Design and Context}

\section{Research Design}

This dissertation employs a mixed methods approach. I do not establish a direct relationship of causality between public administrators' values/attitudes, organizational performance and policy outcomes. The existence of structural factors that also influence, and even cause, PHAs and Section 8 HCV Program's performance -such as budget, market tightness, and landlords' discrimination- impedes this task. In general, there are inherent difficulties in the identification of causes of performance (Lenz, 1981 in March \& Sutton, 1997: 702; Staw, 1975). This study works under the feasible hypothesis that public administrators' actions motivated by different sets of values and attitudes coincide with certain levels of organizational and policy performance. Consequently, this study seeks for correlations and trends that relate public administrators' values and attitudes to organizational performance and policy outcomes.

I conduct two consecutive and interdependent stages of the study. In the first stage, I use quantitative techniques to identify and map the variations and discrepancies in PHAs, and Section $8 \mathrm{HCV}$ programs results across the United States. I also determine how environmental factors impact organizational performance and policy outcomes. In the second stage of the study, I use a qualitative approach to determine the most predominant sets of public values and attitudes among Section $8 \mathrm{HCV}$ program officials (either more democratic or Orthodox/managerial/domination oriented), finding matches between public servants' responses to in-depth interviews, and the results of the quantitative analysis.

First, I will provide the necessary context for the research, focusing on housing policy trends in the recent U.S. history. Second, I will explain Public Housing Authorities 
and Section $8 \mathrm{HCV}$ program's origin, nature and operation. Finally, I will describe in detail the two methodological stages of the study.

\section{Study Context}

\section{Housing Policy Trends in the Recent U.S. History}

Like any other policy, public housing policy in the U.S is a discursive act (Conners, 2017). Originated in the turbulent times of the Great Depression, the American housing policy built itself on the paradigmatic premise that housing ownership and housing security signify “American progress, wealth, and citizenship" (Conners, 2017: 423). Policymakers articulated the act of owning and having a home as "a maker and marker of individual welfare, collective well-being, and civic virtue" (Conners, 2017: 423). Such a symbolic representation of housing, in times of financial crisis, foreclosures, and unemployment (Conners, 2017) allowed the congressional approval of the "first comprehensive federal housing legislation" (Conners, 2017: 422): the National Housing Act of 1934. A child of the New Deal, the NHA favored housing and home ownership affordability while normalizing the acceptance of governmental intervention in the housing market and real estate regulation (Conners, 2017: 426).

This national mindset paved the route to the enacting of the United States Housing Act of 1937. The mission of this federal Act was centered on the provision for the needs of the segment of the population most severely impacted by the consequences of the Great Depression (Bingham \& Kirkpatrick, 1975: 65). This national enterprise of subsidizing housing for low and extremely low-income families across the country became a reality with funding provided by the federal government through the subsequent enacting of the Housing Act of 1949. Under this Act, "construction and management of public housing 
fell to local housing authorities, created by special legislation in individual states or localities (Hays, 1995; Quigley, 2000 in Garshick Kleit \& Page, 2008: 35).

The 1970s marked the end of public housing policy expansion in the country. Nonetheless, it continued to be relevant as a fundamental resource for low and extremelylow income families (Goetz, 2012: 452). By 1985, the public housing program had been operating for half a century. It was the "longest standing program of housing assistance to low-income people in the nation" (Goetz, 2012: 452). With age came criticism, fueled by a substantial change in the political environment and the discursive milieu. Some of the public housing stock located in communities in the east portion of the country seemed "visibly dilapidated" (Garshick Kleit \& Page, 2008: 35). Citizens started to repudiate the image of high-poverty levels' communities with the presence of neglected public housing “projects" (Chaskin, 2016: 372).

By the mid-1990s, the public housing policy in the United States was regarded as "another 'failed big government program"” (Cunningham, 2003: 115). Some events and major political decisions guided the general public to such conclusion, facilitating the dismantling of the program (Goetz, 2012: 452).

The National Commission on Severely Distressed Public Housing (1989 - 1992) had paradoxical and unexpected effects in this regard. It was aimed to assess the situation of severely distressed housing and to formulate recommendations accordingly (Goetz, 2012: 454). After three years of evaluation, the Commission determined that, despite the daunting pictures of many public housing developments across the country, a solid $94 \%$ of public housing nationwide was not 'severely distressed' (Goetz, 2012: 454). Upon this observation, the Commission recommended the preservation of public housing whenever 
possible, the promotion of new developments, the modernization and rehabilitation of severely distressed stock, and the no-relaxation of the one-for-one unit replacement rule. The Commission rejected the "de facto demolitions," and approved replacement only in the most severely distressed cases (Goetz, 2012: 455).

Despite this positive assessment of the public housing policy in the U.S., legislative actions taken after the Commission deviated from its recommendations and conclusions (Goetz, 2012: 456). Although retrench and dismantling was not the Commission's recommendation, the HOPE VI program endorsed a "large-scale demolition and redevelopment that has eliminated over 100,000 units of public housing and inspired the elimination of more than 125,000 additional units outside of the program" (Goetz, 2012: 454).

This contradictory policy shift finds its origin in a combined set of reasons. The urban planning and design mindset had changed in the early 1990s. The principles of the "New Urbanism" questioned the modernist architectural proposal of the public housing stock, claiming that such view "had contributed to the rapid decline in living conditions and the social environment in these communities" (Cisneros, 2009; Katz, 2009 in Goetz, 2012: 458). Meanwhile, the paradigmatic idea of Home as "connected to the moral and spiritual welfare of citizens" (Conners, 2017: 442) that fostered a comprehensive public housing policy after the Great Depression (Goetz, 2012: 453), was replaced by an emphasis on concentrated poverty (Goetz, 2012: 456). This was a problem that, according to new standards, demanded to be addressed through the creation of "mixed-income housing and mobility strategies for low-income, subsidized households" (Goetz, 2012: 452), a distant path from the original mid-1930s policy aim. This view promoted the expansion of the 
Voucher program, reducing funding for developing new public housing and increasing the reliance on the market (Garshick Kleit \& Page, 2008: 36).

A new managerial perspective solidified this vision. A radical public housing reform settled the enactment of the Quality Housing and Work Responsibility Act of 1998. This Act focused on augmenting Public Housing Authorities' flexibility, while drastically reducing their funding (Garshick Kleit \& Page, 2008: 37). This "neoliberal policy implementation and devolution" (Garshick Kleit \& Page, 2015: 621) posed a financial toll on the whole public housing policy infrastructure, where both HUD and public housing authorities across the country faced institutional extinction (Goetz, 2012: 458). Executing an act of political will, "the Clinton administration worked to move social policy away from the New Deal social welfare approach to a neoliberal strategy incorporating market incentives, market discipline, and a reduction in the role of government" (Goetz, 2012: 457).

Gentrification added to this new public housing policy landscape. The property explosion experienced by American cities right after the recession of 1991 led to accelerated redevelopment and private-sector investment in the housing market (Goetz, 2012: 458). Downtown and near-downtown property areas became of interest for developers. Most of this stock belonged to local public housing authorities that acquired them "during the decades of decline following World War II" (Goetz, 2012: 458). Private developers pressured a trend of selling and demolition that, added to the funding situation of many PHAs across the country, resulted in the loss of public housing for the poorest of the poor (Cunningham, 2003: 114; Goetz, 2012: 459). Some scholars go so far as to call this phenomenon "state-led gentrification" (Chaskin, 2016: 372). By 2012, 200,000 public 
housing units were gone by demolition or selling, and "the public housing model that had prevailed for more than 50 years abandoned" (Goetz, 2012: 452).

\section{Public Housing Authorities and Section 8 HCV Program: Origin, Nature and Operation}

Public Housing Authorities (PHAs) in the U.S. are "quasi-governmental agencies with the mission of managing and sometimes constructing affordable housing in local communities" (Garshick Kleit \& Page, 2015: 621). By 2015, there were over 4,000 PHAs in the country (Garshick Kleit \& Page, 2015: 621). PHAs administer either public housing or Section $8 \mathrm{HCV}$ programs, or both programs "for the federal government at the local level" (O'Hara \& Cooper, 2003:15). Children of the U.S. Housing Act of 1937, Public Housing Authorities were created "by special legislation in individual states or localities" (Hays, 1995; Quigley, 2000 in Garshick Kleit \& Page, 2008: 35). Nonetheless, PHAs also operate under federal regulations, HUD being their main source of funding and the public institution that holds them accountable (Cunningham, 2003: 112). Hierarchically speaking (see Figure 2 below), PHAs are administered by Board of Commissioners -appointed by local mayors-, and managed by executive directors in charge of the staff that runs the different programs within the agency (O'Hara \& Cooper, 2003: 15; Cunningham, 2003: 112).

PHAs are "large, locally based, government-linked entities" that deliver "safe, decent, affordable housing to low-income households" (Cunningham, 2003: 97). Their importance lies in their capacity to affront housing market's challenges on behalf of lowincome and extremely low-income families through a "coherent, single-purposed infrastructure staffed with trained professionals to provide a complex service to vulnerable population" (Cunningham, 2003: 113). In practice, PHAs operate as a "private real estate 
management regime," with "rent levels, admission criteria, contracting and procurement procedures, [and] accounting standards and personnel management issues" (Cunningham, 2003: 112).

Figure 2. A Public Housing Authority’s Structure

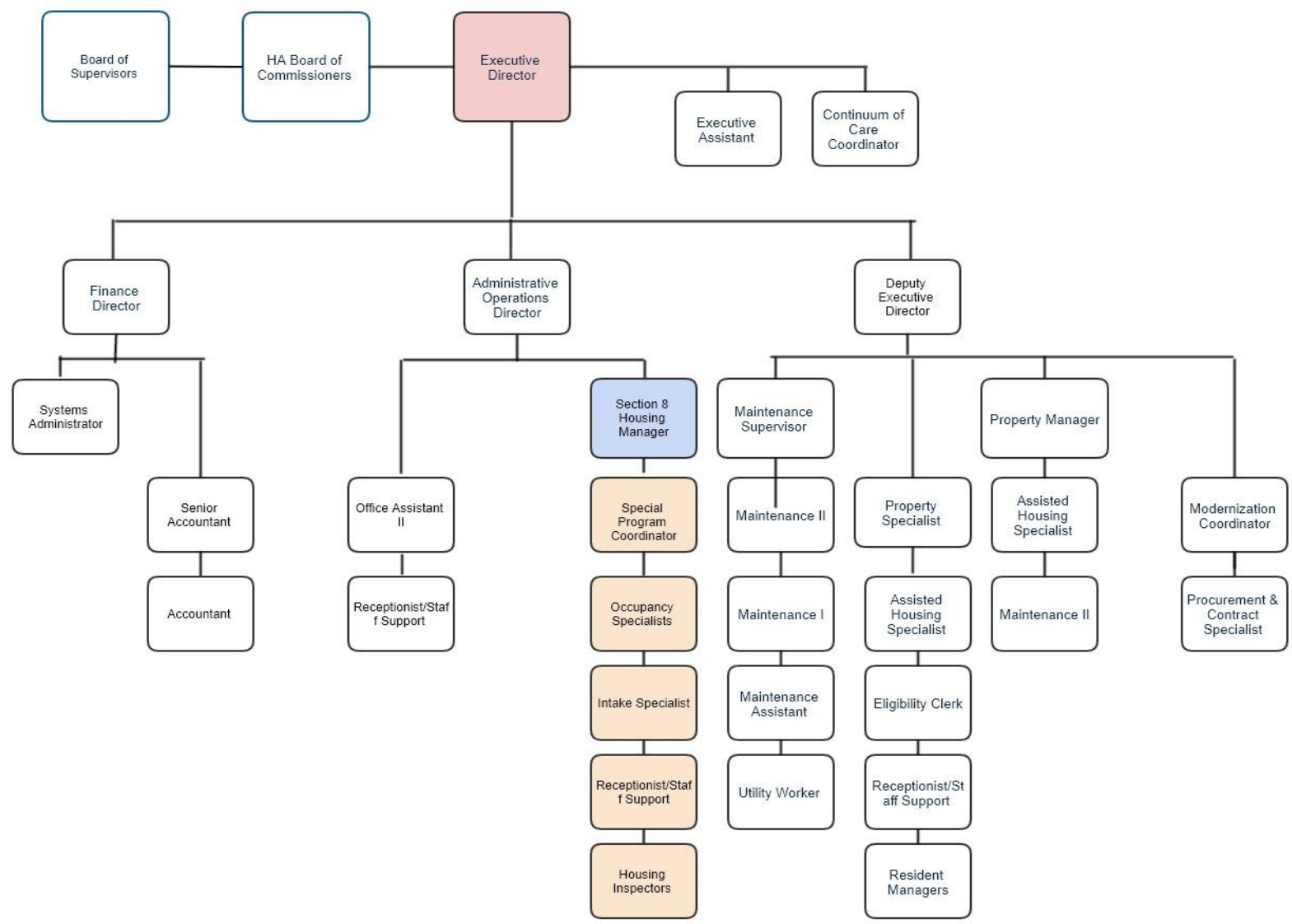

Source: Interviewed PHA's staff member

Policy changes impacted Public Housing Authorities and their ability to deliver. The Quality Housing and Work Responsibility Act of 1998 imposed cuts in public housing funding and voucher expansion with a modification of their funding formulas (Garshick Kleit \& Page, 2008: 34). Public Housing Authorities gained in organizational, program authority and financial flexibility; but saw federal funding shrink and the increase of their 
duties (Garshick Kleit \& Page, 2008: 34). PHAs' core business was not "to construct, manage and maintain public housing" anymore (Lane, 1995; Quercia \& Galster, 1997 in Garshick Kleit \& Page, 2008: 35). Contrariwise, Housing Authorities started to face the “constrained quadrilemma” (Quercia \& Galster, 1997: 552, in Garshick Kleit \& Page, 2008: 35) of conflicting goals: "integrating the poor geographically and socially; maximizing the values of cross-subsidies, maximizing the private capital invested in PHAs, and maximizing the number of poor tenants served by decent, affordable housing" (Garshick Kleit \& Page, 2008: 35).

This policy shift brought significant consequences to current PHAs' execution of their obligations and performance. The first and most important of such effects has to do with the uncertainties and dilemmas posed by the substantial reduction of federal funding (Garshick Kleit \& Page, 2015: 623; Corradino \& Tran, 2005: 33). This reduction turned into an increased reliance on the private market and developers (Garshick Kleit \& Page, 2015: 624), while jeopardizes the provision of housing for the poorest of the poor due to "lack of market visibility" (Fraser et al. 2012, in Garshick Kleit \& Page, 2015: 622). Secondly, although the Quality Housing and Work Responsibility Act promised PHAs discretion to execute and manage their new responsibilities, HUD's administrative and financial measures ended up reducing this discretion, clotting PHAs with procedural and funding complications, and diminishing their ability to deliver housing provision services (Garshick Kleit \& Page, 2008: 37). Finally, the most important consequence of PHAs new policy landscape lies in the danger of "organizational incoherence and ineffectiveness" (Quercias \& Galster, 1997, in Garshick Kleit \& Page, 2q008: 35) when fulfilling their duties. 
The Section 8 Housing Choice Voucher Program is federally funded by HUD and locally administered by Public Housing Authorities across the U.S. PHAs receive funding for administering the program that includes the housing subsidy itself, plus administrative fees aimed to cover operational costs (HUD, 2015: 1). The Program was created by Congress in 1974 (Semuels, 2015), as "a way to assist low-income families, elderly people, and people with disabilities to rent decent, safe and affordable housing in the community" (O'Hara \& Cooper, 2003: 7). Currently, Section 8 is the largest low-income housing assistance program, serving 2.1 million households nationwide (HUD, 2015: 1). The Tenant-based rental assistance is the "most prevalent and well-known type of Section 8 Assistance" (O'Hara \& Cooper: 2003: 8), and the one studied in this dissertation (see Figure 3 below).

In the mid-1980s, curtailment of fund for constructing new public housing coincided with the expansion of the Section $8 \mathrm{HCV}$ Program, a governmental demonstration of its increasing reliance on private markets for the provision of affordable housing (Garshick \& Page, 2008: 36). By the fiscal year 2002, Congress had allocated more than 16 billion dollars for Section $8 \mathrm{HCV}$ program, equivalent to half the entire HUD budget for that year (O’Hara \& Cooper, 2003: 9).

Despite this apparent success, the Section $8 \mathrm{HCV}$ program has too, endured the effects of the changing perspective of federal governments on housing policy. For instance, according to Garshick Kleit \& Page (2008: 38), the voucher renewal funding formula changed each year between 2003 and 2006, causing "flawed funding formulas" (Sard, 2007) that provoked the loss of 150,000 vouchers. PHAs were induced to make cuts while trying to keep their programs alive. Administrative costs have been limited by Congress as 
well (Semuels, 2015). The fee formula currently in place since 2008 -and based on the local Fair Market Rent (FMR)- covered around $90 \%$ of the administrative fees that PHAs would have received if full funding were available, that percentage dropped to $69.26 \%$ in 2013 and raised to $79.76 \%$ in 2014 (HUD, 2015: 1). The severity of the underfunding situation of Section $8 \mathrm{HCV}$ programs across the country starts with the formula itself. The calculation does not incorporate PHAs specific conditions, housing markets, and program particularities (HUD, 2015: 2), along with extra costs -such as office space and personnelthat HUD does not pay (HUD, 2015: 8).

Figure 3. Section 8 HCV Program Process

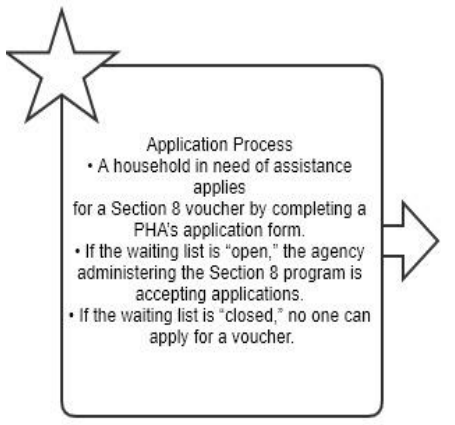

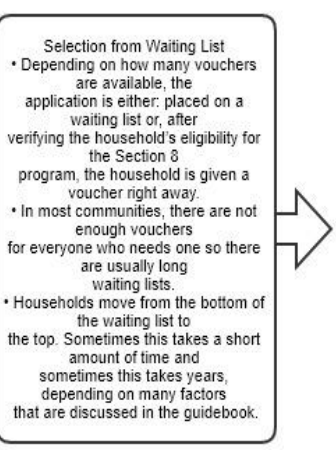

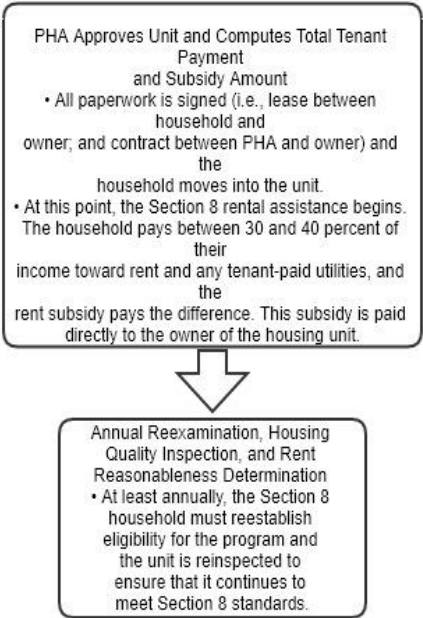

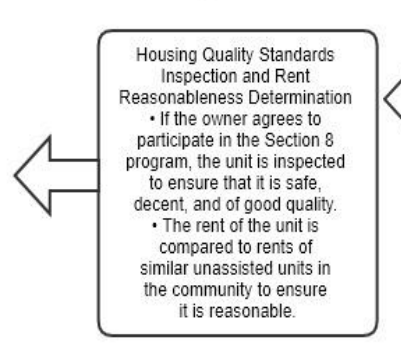

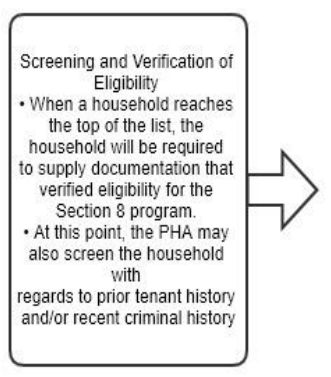
- The Section 8 household then has a short time usually 60 to 120 days) to find a rental unit in the community that meets Section 8 guidelines (i.e. affordable and decent). 8 guidelines and may choose to use the voucher in the existing unit.

Source: O’Hara \& Cooper, 2003: 11 


\section{Methodological Stages of the Research}

\section{Stage 1: Quantitative Analysis}

As mentioned before, in the first stage of this research I use quantitative techniques to identify the factors of performance disparities in Section $8 \mathrm{HCV}$ Program. This stage of the study will address the first research question: if, and to what extent, do organizational and environmental conditions, such as demographics and political preferences of communities, economic factors, and racial disparities affect public organizations' performance? The fundamental aim is to identify and map the variations and discrepancies in PHAs and Section $8 \mathrm{HCV}$ programs results across the United States and to determine if, and how environmental factors impact both, organizational and program's performance.

The factors analyzed encompass five fundamental dimensions. The first three indicate historical program's success: 1. Poverty and race desegregation; 2. Neighborhood quality; and 3. Housing quality. The other two dimensions speak for 4. Section 8 Housing Choice Voucher Program structural factors, and 5. Demographic characteristics of surrounding communities. An ordinary Least Square method is utilized to address this operative question.

After this first analysis, I proceed to test the ability of environmental and organizational factors of PHAs to exacerbate the impact of Section $8 \mathrm{HCV}$ program's hardly-controllable factors, such as the average amount of money expended by HUD per unit, as a way to anticipate and predict program's performance, since there is no direct performance measurement for the program. This phase will address the question: Do environmental and organizational conditions compound the effect of the Section $8 \mathrm{HCV}$ program's hardly-controllable structural factors (as predictor of performance)? 
The final portion of the quantitative stage will focus on the Section $8 \mathrm{HCV}$ Program's main policy objective: racial and poverty desegregation (Schwartz, 2010 in Ross, Shlay \& Picon, 2012: 36). The third and fourth operative questions are: Do environmental, organizational and Section 8 HCV program's hardly-controllable structural factors affect poverty segregation levels in Section 8 HCV recipients? And Do environmental, organizational and Section $8 \mathrm{HCV}$ program's hardly-controllable structural factors affect racial segregation levels in Section 8 HCV recipients? These questions will allow to identify environmental and organizational factors of Section $8 \mathrm{HCV}$ Program and PHAs that influence either the success or failure of the program, when accomplishing the differentiator goal of providing poverty and race deconcentrated housing to vouchers' recipients.

\section{Unit of Analysis and Study Sample}

The unit of analysis and population of interest is the Public Housing Authority, at the County Seat level, nationwide. The sample was selected from HUD's Public Housing Assessment System (NASS-PHAS), as of October 2016. An approximate of 1,106 observations of County Seat composite PHAS' scores comprise the sample.

\section{Data}

Secondary data proves to be extremely useful when analyzing performance disparities in PHAs and Section $8 \mathrm{HCV}$ programs, as well as the factors that influence such disparities. The information required to address the operative questions formulated above comes from institutional sources and comprises the five dimensions discussed in the quantitative analysis (1. Poverty and race desegregation; 2. Neighborhood quality; and 3. Housing quality; 4. Section 8 Housing Choice Voucher Program structural factors, and 5. 
Demographic characteristics of surrounding communities.), at the County and County Seat level.

Poverty and race desegregation indicators come from the "Picture of Subsidized Households 2015" database (Based on 2010 Census), specifically, the section of Housing Choice Vouchers at the County Level. An indicator of Racial Dissimilarity on White to Non-white population was retrieved from the Federal Reserve Bank of St. Louis' database. Housing Market Indicators, such as Housing Unit Estimates (2015), Annual Change in House Price Percentage (2015), and the House Price Index (2015) were collected from the U.S. Census Bureau, Population Division (release Date: May 2016), and the Federal Housing Finance Agency, respectively. Neighborhood quality indicators were gathered from the Distressed Communities Index, a composite score that "combines seven complementary metrics to present a complete and multidimensional picture of economic distress-or prosperity-in U.S. communities"' . A housing quality indicator within PHAs was retrieved from HUD's Public Housing Assessment System (NASS-PHAS), as the Physical Indicator score based on the physical inspection in the Physical Assessment Subsystem (PASS). Section 8 Housing Choice Voucher Program structural factors include Subsidized Units Available, Occupied Units as Percentage of Available, Average HUD Expenditure per Month and Average Months on Waiting List (in Section 8) were gathered from "Picture of Subsidized Households 2015" database as well. Public Housing Authorities' performance indicator was retrieved from HUD's Public Housing Assessment System (NASS-PHAS) database. County Seat data, such as population, housing, and

\footnotetext{
${ }^{1}$ http://eig.org/dci
} 
income was retrieved from the Census Fact Finder, 2015. Finally, Demographic Characteristics of Communities, such as population, poverty and income levels, and rural vs. urban population were retrieved from Census Tract state, and county estimates 2015, the population estimates for 2015 in the American Community Survey, and the 2010 Census Urban and Rural Classification and Urban Area Criteria. American presidential election of 2012 was retrieved from the publically available databases of The Guardian and CNN.

\section{Variables}

Dependent Variables. The first dependent variable, out of four in this study, is an indicator of Public Housing Authorities' performance: The composite PHAS score (CS_PHAScores). This variable is a HUD's instrument of annual assessment that addresses four factors: "PASS Score: Physical Indicator score based on the physical inspection in the Physical Assessment Subsystem (PASS) and ranges from 0 to 40 unless points are redistributed from other PHAS indicators; FASS Score - Financial Indicator score based on the Unaudited or Audited Financial Assessment Subsystem (FASS) submission ranges from 0 to 25 points unless points are redistributed from other PHAS indicators; MASS Score - Management Operations Indicator based on the Unaudited or Audited FASS submission ranges from 0 to 25 points unless points are redistributed from other PHAS indicators; and Capital Fund Score - Capital Fund score based on Capital Fund Program (CFP) obligation data and Inventory Management System (IMS) occupancy data ranges from 0 to 10 points unless points are redistributed from other PHAS indicators." (HUD, 2016). 
The second dependent variable is a composite indicator that comprises the Section $8 \mathrm{HCV}$ program's hardly-controllable structural factors that influence program's performance and may indeed, predict it. Public Housing Authorities and Section 8 HCV program's staff have low margin for maneuver over such factors. These factors are Subsidized Units Available, Occupied Units as Percentage of Available, Average HUD Expenditure per Month and Average Months on Waiting List.

The third and fourth dependent variables are indicators of poverty and race desegregation for Section $8 \mathrm{HCV}$ Program's recipients. On the one hand, there is the percentage of the population below the poverty level in the Census Tract where HUDassisted families reside (Census 2010 designation). On the other hand, there is the minority percentage of total population in the Census Tract where HUD-assisted families reside (Census 2010 designation) (Data Dictionary for Picture of Subsidized Households 2016).

Independent Variables. The independent variables of this research are both environmental and organizational influencers of performance, such as demographic characteristics of communities surrounding PHAs and Section $8 \mathrm{HCV}$ programs, housing markets' tightness or softness, poverty and race percentage, and race disparities at the county level, and neighborhood quality. Organizational factors are interchangeable depending on the model and comprise PHAs scores and Section $8 \mathrm{HCV}$ program factors

Control Variables. Due to the use of County Seat as unit of analysis for the composite PHAS score (CS_PHAScores) within the general use of County for the other variables, a number of County Seat variables have been included in the study for controlling population, income, housing estimates and housing occupancy at the county seat level. Table 2 below provides a substantial variables description. 
Table 2. Variables Description

\begin{tabular}{|c|c|}
\hline Name of Variable & Label/Description \\
\hline $\begin{array}{l}\text { Public Housing } \\
\text { Authorities Performance } \\
\text { Indicator(s) }\end{array}$ & \\
\hline 1. CS_PHAScore & $\begin{array}{l}\text { County Seat Public Housing Authority Score } \\
\text { The score given to the PHA is a general performance } \\
\text { grade that include: PASS Score - Physical Indicator } \\
\text { score based on the physical inspection in the Physical } \\
\text { Assessment Subsystem (PASS) and ranges from } 0 \text { to } 40 \\
\text { unless points are redistributed from other PHAS } \\
\text { indicators } \\
\text { o FASS Score - Financial Indicator score based on the } \\
\text { Unaudited or Audited Financial Assessment Subsystem } \\
\text { (FASS) submission ranges from } 0 \text { to } 25 \text { points unless } \\
\text { points are redistributed from other PHAS indicators } \\
\text { o MASS Score - Management Operations Indicator based } \\
\text { on the Unaudited or Audited FASS submission ranges } \\
\text { from } 0 \text { to } 25 \text { points unless points are redistributed from } \\
\text { other PHAS indicators } \\
\text { o Capital Fund Score - Capital Fund score based on } \\
\text { Capital Fund Program (CFP) obligation data and } \\
\text { Inventory Management System (IMS) occupancy data } \\
\text { ranges from } 0 \text { to } 10 \text { points unless points are redistributed } \\
\text { from other PHAS indicators } \\
\text { o Late Penalty Points (LPP) - Late penalty points may be } \\
\text { applied to the PHAS score where the PHA submits FASS } \\
\text { after the due date } \\
\text { o FASS Submission Type - the unaudited or audited type } \\
\text { of the PHA's financial submission (e.g., Unaudited/Single } \\
\text { Audit, Audited/Non-Single Audit, Unaudited/A-133) }\end{array}$ \\
\hline \multicolumn{2}{|l|}{$\begin{array}{l}\text { Demographic } \\
\text { Characteristics of } \\
\text { Communities (County } \\
\text { level) }\end{array}$} \\
\hline 2. Population & Population Estimates (2015) \\
\hline 3. Poverty & Poverty Percent All Ages (county) 2015 \\
\hline 4. Income & Median Household Income 2015 \\
\hline 5. POPPCT_URBAN & $\begin{array}{c}\text { Percentage Urban Population } \\
2010 \\
\end{array}$ \\
\hline 6. POPPCT_RURAL & Percentage Rural Population 2010 \\
\hline 7. PCT_ObamaVote & Percentage of Votes for Obama 2012 \\
\hline 8. PCT_RomneyVote & Percentage of Votes for Romney 2012 \\
\hline
\end{tabular}




\begin{tabular}{l|c}
\multicolumn{1}{c|}{ 9. Black_PCT } & Black Percentage per County 2015 \\
\hline 10. Hispanic_PCT & Hispanic Percentage per County 2015 \\
\hline $\begin{array}{l}\text { Market } \\
\text { Tightness/Softness } \\
\text { (County level) }\end{array}$ & Housing Unit Estimates 2015 \\
\hline 11. HousingUnit & $\begin{array}{c}\text { Annual Change House Price Percentage 2015 } \\
\text { Captures percentage annual shifts in house price } \\
\text { gradients within counties }\end{array}$ \\
\hline 12. AnnualChange_PCT & $\begin{array}{c}\text { House Price Index 2015 } \\
\text { 13. HPI }\end{array}$ \\
$\begin{array}{c}\text { The house price gradient within a county captures the } \\
\text { tradeoff between demand for housing at different } \\
\text { locations } \\
\text { (dataset of mortgage transactions, which includes } \\
\text { conventional mortgages of single-family purchases and } \\
\text { refinances that are acquired or guaranteed by Fannie Mae } \\
\text { or Freddie Mac) }\end{array}$ \\
\hline $\begin{array}{l}\text { the Section 8 HCV } \\
\text { program's hardly- } \\
\text { controllable structural } \\
\text { factors }\end{array}$ & \\
\hline
\end{tabular}

\begin{tabular}{l|c}
\hline 14. SubdUnitAv & $\begin{array}{c}\text { Subsidized Units Available } \\
\text { (in Section 8) }\end{array}$ \\
\hline 15. Occupied_PCT & Occupied Units as Percentage of Available (in Section 8) \\
\hline 16. AvgHUDExp & Average HUD Expenditure per Month (in Section 8) \\
\hline 17. AvMonths & Average Months on Waiting List (in Section 8) \\
\hline $\begin{array}{l}\text { Poverty and Race } \\
\text { Desegregation in } \\
\text { Vouchers Recipient and } \\
\text { Racial Disparities at the } \\
\text { County Level }\end{array}$ & Percentage Head of Household Minority in Section 8 \\
\hline 18. MinorityS8_PCT & Percentage Head of Household Black in Section 8 HCV \\
\hline 19. Black_S8 & Percentage Head of Household Hispanic in Section 8 \\
\hline 20. Hispanic_S8
\end{tabular}


distribution between white and non-white population groups across all tracts in the county.

\section{Neighborhood Quality}

(County level)

24. DCI

\section{Distressed Communities Index}

The DCI calculates distress scores for every level of geography presented here: zip codes, cities, counties, and congressional districts, and tabulates data by states as

well. Scores are based on a geography's combined performance on the seven well-being metrics. The higher the score, the greater the distress. The scores range from 0 to 100 , moving from dark green in the most prosperous zip codes to dark red in the most distressed ones.

The DCI combines seven complementary metrics to present a complete and multidimensional picture of economic distress-or prosperity-in U.S. communities:

No High School Degree: Percent of the population 25 years and over without a high school degree Housing vacancy: Percent of habitable housing that is unoccupied, excluding properties that are for seasonal, recreational, or occasional use

Adults not working: Share of the population 16 years and over that is not currently employed

Poverty: Percent of population living under the poverty line

Median income relative to state: Ratio of the geography's median income to the state's median income

Change in employment: Percent change in the number of individuals employed between 2010 and 2013

Change in business establishments: Percent change in the number of business establishments between 2010 and 2013

\section{Control Variables: County Seat General Characteristics}

\begin{tabular}{l|c}
\hline 25. CS_Pop & County Seat Population \\
\hline 26. CS_Income & County Seat Income \\
\hline 27. CS_HousingEst & County Seat Housing Estimate (Estimate amount of \\
housing units)
\end{tabular}




\section{Stage 2: Qualitative Analysis}

In this stage of the study, I analyze three non-quantitative aspects of public administrators' values and attitudes towards Section $8 \mathrm{HCV}$ program recipients (see Figure 4 below). First, I address public administrators' discursive devices towards citizens in terms of values and attitudes, especially their capitalization of technical expertise as a source of discretion (Foucault, 1980), the rationale behind their attitudes (Alexander \& Stivers, 2010; Alkadry \& Blessett, 2010; Marr, 2016), and the set of public service values utilized. Second, I inquire into the perceived scope of public administrators' actions during the implementation process, including possible constrictions posed by structural factors affecting the Section 8 HCV Program (Marr, 2016: 225), and, finally, I question public administrators' perceived impact on policy outcomes. During this phase, I address the second research question: If, and to what extent, do public administrators' preferred set of values and attitudes coincide with either positive or negative organizational and policy performance of PHAs and Section 8 HCV Program? To address this question, I interviewed staff members of Public Housing Authorities in the states of California and Florida.

\section{Unit of Analysis and Study Sample}

The unit of analysis is public servants with direct participation in the implementation process of the Section $8 \mathrm{HCV}$ Program at Public Housing Authorities (PHAs) in the states of California and Florida, at the county and county seat level.

A "judgment sample" (Marshall, 1996: 523) is the ideal selection to conduct the research. The sample demands the inclusion of subjects with particular expertise and experience. In consequence, I selected "the most productive one" (Marshall, 1996: 523). In this case, the sample was satisfied with 15 experienced public administrators of the high 
and medium level of authority (Carpenter, 2001) working as case managers and front-line practitioners at the Section $8 \mathrm{HCV}$ Program and PHAs at the county and county seat level, in the states of California and Florida. These officials must be formally separated from elected ones. They must be executors of policy decisions, appointed and promoted by merit, and not be engaged in partisan political activities (Kernaghan, 1976: 433). I combined the initial 'judgment sample' with a Chain Referral or Snowball sampling technique (Biernacki \& Waldorf, 1981: 144), anticipating the construction of an eventual network along the interviewing process.

Qualitative Research Strategy \& Data

I use organizational ethnography (Watkins-Hayes, 2009: 34) as a qualitative research strategy to collect and analyze data about public administrators' values and attitudes towards Section $8 \mathrm{HCV}$ Program's recipients. According to Watkins-Hayes (2009), organizational ethnography allows researchers to explore the intersection between administrators' social (attitudes) and professional (public service values) identities. I address this intersection by observing the rapports between recipient citizens of the Section 8 HCV Program and public administrators during the decision-making and implementation process. 
Figure 4. Qualitative Research Strategy

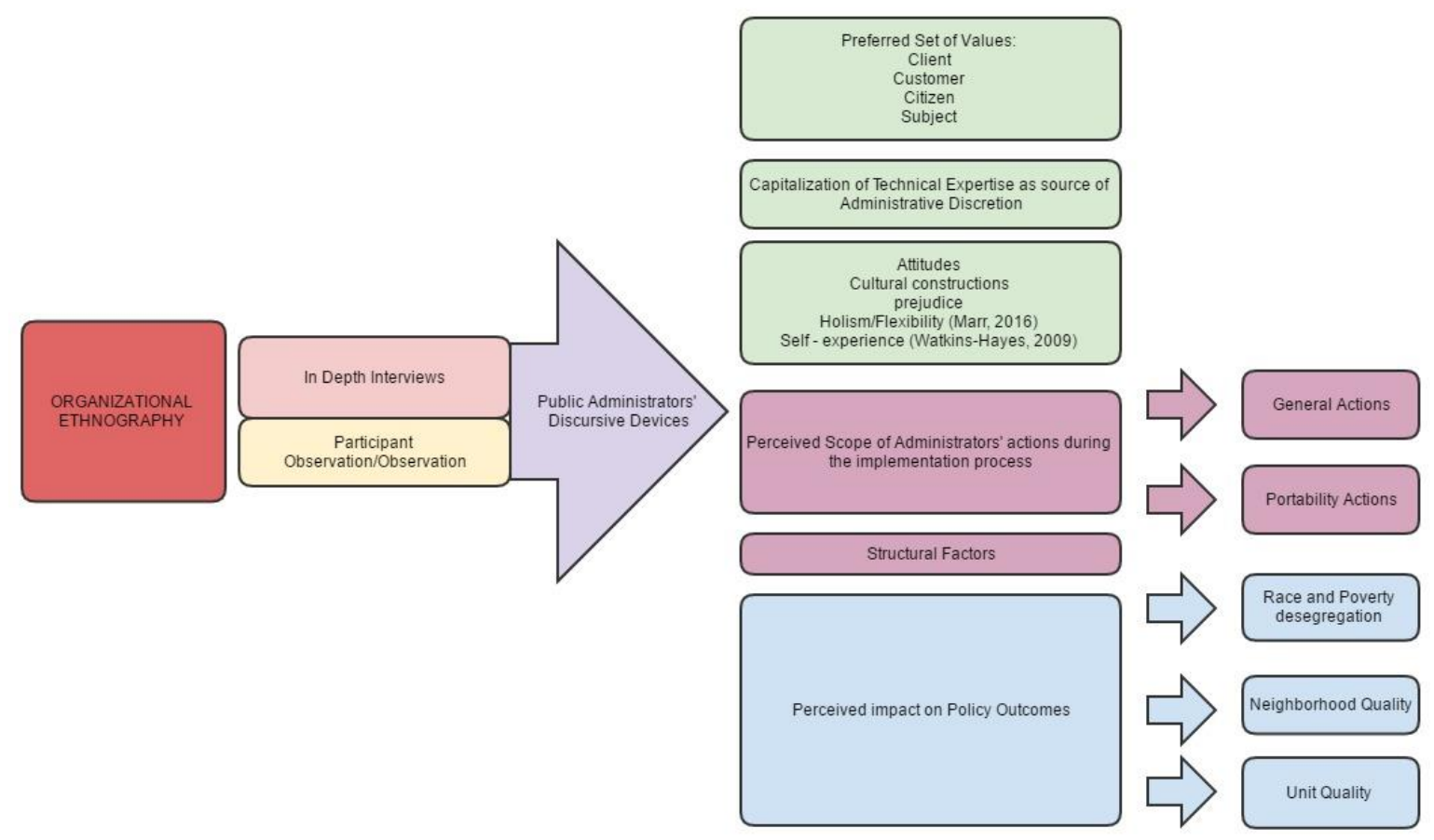

The data collection comes from in-depth interviews with PHAs practitioners. I utilize non-structured and ethnographic methods to interview public administrators. I expect that through a "particular kind of speech event" (Spradley, 1979: 18, in Marshall \& Rossman, 2011: 146) the interviewees share "their experiences, their daily activities, and the objects, and people in their lives" (Westby, Burda, \& Mehta, n.d. in Marshall \& Rossman, 2011: 146).

Rationale behind the Selection of the States of California and Florida

The justification for the selection of Florida and California for the conduction of the qualitative research has to do with a number of characteristics that add complexity to the decision-making process and implementation environment of the Section $8 \mathrm{HCV}$ program. According to the 2010 Census estimations, California is the most populated state 
in the country $(37,253,956)$, while Florida remains as the third most populated $(18,801,310)$, outnumbered by Texas. Beyond population size, both California and Florida comprise high levels of diversity regarding race and ethnicity, with representative amounts of White, African-American, Asian, and Hispanic or Latino population. In both states, the Housing Choice Voucher Programs at the county level experience sharp contrasts in accordance with the demographic differences found from one community to the other. While South Florida and the southern portion of California deal with tight housing markets, unaffordability, and fierce competition; northern territories in both states face less pressure regarding housing affordability. More importantly, California and Florida present multiple heterogeneities. The most relevant ones are related to the substantial differences of income and wealth from county to county, the existence of both, rural and urban areas, and a considerable performance disparity among Public Housing Authorities at the local level (HUD, 2015). 


\section{Chapter 5: Environmental and Organizational Influencers of Performance at PHAs and the Section 8 HCV Program}

For some authors, the evidence on the determinants of performance in public organizations is rather limited (Boyne, 2003; O’Toole \& Meier, 1999 in Boyne, Meier,

O’Toole \& Walker, 2006). Nonetheless, a substantial body of literature within the field helps to identify the most common environmental and organizational influencers of performance, in public organizations and policy (Amirkhanyan, Kim \& Lambright, 2013; Avellaneda, 2008; Lee \& Whitford, 2012; Moynihan, 2005; O’Toole \& Meier, 2011; Walker, Boyne \& Brewer, 2010).

Among organizational influencers of performance, the most prominent by far is Management (Meier et al. 2006). Management variables such as "innovation, leadership, managerial quality, and strategy" are broadly analyzed factors of organizational goals' achievement (Boyne, Meier, O’Toole \& Walker, 2006: 7). By anticipating and responding to external challenges and constraints, managers can positively influence organizational performance (Heckman, 2012: 473). Their ability to interpret the context also impacts organizational stability (O’Toole \& Meier, 1999 in Walker et al. 2010: 6). Scholars emphasize on management as a determinant of organizational performance to the point of claiming that "what makes the difference between the success and failure of a program is public management” (Boyne, 2003; Lynn, 1984, 1987; Meier \& O’Toole, 2002; O’Tolle \& Meier, 1999 in Avellaneda, 2008: 287).

There are other influencers of performance to be found within organizations. On the one hand, individual-level factors such as "job satisfaction, organizational commitment, public service motivation, and organizational citizenship behavior" (Kim, 
2004: 245) contribute to the completion of organizational and program' objectives. On the other hand, organizational resources, namely "administrative, human, financial, physical, political and reputation" (Lee \& Whitford, 2012: 689) impact organizational and policy performance as well.

Environmental influencers of performance receive less investigative attention than their organizational counterparts (Martin \& Smith, 2005: 602). The population ecology's perspective grants importance to environmental conditions in organizational chances to thrive (O'Toole \& Meier, 2011: xii). This view also minimizes the relevance of managerial decisions in the accomplishment of organizational goals (Belton \& Dess, 1985; Hannan \& Freeman, 1977 in Meier, Favero \& Zhu, 2015: 1224). Lately, a more comprehensive approach has come to recognize the importance of environment in organizational and policy performance, above all, as an external influencer of the "management-performance linkage" (O’Toole \& Meier, 2014: 237).

This chapter addresses environmental and organizational influencers of performance in Public Housing Authorities and Section $8 \mathrm{HCV}$ programs' outcomes nationwide. The main hypothesis of this portion of the research is that environmental and agencies' structural factors impose a toll on organizational and policy performance and outcomes.

\section{Descriptive Statistics}

This section introduces dependent, independent and control variables of the study. Such variables fall into the named categories of demographic characteristics, market tightness/softness, Section 8 HCV Program's hardly-controllable structural factors, PHAs' performance indicators, Section $8 \mathrm{HCV}$ Program's outcomes indicators of poverty and race 
desegregation, neighborhood and housing quality, and control variables. A number of these variables operate as both, dependent and independent variables in different circumstances and models. I marked these variables with an asterisk (*).

Independent Variables: Environmental and Organizational Influencers of Performance

The literature on Public Housing Authorities and Section 8 HCV Program (see Chapter 2 and Chapter 4) agrees on the factors that influence PHAs' performance and Section $8 \mathrm{HCV}$ program's outcomes. These influencers of organizational and policy performance are the demographic characteristics of surrounding communities such as poverty levels, racial composition, and political preferences, neighborhood and housing quality within the area, assigned budget by HUD, Section $8 \mathrm{HCV}$ program's hardlycontrollable structural factors, and conditions of the housing market, among others. Table 3 below displays the descriptive statistics of PHAs and Section $8 \mathrm{HCV}$ program's environmental and organizational influencers of performance.

Table 3. Independent Variables: Environmental and Organizational Influencers of Performance

\begin{tabular}{l|l|l|l|l|l}
\multicolumn{1}{c|}{ Variable } & Obs. & Mean & Std. Dev. & Min & Max \\
\hline Demographic Characteristics & & & & & \\
\hline Population & 3140 & 100793.9 & 323129.4 & 85 & $1.00 \mathrm{e}+07$ \\
\hline Poverty & 3141 & 16.27482 & 6.465473 & 3.4 & 47.4 \\
\hline Income & 3141 & 48600.6 & 12355.27 & 22894 & 125900 \\
\hline POPPCT_URBAN & 3142 & 41.33212 & 31.50149 & 0 & 100 \\
\hline PCT_ObamaVote & 3109 & 38.40997 & 14.70253 & 3.4 & 93.4 \\
\hline Black_PCT & 3140 & 9.008503 & 14.46118 & 0 & 85.9 \\
\hline Hispanic_PCT & 3140 & 8.830955 & 13.49821 & 0 & 98.7 \\
\hline Market Tightness/Softness & & & & & \\
\hline HousingUnit & 3140 & 42924.9 & 125820.2 & 50 & 3504139 \\
\hline AnnualChange_PCT & 2674 & 3.081765 & 4.849619 & -56.11 & 29.96 \\
\hline HPI & 2686 & 258.3951 & 165.2065 & 69.67 & 1793.12 \\
\hline Section 8 HCV Structural & & & & &
\end{tabular}




\begin{tabular}{l|l|l|l|l|l} 
SubdUnitAv & 2923 & 819.6911 & 3345.564 & 1 & 93270 \\
\hline Occupied_PCT & 2923 & 72.1755 & 34.99423 & -5 & 290 \\
\hline AvgHUDExp & 2923 & 484.5101 & 287.4167 & -5 & 5749 \\
\hline AvMonths & 2923 & 17.36059 & 30.6912 & -5 & 1202 \\
\hline Racial Disparity & & & & & \\
\hline Diss_Index & 3125 & 27.91987 & 14.54925 & 0 & 77.7 \\
\hline Neighborhood Quality & & & & & \\
\hline DCI & 3128 & 50.01173 & 28.8799 & 0 & 100 \\
\hline $\begin{array}{l}\text { County Seat Control } \\
\text { Variables }\end{array}$ & & & & & \\
\hline CS_Pop & 1101 & 44856.49 & 170111.4 & 326 & 3900794 \\
\hline CS_Income & 1102 & 37395.97 & 9755.678 & 14254 & 89134 \\
\hline CS_HousingEst & 1102 & 19429.25 & 68343.37 & 160 & 1436543 \\
\hline CS_HousingOcc & 1102 & 17121.44 & 61603.64 & 142 & 1342761
\end{tabular}

Dependent Variable 1: County Seat Public Housing Authority Score

As mentioned in Chapter 4, the first dependent variable in this study is an indicator of Public Housing Authorities' performance (see Table 4 below for descriptive statistics). The Public Housing Assessment System, or PHAS, is the system utilized by HUD to evaluate a PHA's performance in managing its low-rent public housing programs. HUD's Real Estate Assessment Center "effectively and fairly measures the performance of a public housing agency" (HUD.GOV). According to HUD, "scores are generated for each development, or Asset Management Project (AMP). AMP scores are weighted by how many units are in the AMP and then combined into the agency-wide score".

HUD uses a centralized system to gather individual subsystem scores by the use of various sub-indicators, then produces a composite PHAS score representing PHA's general performance. PHAS uses a 100-point scoring system. The composite PHAS score (CS_PHAScores) addresses and unifies four factors: "PASS Score: Physical Indicator score based on the physical inspection in the Physical Assessment Subsystem (PASS) and 
ranges from 0 to 40 unless points are redistributed from other PHAS indicators; FASS Score - Financial Indicator score based on the Unaudited or Audited Financial Assessment Subsystem (FASS) submission ranges from 0 to 25 points unless points are redistributed from other PHAS indicators; MASS Score - Management Operations Indicator based on the Unaudited or Audited FASS submission ranges from 0 to 25 points unless points are redistributed from other PHAS indicators; and Capital Fund Score - Capital Fund score based on Capital Fund Program (CFP) obligation data and Inventory Management System (IMS) occupancy data ranges from 0 to 10 points unless points are redistributed from other PHAS indicators." (HUD, 2016). This dissertation utilizes both, the composite indicator of PHAs' performance, and three of the sub-indicators that comprise it (PASS, MASS and FASS). HUD utilizes the total score to determine the PHA's designation under PHAS: "Scores below 60 result in a troubled designation. Scores of 90 points or above result in a high performer designation. Scores below 90 but above 60 are designated as a standard performer. If your PHA scores below 60 in any one indicator, you will be designated as a substandard performer" (HUD.GOV).

Initially, this study's sample was Public Housing Authorities at the county level. Nonetheless, PHAs scores at the county level resulted in a reduced sample of 327 observations. To increase the sample size, I decided to use PHAs at the County Seat level, augmenting the sample size to 1106 observations, while keeping the rest of the variables at the County level and adding control variables at the County Seat level. 
Table 4. Dependent Variable: County Seat Public Housing Authorities Performance Indicator(s)

\begin{tabular}{l|l|l|l|l|l} 
Variable & Obs. & Mean & Std. Dev. & Min & Max \\
\hline CS_PHAScore* & 1106 & 89.31374 & 8.676286 & 41 & 100 \\
\hline FASS & 1102 & 23.46461 & 3.95411 & 0 & 25 \\
\hline MASS* & 1102 & 20.70871 & 4.826838 & 3 & 25 \\
\hline PASS & 1106 & 35.35443 & 4.419523 & 14 & 78
\end{tabular}

Since a substantial amount of counties/county seats did not have a PHA score, I conducted independent samples t-tests to compare County seats with and without PHAs' scores. On the one hand, there is "Group 0," that comprises the county seats without PHAs' score. On the other hand, there is "Group 1", which encompasses those county seats with a PHAs' score. I created a new group variable that records whether a county has the PHAS score or not $(1=$ Yes; $0=\mathrm{No})$. The purpose of this analysis is to examine the most relevant demographic and organizational characteristics and differences of those Public Housing Authorities with, and without PHAS score.

Table 5 displays significant differences between Group 0 and Group 1 means in the scores for Poverty, Income, Percentage of Urban Population, Percentage of rural population, and Black population Percentage per County, at the .001 significance level. At the .05 significance level, one environmental influencer (Population), and three out of four organizational influencers, Subsidized Units Available, Occupied Units as Percentage of Available, and Average Months on Waiting List, in Section 8, are also statistically significant regarding mean differences. 
Table 5. Demographic Analysis of CS_PHAScore - Comparison of Mean Results

\begin{tabular}{|c|c|c|c|c|c|c|c|}
\hline & \multicolumn{3}{|c|}{ CS_PHAScore Group 0} & \multicolumn{3}{|c|}{ CS_PHAScore Group 1} & \multirow[t]{2}{*}{ p-value } \\
\hline & Obs. & Mean & $\begin{array}{l}\text { Std. } \\
\text { Dev. }\end{array}$ & Obs. & Mean & $\begin{array}{l}\text { Std. } \\
\text { Dev. }\end{array}$ & \\
\hline Population & 2,034 & 87709.86 & 267014.1 & 1,106 & 124856.3 & 405635.4 & $0.0021 * *$ \\
\hline Poverty & 2,035 & 15.74983 & 6.576041 & 1,106 & 17.24078 & 6.143645 & $0.000 * * *$ \\
\hline Income & 2,035 & 49694.4 & 13076.29 & 1,106 & 46588.05 & 10619.83 & $0.000 * * *$ \\
\hline POPPCT_URBAN & 2,036 & 37.5671 & 31.69488 & 1,106 & 48.26303 & 29.94219 & $0.000 * * *$ \\
\hline POPPCT_RURAL & 2,036 & 62.4329 & 31.69488 & 1,106 & 51.73697 & 29.94219 & 0.000 *** \\
\hline PCT_ObamaVote & 2,003 & 38.10479 & 14.8133 & 1,106 & 38.96267 & 14.49005 & 0.1194 \\
\hline PCT_RomneyVote & 2,003 & 60.07734 & 14.76473 & 1,106 & 59.44941 & 14.48271 & 0.2531 \\
\hline Black_PCT & 2,034 & 8.129941 & 14.35738 & 1,106 & 10.62423 & 14.51844 & $0.000^{* * *}$ \\
\hline Hispanic_PCT & 2,034 & 8.639626 & 13.39013 & 1,106 & 9.182821 & 13.69386 & 0.2815 \\
\hline SubdUnitAv & 1,868 & 709.8217 & 3158.909 & 1,055 & 1014.227 & 3646.193 & $0.0181 * *$ \\
\hline Occupied_PCT & 1,868 & 71.06959 & 36.37242 & 1,055 & 74.13365 & 32.33462 & 0.0230 ** \\
\hline AvgHUDExp & 1,868 & 483.0819 & 310.9267 & 1,055 & 487.0389 & 240.3314 & 0.7208 \\
\hline AvMonths & 1,868 & 16.47002 & 22.5345 & 1,055 & 18.93744 & 41.32763 & $0.0368 * *$ \\
\hline
\end{tabular}

Dependent Variable 2: The Section 8 HCV program's Hardly-Controllable Structural

\section{Factors (as predictor of performance)}

Section $8 \mathrm{HCV}$ program's hardly-controllable structural factors is the name assigned to those performance influencers, idiosyncratic of the Section $8 \mathrm{HCV}$ programs across the country (see descriptive statistics in Table 6 below). I hypothesize that these variables impact Public Housing Authorities, and that environmental and organizational Influencers Compound their effect. The common attribute of these factors is that they are hardly controllable, meaning that PHAs do not have the substantial capacity or power to modify them easily.

The first variable of this hardly-controllable group of factors is Subsidized Units Available (SubdUnitAv), which stands for the "number of units under contract for federal subsidy and available for occupancy" (Data Dictionary for Picture of Subsidized Households: 2016). The second variable is Occupied Units as Percentage of Available 
(Occupied_PCT) that counts for the number of occupied units in Section 8 HCV program, as a percentage of those available. The third variable is the Average HUD Expenditure per Month (AvgHUDExp) that captures "the monthly housing assistance payment (HAP), divided by the total number of occupied units" (Data Dictionary for Picture of Subsidized Households: 2016). Finally, there is the Average Months on Waiting List (AvMonths), or the time expended by Section 8 HCV Program's participant households before receiving a voucher.

The underlying hypothesis behind the analysis of these variables is the possibility for them to assist in the prediction of Section $8 \mathrm{HCV}$ Program's performance, in the absence of a specific indicator for such purpose. If inherent conditions and resources are not ideal during the implementation process of a given policy, one may expect to find a certain impact on its resulting outcomes.

Table 6. Dependent Variable: Hardly Controllable Section 8 HCV Program's Structural Factors (as predictor of performance)

\begin{tabular}{l|l|l|l|l|l} 
Variable & Obs. & Mean & Std. Dev. & Min & Max \\
\hline SubdUnitAv* & 2923 & 819.6911 & 3345.564 & 1 & 93270 \\
\hline Occupied_PCT* & 2923 & 72.1755 & 34.99423 & -5 & 290 \\
\hline AvgHUDExp* & 2923 & 484.5101 & 287.4167 & -5 & 5749 \\
\hline AvMonths* & 2923 & 17.36059 & 30.6912 & -5 & 1202
\end{tabular}

For the construction of one single variable that accounts for the Section $8 \mathrm{HCV}$ Program's hardly-controllable structural factors, I utilized data from the Picture of Subsidized Households 2016 that comprises the information collected for the Section 8 HCV Program. I selected the variables mentioned above that represent performance influencers within PHAs and Section $8 \mathrm{HCV}$ programs in the country. Subsequently, I used 
Principal Component Factor Analysis (PCF) and factored together the four variables (SubdUnitAv, Occupied_PCT, AvgHUDExp, AvMonths) and obtained a composite value (Factor1, or S8_StFactors), that operates as a dependent variable in Model 3. Table 7 below presents how the four variables factored together while Table 8 shows the descriptive statistics of the factored resulting variable. Although Cronbach's alpha for S8_StFactors is discouragingly low, I chose to conduct the analysis for exploratory purposes as there is no antecedent of a similar exercise.

Table 7. Constructing S8_StFactors using Principal Component Factoring (PCF)

\begin{tabular}{l|l|l} 
Variable & Factor1 (S8_StFactors) & Uniqueness \\
\hline SubdUnitAv & & 0.8482 \\
\hline Occupied_PCT & 0.8554 & 0.2683 \\
\hline AvgHUDExp & 0.8861 & 0.2148 \\
\hline AvMonths & 0.5642 & 0.6817 \\
\hline $\begin{array}{l}\text { (blanks represent } \\
\text { abs(loading)<.5) }\end{array}$ & $\begin{array}{l}\text { Eigenvalue: } 1.98700 \\
\text { Cronbach's alpha: } 0,0617\end{array}$ &
\end{tabular}

Table 8. Dependent Variable: The Section 8 HCV Program's Hardly-Controllable Structural Factors

\begin{tabular}{l|l|l|l|l|l} 
Variable & Obs. & Mean & Std. Dev. & Min & Max \\
\hline S8_StFactors & 2923 & $-4.39 \mathrm{e}-10$ & 1 & -1.962722 & 11.30745
\end{tabular}

Dependent Variable 3: Poverty Segregation Indicator

Poverty desegregation is one of the signature outcomes of the Section $8 \mathrm{HCV}$ program. Nonetheless, Section $8 \mathrm{HCV}$ 's recipient households are too, affected by concentrated poverty (Austin Turner, 2003: 2; Carlson, Haveman, Kaplan \& Wolfe, 2009; Deng 2007). In theory, the voucher gives households the freedom to select a home; however, many of them end up living in low and extremely-low income neighborhoods. 
The Poverty Segregation Indicator stands for the percentage of the population below the poverty level in the Census Tract where HUD-assisted families reside (PovertyCensus) (Census 2010 designation) (Data Dictionary for Picture of Subsidized Households 2016). This variable will assist in determining the factors that impact poverty segregation among Section 8 HCV program's holders. Table 9 comprises the descriptive statistic for dependent variable PovertyCensus.

Table 9. Dependent Variable: Poverty Segregation Indicator

\begin{tabular}{l|l|l|l|l|l} 
Variable & Obs. & Mean & Std. Dev. & Min & Max \\
\hline PovertyCensus & 2923 & 16.79747 & 11.33175 & -5 & 54
\end{tabular}

\section{Dependent Variable 4: Minority Segregation Indicator}

The second distinctive policy outcome of Section $8 \mathrm{HCV}$ program is minority desegregation. As the literature review in this study assert (see Chapter 2), disproportionate rates of minority recipients of the Section 8 Housing Choice Voucher Program live in ethnic and racially clustered neighborhoods across the country (Varady \& Walker, 2000; Varady, 2010: 402; Deng, 2007: 22; Newman \& Schnare). The Minority Segregation Indicator accounts for the minority percentage of total population in the Census Tract where HUD-assisted families reside (Census 2010 designation) (Data Dictionary for Picture of Subsidized Households 2016). This variable will allow identifying environmental and organizational influencers of minority segregation among Section 8 HCV recipients, according and beyond those defined by the literature. Table 10 displays MinorityCensus descriptive statistics. 
Table 10. Dependent Variable: Minority Segregation Indicator

\begin{tabular}{l|l|l|l|l|l} 
Variable & Obs. & Mean & Std. Dev. & Min & Max \\
\hline MinorityCensus & 2923 & 22.82381 & 24.38091 & -5 & 97
\end{tabular}

\section{Regression Diagnostics}

To confirm that regression models in this study meet OLS regression normality assumptions, I applied a number of diagnostic tests after conducting Ordinary Least Square (OLS) analysis. To assure that the models are linear in the relationship between variables (Gujarati \& Porter, 2009: 38), I plotted the standardized residuals of the regressions line against each independent variable. Despite eye-balling subjectivity, I confidently did not find distinct patterns displayed on the plots; but equally spread residuals around a horizontal line. A sign of the conditional expectation of the dependent variables as a linear function of the models' independent variables.

For ratifying the normality of residuals, I conducted a Kernel density plot of residuals. In Figure 5 it can be seen how the distribution deviates from the theoretical normal one. A Skewness/Kurtosis test for normality underpins the visual evidence, resulting in a Prob $>$ chi $2=0.00$, indicating a normality problem. Nonetheless, because of the test's bias against large datasets, the normality assumption can be relaxed as the sample size used in this dissertation is greater than 500 observations. 
Figure 5. Kernel Density Plot of Residuals

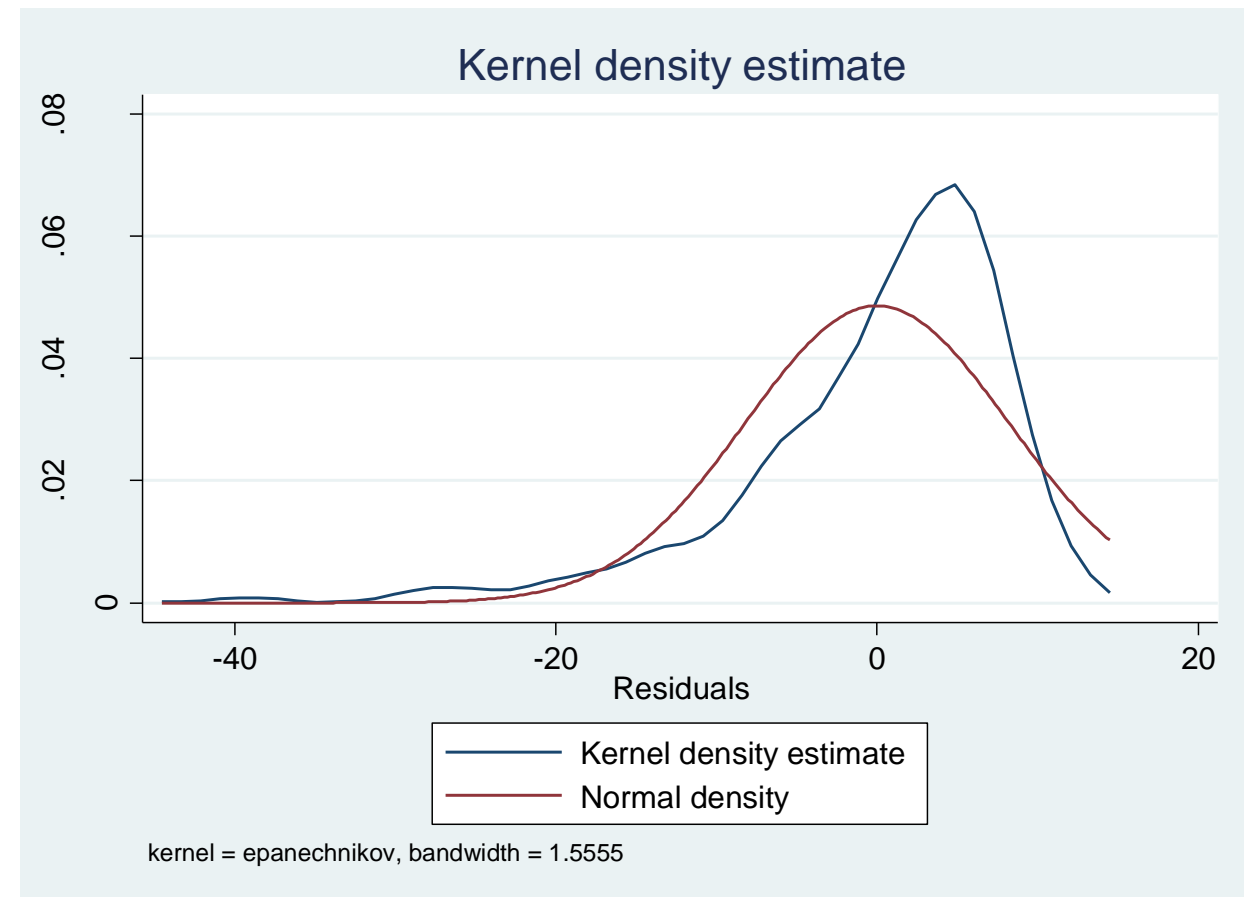

I detected multicollinearity (Baum, 2006: 84) in the four regression models. I conducted the Variance Inflation Factor test finding some problematic variables. I dropped CS_HousingEst, CS_HousingOcc, CS_Pop, Population, HousingUnit, and SubdUnitAv from Model 1, 3 and 4, being these variables' VIF greater than 10 (Baum, 2006: 85). Independent variables HousingUnit and Population were also dropped from Model 2. These drops do not hurt the analysis as such variables share similarities with others that stayed in the models. For instance, Population and the percentage of urban population.

The Breusch-Pagan test confirmed that three out of the four regression models violate the assumption of homoscedasticity of the error terms (Gujarati \& Porter, 2009: 544). Model 1, 2 and 3 displayed heterogeneity of the error terms. To correct for this condition, I utilized robust standard errors assisted by STATA. 


\section{Results}

Model 1: Environmental and Organizational Influencers of PHAs' Performance

The research question that animates the first regression analysis in this dissertation is If, and to what extent, do organizational and environmental conditions, such as demographics and political preferences of communities, economic factors, and racial disparities, affect public organizations' performance? I hypothesize that both, environmental and organizational factors, pose a toll on organizational performance. The quantitative analysis contained in Model 1 accounts for the impact of hardly modifiable environmental and organizational conditions on Public Housing Authorities at the County seat level across the country. Using an Ordinary Least Square (OLS) regression analysis, I explore the relationship between County Seat Public Housing Authorities' Score and the demographic characteristics of communities surrounding these agencies, conditions of tightness or softness of the housing market, poverty and race levels within the county, racial disparities, and neighborhood quality. In this Model, I also consider the influence of Section $8 \mathrm{HCV}$ program's hardly-controllable structural factors as feasible influencers of Public Housing Authorities' performance.

Table 11 presents the results that partially endorse the hypothesis mentioned above. Holding all other variables constant, the analysis accounts for the statistical significance of Poverty as a predictor of PHAs score performance. At less than .05 significance level, Poverty has a negative relationship with County Seat PHAs' score. The other socioeconomic independent variable, Income, is also a negative significant predictor of Public Housing Authority's Score at less than .01 significance level. Among the demographic predictors of the analysis and holding all other variables constant, the 
Percentage of Urban Population is statistically significant at less than .01 significance level and has a negative relationship with PHAs' score. The regression also reports a statistically significant relationship between the percentage of Hispanic population per county and PHAs' scores. Such relationship is positive. The OLS analysis confirms, holding all other variables constant, that White to Non-White Racial Dissimilarity within counties has a negative and significant relationship with the dependent variable (at 0.028 alpha level). In the same vein, the predictor Distressed Community Index, which accounts for distressed scores related to neighborhood quality, has a negative and statistically significant relationship with PHAs' score, at 0.011 level of significance.

Only one of the Section $8 \mathrm{HCV}$ Program's hardly-controllable structural factors accounts for a significant relationship with the dependent variable, CS_PHAScore. Holding all other variables constant, Occupied Units as Percentage of Available in Section 8 has a positive and significant relationship at 0.035 alpha level.

Table 11. Environmental and Organizational Influencers of PHAs’ Performance

\begin{tabular}{l|c} 
Dependent Variable: CS_PHAScore & Coef. \\
Regressor & -.28 \\
\hline Poverty & $(.112)^{* *}$ \\
\hline Income & -.000 \\
& $(.000)^{* * *}$ \\
\hline POPPCT_URBAN & -.04 \\
& $(.014)^{* * *}$ \\
\hline PCT_ObamaVote & -.00 \\
& $(.025)$ \\
\hline Black_PCT & -.01 \\
& $(.028)$ \\
\hline AnnualChange_PCT & .04 \\
& $(.022)^{* *}$ \\
\hline
\end{tabular}




\begin{tabular}{l|c} 
HPI & .00 \\
& $(.002)$ \\
\hline Occupied_PCT & .027 \\
& $(.013)^{* * *}$ \\
\hline AvgHUDExp & -.00 \\
\hline AvMonths & $(.001)$ \\
\hline Diss_Index & -.00 \\
& $(.006)$ \\
\hline DCI & -.04 \\
& $(.022)^{* *}$ \\
\hline CS_Income & -.05 \\
& $(.020)^{* *}$ \\
\hline R-squared & .00 \\
$\mathbf{n}$ & $(.000)$ \\
$* \mathrm{p}<.10, * * \mathrm{p}<.05, * * * \mathrm{p}<.01$ & 0.075 \\
& 970
\end{tabular}

R-squared values are substantially low in the OLS linear regressions that analyze the environmental and organizational influencers of organizational performance in Public Housing Authorities. Nonetheless, the exploratory nature of this dissertation allows experimenting with indicators that are not commonly related on the field, "in the quest of a more general theory" (O'Toole \& Meier, 2014: 237) of performance. In this vein, Models $1 \mathrm{~A}, 1 \mathrm{~B}$, and $1 \mathrm{C}$ utilize three out of the four sub-indicators that compose dependent variable County Seat Public Housing Authority Score (CS_PHAScore). These sub-indicators are used as dependent variables in separate and more specific models. As previously mentioned, such sub-indicators account for PASS Score: Physical Indicator score based on the physical inspection in the Physical Assessment Subsystem (PASS) and ranges from 0 to 40; FASS Score: Financial Indicator score based on the Unaudited or Audited Financial Assessment Subsystem (FASS) submission, ranges from 0 to 25 points; and MASS Score 
or Management Operations Indicator based on the Unaudited or Audited FASS submission ranges from 0 to 25 points (HUD, 2016).

Model 1A: Environmental and Organizational Influencers of PHAs' Management Operations

Model 1A addresses the specific question: If, and to what extent, do organizational and environmental conditions influence Managerial Action within Organizations? I hypothesize that organizational and environmental conditions influence managerial action, limiting or enhancing managerial decision-making. Public Housing Authorities performance score's sub-indicator, Management Operations Indicator (MASS), serves as the dependent variable. An Ordinary Least Square regression was conducted to predict the relationship between the dependent and independent variables.

Table 12 below displays the results of the analysis. Holding all variables constant, Income is a statistically significant predictor of managerial action within Public Housing Authorities at the County Seat level, at 0.067 significance level. The relationship between Income and managerial action is negative. The percentage of urban population within the county also has a statistically significant relationship with PHAs' management operations, at a 0.036 significance level. Such relationship is negative as well. Finally, the Distressed Community Index, which accounts for neighborhood quality, has a negative and statistically significant relationship with PHAs' managerial actions, holding all other variables constant, at 0.049 alpha level. 
Table 12. Environmental and Organizational Influencers of PHAs' Management Operations

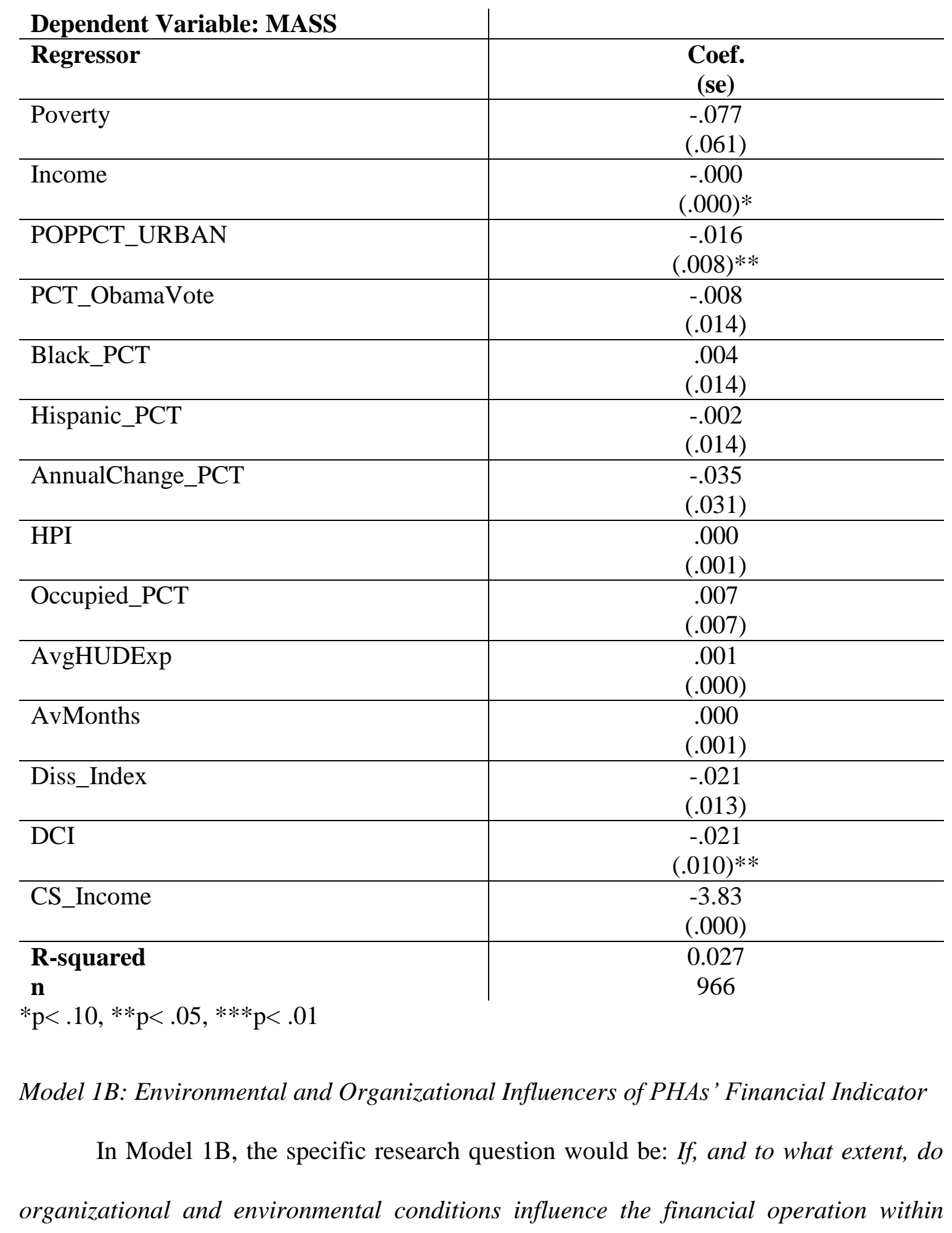


public organizations? I hypothesize that organizational and environmental conditions impact the financial operation of public organizations, in this particular case, Public Housing Authorities across the country at the County seat level. Public Housing Authorities performance score's sub-indicator, Financial Indicator (FASS), operates as the dependent variable. Once again, an Ordinary Least Square regression was conducted to predict the relationship between the dependent and independent variables.

Again, and holding all other variables constant, Income appears as a negative and significant predictor of PHAs' financial indicator, at 0.019 alpha level (see Table 13 below). Another statistically significant predictor that holds an equally negative relationship with the dependent variable, FASS, is the percentage of urban population in the county (at 0.001 significance level). In addition to these predictors, the White to NonWhite Racial Dissimilarity within counties is a statistically significant and negative predictor of PHAs' financial indicator at 0.037 significance level. Holding all other variables constant, the percentage of the Hispanic population at the county level has a statistically significant and positive relationship with PHAs' financial indicator. County Seat income has a positive and significant relationship with public housing authorities' financial indicator at 0.051 alpha level.

The only statistically significant organizational factor in this regression is Occupied Units as Percentage of Available in Section 8, which has a positive relationship with PHAs' financial indicator a 0.050 significance level. 
Table 13. Environmental and Organizational Influencers of PHAs' Financial Indicator

\begin{tabular}{|c|c|}
\hline Dependent Variable: FASS & \\
\hline Regressor & $\begin{array}{c}\text { Coef. } \\
\text { (se) }\end{array}$ \\
\hline Poverty & $\begin{array}{l}-.081 \\
(.079)\end{array}$ \\
\hline Income & $\begin{array}{c}-.000 \\
(.000) * *\end{array}$ \\
\hline POPPCT_URBAN & $\begin{array}{c}-.021 \\
(.006) * * *\end{array}$ \\
\hline PCT_ObamaVote & $\begin{array}{c}-.010 \\
(.011)\end{array}$ \\
\hline Black_PCT & $\begin{array}{c}.021 \\
(.014) \\
\end{array}$ \\
\hline Hispanic_PCT & $\begin{array}{c}.028 \\
(.008)^{* * *}\end{array}$ \\
\hline AnnualChange_PCT & $\begin{array}{c}.007 \\
(.019) \\
\end{array}$ \\
\hline HPI & $\begin{array}{l}-.000 \\
(.001) \\
\end{array}$ \\
\hline Occupied_PCT & $\begin{array}{c}.012 \\
(.006) *\end{array}$ \\
\hline AvgHUDExp & $\begin{array}{c}-.001 \\
(.000)\end{array}$ \\
\hline AvMonths & $\begin{array}{c}-.002 \\
(.003)\end{array}$ \\
\hline Diss_Index & $\begin{array}{c}-.021 \\
(.010) * *\end{array}$ \\
\hline DCI & $\begin{array}{c}-.014 \\
(.010)\end{array}$ \\
\hline CS_Income & $\begin{array}{c}.000 \\
(.000)^{*}\end{array}$ \\
\hline $\begin{array}{l}\text { R-squared } \\
\mathbf{n} \\
* \mathrm{p}<.10, * * \mathrm{p}<.05, * * * \mathrm{p}<.01\end{array}$ & $\begin{array}{c}0.057 \\
966\end{array}$ \\
\hline
\end{tabular}

Model 1C: Environmental and Organizational Influencers of PHAs' Physical Indicator

Model 1C addresses the question: If, and to what extent, do organizational and environmental conditions influence PHAs' Physical Indicator? The Physical Indicator accounts for the physical inspection of PHAs' stock and 'determine whether public 
housing units are decent, safe, sanitary and in good repair" (HUD 2016). I hypothesize that organizational and environmental conditions influence physical conditions of PHAs' housing stock, and better environment and organizational wellness can be associated with better housing quality. Public Housing Authorities performance score's sub-indicator, Physical Indicator (PASS), serves as the dependent variable. An Ordinary Least Square regression was conducted to predict the relationship between the dependent and independent variables.

Table 14 below reports the results of the OLS regression analysis. Holding all other variables constant, poverty is a negative and statistically significant predictor of physical conditions of PHAs' housing stock, at a 0.005 significance level. Income is the strongest predictor of PHAs' Physical Indicator, with a significance level of 0.001 alpha. The relationship between Income and PASS is negative. Independent variables that account for diversity are also statistically significant predictors of PHAs' Physical Indicator. The percentage of the Black and Hispanic population within the county are significant at the 0.052 and 0.024 alpha level, respectively. While the relationship between percentages of Black population with Physical Indicator is negative; the one between this dependent variable and Hispanic population is positive. Finally, the Distressed Community Index, an indicator of neighborhood quality has a negative and statistically significant relationship with PHAs' Physical Indicator, at 0.052 significance level. 
Table 14. Environmental and Organizational Influencers of PHAs' Physical Indicator

\begin{tabular}{|c|c|}
\hline Dependent Variable: PASS & \\
\hline Regressor & $\begin{array}{c}\text { Coef. } \\
\text { (se) }\end{array}$ \\
\hline Poverty & $\begin{array}{c}-.159 \\
(.056) * * *\end{array}$ \\
\hline Income & $\begin{array}{c}-.000 \\
(.000) * * *\end{array}$ \\
\hline POPPCT_URBAN & $\begin{array}{l}-.009 \\
(.009)\end{array}$ \\
\hline PCT_ObamaVote & $\begin{array}{c}.021 \\
(.014)\end{array}$ \\
\hline Black_PCT & $\begin{array}{c}-.032 \\
(.016) *\end{array}$ \\
\hline Hispanic_PCT & $\begin{array}{c}.022 \\
(.010)^{* *}\end{array}$ \\
\hline AnnualChange_PCT & $\begin{array}{c}.005 \\
(.028)\end{array}$ \\
\hline HPI & $\begin{array}{c}.000 \\
(.001)\end{array}$ \\
\hline Occupied_PCT & $\begin{array}{c}.007 \\
(.006)\end{array}$ \\
\hline AvgHUDExp & $\begin{array}{l}-.001 \\
(.000)\end{array}$ \\
\hline AvMonths & $\begin{array}{l}-.000 \\
(.001)\end{array}$ \\
\hline Diss_Index & $\begin{array}{c}-.001 \\
(.011)\end{array}$ \\
\hline DCI & $\begin{array}{c}-.018 \\
(.009)^{*}\end{array}$ \\
\hline CS_Income & $\begin{array}{l}-1.67 \\
(.000)\end{array}$ \\
\hline $\begin{array}{l}\text { R-squared } \\
\mathbf{n} \\
{ }^{*} \mathrm{p}<.10, * * \mathrm{p}<.05, * * * \mathrm{p}<.01\end{array}$ & $\begin{array}{c}0.058 \\
970\end{array}$ \\
\hline
\end{tabular}


Model 2: Compounded Effect of Environmental and Organizational Influencers on the Section 8 HCV program's hardly-controllable structural factors (as predictor of performance)

The second model in this study responds to the research question: Do environmental and organizational conditions compound the effect of the Section 8 HCV program's hardly-controllable structural factors (as a predictor of performance)? I hypothesize that environmental and organizational conditions compound the effect of hardly controllable Section $8 \mathrm{HCV}$ program's structural factors. By establishing this statistically significant relationship, one can predict Section $8 \mathrm{HCV}$ programs' performance, in the absence of a performance indicator for it. In essence, Model 2 examines the relationship between environmental conditions surrounding Section $8 \mathrm{HCV}$ programs' implementation and other internal conditions of Public Housing Authorities -such as County Seat PHAs' performance indicator-, with the Section 8 HCV program's hardlycontrollable structural factors. As in previous models, I use an Ordinary Least Square (OLS) regression analysis to predict the relationship between the dependent and independent variables.

Results displayed in Table 15 below report the statistical significance of the percentage of urban population in the range of .01 significance level. The relationship between this independent variable and the factored dependent variable that comprises the Section $8 \mathrm{HCV}$ program's hardly-controllable structural factors (S8_StFactors) is positive. In the same vein, the independent variable that accounts for the percentage of votes for Obama 2012, has a positive and significant relationship with the dependent variable at a 0.001 significance level. Housing market's tightness at the county level -represented in the 
independent variable House Prince Index (HPI)-, is a significant and positive predictor of S8_StFactors, with a 0.000 significance level. The White to Non-White racial dissimilarity Index has a positive and statistically significant relationship with S8_StFactors, at a 0.000 alpha level. Finally, the Distressed Community Index that comprises Neighborhood quality characteristics is a positive and statistically significant predictor of Hardly Controllable Section 8 HCV Program's Structural Factors, at 0.019 significance level.

Table 15. Compounded Effect of Environmental and Organizational Influencers on the Section $8 \mathrm{HCV}$ program's hardly-controllable structural factors (as predictor of performance)

Dependent Variable: Factor 1 (S8_StFactors)

\begin{tabular}{|c|c|}
\hline Regressor & $\begin{array}{c}\text { Coef. } \\
\text { (se) }\end{array}$ \\
\hline Income & $\begin{array}{c}3.18 \mathrm{e}-06 \\
(3.88 \mathrm{e}-06)\end{array}$ \\
\hline POPPCT_URBAN & $\begin{array}{c}.005 \\
(.001)^{* * *}\end{array}$ \\
\hline PCT_ObamaVote & $\begin{array}{c}.006 \\
(.001)^{* * *}\end{array}$ \\
\hline HPI & $\begin{array}{c}.001 \\
(.000)^{* * *}\end{array}$ \\
\hline Diss_Index & $\begin{array}{c}.011 \\
(.002)^{* * *}\end{array}$ \\
\hline DCI & $\begin{array}{c}.003 \\
(.001)^{* *}\end{array}$ \\
\hline CS_PHAScores & $\begin{array}{c}.002 \\
(.002)\end{array}$ \\
\hline $\begin{array}{l}\text { R-squared } \\
\text { n }\end{array}$ & $\begin{array}{l}0.30 \\
975\end{array}$ \\
\hline
\end{tabular}


Model 3: Environmental and Organizational Influencers of Poverty Segregation Levels on Section 8 HCV Recipients

The third OLS regression analysis in this dissertation addresses the following research question: Do environmental, organizational and Section $8 \mathrm{HCV}$ program structural factors affect poverty segregation levels in Section 8 HCV recipients? I hypothesize that environmental, organizational, and Section 8 structural factors impact poverty segregation levels on Section $8 \mathrm{HCV}$ recipients. Model 3 focuses on the relationship between environmental, organizational and policy factors and levels of poverty segregation among housing voucher holders. The dependent variable PovertyCensus stands for the percentage of the population below the poverty level in the Census Tract where HUD-assisted families reside (PovertyCensus) (Census 2010 designation) (Data Dictionary for Picture of Subsidized Households 2016). PovertyCensus operates as a poverty segregation indicator. Independent variables are outcome influencers at the policy, organization and environment level.

According to the results displayed in Table 16, and holding all other variables constant, the percentage of Poverty at the county level is a significant predictor of poverty segregation among Section $8 \mathrm{HCV}$ program's recipients. This relationship is positive at the strongest confidence level $(\mathrm{p}=0.000)$. Both Income and County Seat Income have a negative and statistically significant relationship with poverty segregation at 0.015 and 0.000 alpha level respectively. In addition to these socioeconomic influencers, the percentage of urban population is also a positive and statistically significant predictor of poverty segregation levels among Section 8 recipients ( 0.001 alpha level). Indicators of race and ethnicity, such as Percentage of Black and Hispanic population within the county 
are too, positive and statistically significant predictors of poverty segregation at $\mathrm{p}=0.000$ and $\mathrm{p}=0.001$ significance level, each. The White to Non-White Racial Dissimilarity Index, which accounts for racial disparities at the county level, holds a positive and statistically significant relationship with poverty segregation at the highest level of confidence $(\mathrm{p}=0.000)$. Section 8 Housing Choice Voucher Program Structural Factors are positive and statistically significant predictors of poverty segregation levels among program's voucher recipients. Occupied Units as Percentage of Available in Section 8, has the most reliable significance level (0.000), while Average HUD Expenditure per Month in the program impacts poverty segregation at 0.001 alpha level. Finally, the Average Months expended by recipients in the Waiting List is statistically significant within the range of $p<0.1$.

Table 16. Environmental and Organizational Influencers of Poverty Segregation Levels on Section 8 HCV Recipients

\begin{tabular}{l|c} 
Dependent Variable: PovertyCensus & \\
\hline Regressor & $\begin{array}{c}\text { Coef. } \\
(\mathbf{s e})\end{array}$ \\
\hline Poverty & .394 \\
& $(.064)^{* * *}$ \\
\hline Income & -.000 \\
& $(.000)^{* *}$ \\
\hline POPPCT_URBAN & .057 \\
& $(.008)^{* * *}$ \\
\hline PCT_ObamaVote & -.021 \\
& $(.013)$ \\
\hline Black_PCT & .103 \\
& $(.016)^{* * *}$ \\
\hline Hispanic_PCT & .038 \\
& $(.011)^{* * *}$ \\
\hline AnnualChange_PCT & -.046 \\
& $(.038)$ \\
\hline HPI & -.000 \\
& $(.001)$ \\
\hline Occupied_PCT & .186 \\
& $(.019)^{* * *}$
\end{tabular}




\begin{tabular}{l|c} 
AvgHUDExp & $\begin{array}{c}.007 \\
(.002)^{* * *}\end{array}$ \\
\hline AvMonths & .007 \\
& $(.004)^{*}$ \\
\hline CS_PHAScore & -.013 \\
& $(.018)$ \\
\hline Diss_Index & .053 \\
& $(.015)^{* * *}$ \\
\hline DCI & -.015 \\
\hline CS_Income & $(.011)$ \\
\hline R-squared & -.000 \\
$\mathbf{n}$ & $(.000)^{* * *}$ \\
$* \mathrm{p}<.10, * * \mathrm{p}<.05, * * * \mathrm{p}<.01$ & 0.77 \\
\end{tabular}

Model 4: Environmental and Organizational Influencers of Racial Segregation Levels on Section 8 HCV Recipients

The fourth and final Ordinary Least Square regression analysis responds to the following research question: Do environmental, organizational and Section 8 program structural factors affect racial segregation levels in Section 8 HCV recipients? Once again, I hypothesize that environmental, organizational, and Section 8 structural factors impact racial segregation levels on Section $8 \mathrm{HCV}$ holders. Model 4 addresses the connection between environmental, organizational and policy influencers of outcomes and performance, with levels of racial and minority segregation among Section 8 Housing Choice Voucher recipients. The dependent variable MinorityCensus accounts for the minority percentage of total population in the Census Tract where HUD-assisted families reside (Census 2010 designation) (Data Dictionary for Picture of Subsidized Households 2016). MinorityCensus serves as a minority/race segregation indicator. As in Model 3, 
Independent variables are outcome influencers at the policy, organization and environment level.

Holding all other variables constant (see Table 17), the regression analysis reports that both, Income and County Seat Income are significant predictors of racial segregation among Section 8 voucher holders. While Income at the County level holds a positive relationship with the dependent variable, at 0.081 significance level; County Seat Income has a negative relation with MinorityCensus, at the highest level of statistical significance $(\mathrm{p}=0.000)$. The percentage of urban population within the county is a positive and statistically significant predictor of minority segregation (at 0.000 alpha level). Race and ethnicity predictors, such as Black and Hispanic percentage of County's population have a positive relationship with minority segregation levels among Section $8 \mathrm{HCV}$ program's recipients. The black percentage is statistically significant at $\mathrm{p}=0.000$ alpha level, the same level of significance for the Hispanic percentage of the population within county limits. Market tightness -as House Price Index- is a significant predictor of minority segregation, at less than .05 level of significance. The relationship between House Price Index and MinorityCensus is positive. The White to Non-White Racial Dissimilarity Index is a significant and positive predictor of levels of minority segregation among Section $8 \mathrm{HCV}$ program's recipients.

The organizational performance represented in the independent variable that accounts for PHAS' performance, County Seat Public Housing Authority Score, has a negative and statistically significant relationship with levels of minority segregation, at 0.001 significance level. As in the case of poverty segregation in Model 3, Section 8 Housing Choice Voucher Program Structural Factors are also positive and statistically 
significant predictors of minority segregation levels among program's voucher holder. Occupied Units as Percentage of Available in Section 8, has a significance level of 0.000. Average HUD Expenditure per Month in the program impacts poverty segregation at the highest statistically significant level as well $(\mathrm{p}=0.000)$. Last but not least, the Average Months expended by recipients in the Waiting List is statistically significant at 0.013 alpha level.

Table 17. Environmental and Organizational Influencers of Racial Segregation Levels on Section 8 HCV Recipients

\begin{tabular}{l|c} 
Dependent Variable: MinorityCensus & \\
\hline Regressor & $\begin{array}{c}\text { Coef. } \\
\text { (se) }\end{array}$ \\
\hline Poverty & .055 \\
& $(.111)$ \\
\hline Income & .000 \\
& $(.000)^{*}$ \\
\hline POPPCT_URBAN & .061 \\
& $(.016)^{* * *}$ \\
\hline PCT_ObamaVote & -.038 \\
& $(.025)$ \\
\hline Black_PCT & 1.14 \\
& $(.027)^{* * *}$ \\
\hline Hispanic_PCT & .923 \\
& $(.026)^{* * *}$ \\
\hline AnnualChange_PCT & -.050 \\
& $(.062)$ \\
\hline HPI & .009 \\
& $(.003)^{* * *}$ \\
\hline Occupied_PCT & .163 \\
& $(.014)^{* * *}$ \\
\hline AvgHUDExp & .011 \\
& $(.002)^{* * *}$ \\
\hline AvMonths & .017 \\
& $(.006)^{* *}$ \\
\hline CS_PHAScore & $-.113(.034)^{* * *}$ \\
\hline Diss_Index & .146 \\
& $(.026)^{* * *}$
\end{tabular}




\begin{tabular}{l|c} 
DCI & -.036 \\
& $(.022)$ \\
\hline CS_Income & -.000 \\
& $(.000) * * *$ \\
\hline $\mathbf{R}$-squared & 0.86 \\
$\mathbf{n}$ & 970 \\
$* \mathrm{p}<.10, * * \mathrm{p}<.05, * * * \mathrm{p}<.01$ &
\end{tabular}

\section{Discussion}

The final portion of this chapter discusses the statistical findings of the dissertation in the light of previous research on performance and public housing. Firstly, the discussion focuses on the environmental and organizational influencers of performance, specifically to Public Housing Authorities in the U.S. Secondly, the section addresses Section 8 Housing Choice Voucher Program's predictors of performance, analyzing compounding factors of this policy's structural conditions. Finally, the chapter concludes with the interpretation of results on Section $8 \mathrm{HCV}$ program's influencers of poverty and race segregation, and their impact on the most distinctive outcomes of this housing policy. Influencers of Organizational Performance: Public Housing Authorities in the U.S.

Public Housing Authorities' scholars concentrate their efforts on accounting for the evident: the federal government's historical neoliberal shift in housing policy (Goetz, 2012: 457), and the resultant financial hardship for programs' execution at every PHA in the nation (Garshick Kleit \& Page, 2008: 34; 2015: 623; Goetz: 2012: 457). In this same logic, Public Housing Authorities are also studied from an efficiency perspective, following the incorrect assumption that "the private market could operate more efficiently than bureaucratic entities” (Cunningham, 2003: 96). Nonetheless, Public Housing Authorities’ performance is hardly related to local environmental influencers, and to internal organizational predictors within the agencies. 
The literature on organizational performance helps to understand the relationship between Public Housing Authorities and their environment. There is a partial affirmative response to Model 1 research question: If, and to what extent, do organizational and environmental conditions, such as demographics and political preferences of communities, economic factors, and racial disparities, affect public organizations' performance? Confirming the hypothesis that organizational and environmental factors impose a toll on organizational performance (Smith in Boyne, Meier, O’Toole \& Walker, 2006: 87).

Demographic and socioeconomic characteristics of communities partially explain organizational performance. Following OLS regression outcomes in Model 1, Public Housing Authorities' performance is negatively affected if they are surrounded by high levels of poverty, predominantly urban counties, substantial racial disparities between White and Non-White population, and counties with signs of neighborhood's low quality and distress, such as No High School degree, adults not working, and housing vacancy. According to Avellaneda (2008: 293), these complex and heterogeneous environments impose a toll in terms of the size and nature of the organization's target group. The smaller and more homogeneous the target, the higher the possibilities of success, as the cost of information and classification of recipients can be reduced and coverage incremented. Unexpectedly, political preferences (Avellaneda, 2008: 291; Rainey \& Jung, in Walker, Boyne \& Brewer, 2010: 41) are not significant in this regression.

The only relevant organizational influencer of PHAs' performance is Occupied Units as Percentage of Available in Section 8 HCV Program. The higher the occupancy level, the higher the performance. This is an understandable relationship when addressing occupancy levels as a manifestation of program's success. However, this correlation can 
mask the need for additional housing provision within localities (Turner \& Kingsley, 2008:

$3)$.

\section{Predictors of Policy Performance: The Case of Section 8 HCV Program}

Section $8 \mathrm{HCV}$ program does not have a direct measure of policy performance. Yet, a number of structural and hardly-controllable factors may help to predict program performance. Such factors stand for important program's resources, as some authors claim that "variations in resources act in a similar way to variations in environmental factors in altering the capacity of the organization to secure good performance" (Smith in Boyne, Meier, O'Toole \& Walker, 2006: 87). Section $8 \mathrm{HCV}$ program's resources are: the Subsidized Units Available per PHA, the Occupied Units as Percentage of Available, the Average amount of HUD Expenditure per Month, and the Average of Months expended by recipients on the Waiting List. I consider these factors both, structural and hardly controllable, as PHAs' managers and administrators' room to maneuver is very limited, if perhaps inexistent.

The existing literature on Section 8 HCV Program's performance (see Chapter 2) provides a number of arguments that explain the lack of success of the housing vouchers policy. Among these causes (market, budget, family preferences, landlords' discrimination, and obstacles inherent to the program), two of them are fully quantifiable: The "market tightness" causes (Austin Turner, 2003: 1; Deng, 2007: 22; Ross, Shlay \& Picon, 2012: 39; Williamson, Smith \& Strambi-Kramer, 2009: 121), and the "budgeting causes" (Austin Turner, 2003: 1).

Model 2 addresses the question: Do environmental and organizational conditions compound the effect of the Section 8 HCV program's hardly-controllable structural factors 
(as a predictor of performance)? I hypothesize that environmental and organizational conditions compound the effect of Section $8 \mathrm{HCV}$ program's hardly-controllable structural factors. Ordinary Least Square regression supports the hypothesis when confirming that, on one hand, complex demographic and socioeconomic characteristics of communities, as found in predominantly urban counties, with important racial disparities between White and Non-White population, and signs of neighborhood's low quality and distress, exert pressure over Section $8 \mathrm{HCV}$ program's resources (Smith in Boyne, Meier, O'Toole \& Walker, 2006: 87). In the particular case of budget limitations, I explained before how the fee formula based on the local Fair Market Rent (FMR), covers only around 90\% of the administrative fees that PHAs would have received if full funding were available, that percentage dropped to 69.26\% in 2013 and raised to 79.76\% in 2014 (HUD, 2015: 1). If underfunding is already severe, it turns extreme when considering the external pressures from the environment, as presented in Model 2.

On the other hand, the regression confirms that a tight housing market, measured through the predictor "House Price Index" (HPI), influences Section 8 HCV program's hardly controllable structural factors, exerting pressure on both, program's resources and hence, performance (Austin Turner, 2003: 1; Deng, 2007: 22; Ross, Shlay \& Picon, 2012: 39; Williamson, Smith \& Strambi-Kramer, 2009: 121).

Influencers of Policy Outcomes: Addressing Poverty and Minority Segregation among Section 8 HCV Program's Recipients

Poverty and race desegregation are the signature outcome and distinctive element of Section 8 Housing Choice Voucher program (Devine et al. 2003; Galvez, 2010; Hartung and Henig 1997; Pendall 2000; Varady \& Walker, 2000; Varady, 2010). This policy aim 
derives from the idea, popular since the decade of 1980's that urban poverty and racial concentration had to be tackled through the development of desegregation strategies, namely mixed-income housing and population mobility (Goetz, 2011: 456). Section 8 HCV program acquired increasing importance due to HUD's preference for a tenant-based rental assistance strategy to provide for housing needs across the country (Garshick Kleit \& Page, 2015: 622). Nevertheless, Section 8 does not seem to be delivering its most valuable promise to their clients (Deng, 2007; Devine et al. 2003; Newman \& Schnare, 1997). The literature concentrates the causes of this policy failure in five rationales: 1 . The shortages of moderately priced rental housing and the tightness of local housing markets (Austin Turner, 2003: 1; Deng, 2007: 22; Ross, Shlay \& Picon, 2012: 39; Williamson, Smith \& Strambi-Kramer, 2009: 121); 2. The budgetary limitations externally imposed by HUD (Austin Turner, 2003: 1; Turner and Kingsley, 2008: 3); 3. The recipients' preferences or "individual needs" (Deng, 2007: 22); 4. Landlords' racial and ethnic discrimination (Beck, 1996: 159; HUD, 2013: 39); and 5. The intrinsic administrative limitations of the Housing Choice Voucher Program (Tegeler et al., 1995).

According to Galvez (2010), "the typical voucher household experiences neighborhood poverty rates in the $20 \%$ range". Data gathered for this dissertation agrees with this statement, registering a mean of $16.7 \%$ for the population below the poverty level in the Census Tracts where HUD-assisted families reside (Census 2010 designation) (Data Dictionary for Picture of Subsidized Households 2016). Concerning racial disparities within Section 8 HCV program's households, Picture of Subsidized Households 2016 data does not discriminate for the geographical location of voucher's holders from minority groups. Nonetheless, the general distribution of minority percentage in the surrounding 
Census Tract where Section $8 \mathrm{HCV}$ program's households live shows that the presence of minority population in these Tracts has a mean of $22.8 \%$. Section $8 \mathrm{HCV}$ program serves to a mean of $25.11 \%$ of Black households; while the Hispanic households account for $5.4 \%$ (Picture of Subsidized Households 2016).

I identify levels of minority and race segregation among Section 8 HCV program's recipients in this dissertation dataset and compare them with the available data (Galvez, 2010). I generated dummy variables by using the Minority and Poverty Segregation Indicators that account for the minority and poverty percentages of total population in the Census Tract where HUD-assisted families reside (Census 2010 designation) (Data Dictionary for Picture of Subsidized Households 2016). Firstly, I identified HUD's threshold for racially or ethnically-concentrated areas of poverty (R/ECAPs): a non-white population of $50 \%$ or more speaks for minority segregation. In the meantime, Census Tracts with $40 \%$ or more of individuals living at or below the poverty line defines neighborhoods of "extreme poverty" (Wilson, 1980 in HUD, AFFH-Data Documentation, 2016). Secondly, I utilized such thresholds to capture the number of households living in poverty and ethnic segregation in the Census Tract where HUD-assisted families live, at the county level (poverty segregation: 1 if PovertyCensus > 40; minority segregation: 1 if MinorityCensus $>50$ ). From a total of 3132 observations, only in 238 counties, the percentage of poverty is higher than $40 \%$ ( $7.6 \%$ of the total sample). Meanwhile, from a total sample of 3118 observations, 705 Counties display levels of minority segregation higher than the $50 \%$ threshold determined by HUD (22.6\% of the total sample). These figures show a significant improvement compared to the available data. 
Model 3 addresses the influencers of poverty segregation among Section $8 \mathrm{HCV}$ Program's recipients. The research question of this model is: Do environmental, organizational and Section 8 HCV program structural factors affect poverty segregation levels in Section 8 HCV recipients? The hypothesis that environmental, organizational, and Section 8 structural factors impact poverty segregation levels on Section $8 \mathrm{HCV}$ recipients is partially confirmed by the quantitative analysis. According to the OLS regression results, complex environmental circumstances (Avellaneda, 2008: 293), such as high poverty levels in predominantly urban counties with significant racial disparities between White and Non-White population, increase the percentage of poverty in the Census Tracts where Section $8 \mathrm{HCV}$ program's recipients inhabit. The presence of high percentages of the Black and Hispanic population within the county also aggravates the levels of poverty in Section 8 HCV Tracts. Conversely, when Income at the county and county seat level increase, poverty levels within Section $8 \mathrm{HCV}$ Tracts tend to diminish.

The Section $8 \mathrm{HCV}$ program's hardly-controllable structural factors as organizational and policy resources (Smith in Boyne, Meier, O'Toole \& Walker, 2006: 87) have a positive relationship with poverty level in the Census Tract where HUD-assisted families reside. The highest the percentage of Occupied Units and amount of time expended by households in the waiting list, the higher the levels of poverty in Section 8 HCV program's tracts.

Model 4 accounts for environmental and organizational influencers of minority segregation in Section 8 HCV Program's recipients. This model research question is: Do environmental, organizational and Section 8 HCV program structural factors affect minority segregation levels in Section 8 HCV recipients? I hypothesize that environmental, 
organizational, and Section 8 structural factors influence minority segregation levels among Section $8 \mathrm{HCV}$ recipients. The research hypothesis is partially demonstrated by the Ordinary Least Square regression results. Following Avellaneda (2008: 293), complex environmental circumstances, which are again, high poverty levels in predominantly urban counties, with substantial racial disparities between White and Non-White population, augment minority levels in the Census Tracts where Section $8 \mathrm{HCV}$ program's recipients reside. Once more, high percentages of Black and Hispanic population within the county exacerbates minority percentages in Section $8 \mathrm{HCV}$ Tracts. Hardly controllable Section 8 HCV program's structural factors -as organizational and policy resources- (Smith in Boyne, Meier, O’Toole \& Walker, 2006: 87) repeat in their positive relationship with minority percentage within Census Tracts where HUD-assisted families live, expressing a similar behavior that the one displayed with the poverty levels in Section $8 \mathrm{HCV}$ program's Census tracts.

Model 4 partially confirms a certain institutional responsibility in Section $8 \mathrm{HCV}$ program's recipients' levels of minority segregation (Turner, Popkin, and Cunningham in Austin Turner, 2003: 3; Tegeler et al., 1995: 467). Public Housing Authorities with higher performance scores tend to have their voucher holders living in tracts with lower percentages of minority segregation. Finally, regression results support the literature (Austin Turner, 2003: 1; Deng, 2007: 22; Ross, Shlay \& Picon, 2012: 39; Williamson, Smith \& Strambi-Kramer, 2009: 121), by confirming that a tight housing market, measured by the predictor "House Price Index" (HPI), has a positive influence on minority segregation in Section $8 \mathrm{HCV}$ program's Census tracts. The tightest the market, the highest the minority concentrations in Census Tracts where HUD-assisted families reside. 


\section{Chapter 6: Public Administrators' Values and Attitudes towards Citizens during Section 8 HCV Program's Implementation Process}

After analyzing the environmental and organizational influencers of Public Housing Authorities and Section $8 \mathrm{HCV}$ program's performance, I examine three qualitative aspects of public administrators' values and attitudes towards the program recipients. This dissertation ultimately hypothesizes that such aspects are unquantifiable shapers of policy implementation and eventual influencers of organizational and program performance.

First, I address public administrators' discursive devices towards citizens in terms of values and attitudes. I pay special attention to neutrality and their capitalization of their technical expertise as a source of discretion (Foucault, 1980). I also examine the rationale behind their attitudes (Alexander \& Stivers, 2010; Alkadry \& Blessett, 2010; Marr, 2016), and the particular set of public service values utilized by Section 8 workers while implementing the Program. Second, I study public administrators' perceived scope of their actions during the implementation process. Next, I explore practitioners' perceived impact on Section $8 \mathrm{HCV}$ program's outcomes: housing and neighborhood quality, and poverty and race desegregation. Finally, I include administrators' perception on the constrictions posed by hardly controllable structural factors that affect the program (Marr, 2016: 225).

This qualitative phase of the dissertation addresses the fifth research question: If, and to what extent, do public administrators' preferred set of values and attitudes coincide with either positive or negative organizational and policy performance of PHAs and Section 8 HCV Program? I hypothesize on the existence of four sets of public service values that define the behavior of public administrators towards citizens: Client 
(Orthodoxy); Customer (NPM); Citizen (NPA - NPS); and Subject (Critical Theory). Following this rationale, I further hypothesize that, on the one hand, a more democraticcentered set of public values and attitudes will coincide with positive policy performance in terms of poverty/race desegregation and higher levels of housing and neighborhood quality. On the other hand, an orthodox/NPM/domination-oriented set of public values (Client/Customer/subject types) will coincide with negative policy performance. I interviewed Section 8 HCV Program's implementers and staff members of Public Housing Authorities in the states of California and Florida.

\section{The Semi-Structured Interview}

The semi-structured interview questions qualitative aspects of public administrators' values and attitudes towards Section $8 \mathrm{HCV}$ program's recipients. In the first section, I asked public administrators about their preferences regarding public service values utilized during the implementation process. I provided an open question about values preferences: "In your opinion, what are the main values that guide your work at the Section 8 HCV Program?" Then, I asked Section 8 implementers to choose amongst a specific selection of values trios. These trios speak for the four possible sets of public values that define the behavior of public administrators towards citizens: Client (Efficiency, accountability \& neutrality); Customer (Economy, performance \& entrepreneurship); Citizen (Social equity, sovereignty of the people \& participation); and Subject (Control, domination \& power). Following this discussion, I asked administrators to select between two case scenarios where democratic and bureaucratic values compete. Hereafter, the questionnaire explores Section 8 workers' neutrality and uses of expertise as a source of discretion (Foucault, 1980), and questions the rationale behind public 
administrators' attitudes towards citizens (Alexander \& Stivers, 2010; Alkadry \& Blessett, 2010; Marr, 2016).

In the second part of the interview, I asked Program administrators about the perceived scope of their actions during the implementation process. I included questions on the limitations derived from PHAs and Section $8 \mathrm{HCV}$ program's hardly-controllable structural factors -such as budget- that affect program's performance (Marr, 2016: 225). This section includes questions related to public administrators' specific actions and quotidian decisions while implementing the program.

In the final section, I interrogate public administrators' perceived impact on policy outcomes by asking them questions about Section $8 \mathrm{HCV}$ program's signature outcomes and their actions to tackle both, neighborhood and unit quality problems, and race and poverty segregation.

\section{Participant Observation}

I conducted participant observation (Peek \& Fothergill, 2009: 46) and observation techniques, accounting for Section $8 \mathrm{HCV}$ program administrators' milieu, their quotidian routines, and the verbal and nonverbal details of their interactions and rapport with program recipients. I initially introduced myself into the fieldwork as the "credentialed expert" (Snow, Benford \& Anderson, 1986: 385). Nevertheless, a more accurate introduction as a graduate student in the pursuit of her Ph.D. degree, seeking for learning about the Section $8 \mathrm{HCV}$ program and Housing Authorities, proved itself as a better starting point. I visited six Public Housing Authorities in total. Three in California, and three in Florida. My fieldwork notes account for every contact established at PHAs. From minimal encounters with reluctant clerks at uncooperative agencies, to interviews, and tours inside more 
responsive Housing Authorities, to an extended visit for a full working week, from 9:00 am to 5:00 pm, inside a cooperative Housing Authority in Northern California.

\section{Selection and Depiction of the Study Participants}

As explained in Chapter 4, I utilized a "judgment sample" criteria to select the participants of the study (Marshall, 1996: 523). A first attempt to access the field occurred through a number of reliable contacts. Housing policy scholars in California, and housing practitioners and PA scholars connected to the housing world in Florida. Such action resulted in the first interview with a Section 8 Administrative Analyst at a Californian major Public Housing Authority. In a second phase, I randomly contacted Public Housing Authorities executive directors and Section 8 HCV Program's managers via email in the pursuit of interviews with both, managerial and operative levels of the Program. I also emailed specific caseworkers and practitioners within Housing Authorities and Section 8 $\mathrm{HCV}$ programs across the country, in the hope to receive individual responses to the interview requests. This strategy produced three more interviews, the first one with an Executive Director of a rural Public Housing Authority in Northern California that connected me with his Section 8 HCV program's Manager. I conducted the third interview of this round with an Assistant Manager at a large urban PHA in the Southern California area. After exhausting the email/telephonic contact resources with no further success, I followed the advice of pursuing a "show up" strategy, visiting six Public Housing Authorities in total, three in Florida, and three in California. Because of that action, I obtained my only interview within Floridian territory, a Director of the Section 8 Housing Choice Voucher Program in a populated city located south of the state. 
As a final resource, I decided to take my chances and travel to California. I contacted again with initial participants of the study in the state, being able to interview up to eight more Section $8 \mathrm{HCV}$ practitioners at the rural Northern Californian Housing Authority. After contacting the Assistant Manager at the urban, large PHA in the southern California area, I was able to interview one Section $8 \mathrm{HCV}$ program's supervisor and one caseworker. In total, I interviewed fifteen PHAs and Section 8 practitioners at both, managerial and operative level (see Table 18 below).

Table 18 - Depiction of Participants of the Study

\begin{tabular}{|c|c|c|c|c|c|}
\hline $\begin{array}{l}\text { Interviewee } \\
\text { Position } \\
\end{array}$ & Gender & Ethnicity/race & $\begin{array}{l}\text { Years of } \\
\text { experience }\end{array}$ & $\begin{array}{l}\text { PHA } \\
\text { location }\end{array}$ & $\begin{array}{l}\text { PHA } \\
\text { score }\end{array}$ \\
\hline $\begin{array}{l}\text { Administrative } \\
\text { Analyst* }\end{array}$ & Male & -- & 11 & $\begin{array}{c}\text { Urban } \\
\text { City }\end{array}$ & 94 \\
\hline $\begin{array}{l}\text { Assistant } \\
\text { Manager }\end{array}$ & Male & $\begin{array}{c}\text { African } \\
\text { American }\end{array}$ & - & $\begin{array}{l}\text { Urban } \\
\text { County }\end{array}$ & 96 \\
\hline $\begin{array}{c}\text { Executive } \\
\text { Director }\end{array}$ & Male & White & 30 & $\begin{array}{l}\text { Rural } \\
\text { County }\end{array}$ & 96 \\
\hline $\begin{array}{c}\text { S8 Program } \\
\text { Manager }\end{array}$ & Male & White & 8 & $\begin{array}{l}\text { Rural } \\
\text { County }\end{array}$ & 96 \\
\hline $\begin{array}{l}\text { S8 Program } \\
\text { Director }\end{array}$ & Female & White & $\begin{array}{c}37 \text { (PHA) } \\
5 \text { months } \\
(\mathrm{S} 8)\end{array}$ & $\begin{array}{c}\text { Urban } \\
\text { City }\end{array}$ & 85 \\
\hline $\begin{array}{c}\text { A\&E } \\
\text { Supervisor }\end{array}$ & Male & $\begin{array}{c}\text { White } \\
\text { Hispanic }\end{array}$ & 10 & $\begin{array}{l}\text { Urban } \\
\text { County }\end{array}$ & 96 \\
\hline Caseworker & Female & $\begin{array}{c}\text { White } \\
\text { Hispanic }\end{array}$ & 11 & $\begin{array}{l}\text { Urban } \\
\text { County }\end{array}$ & 96 \\
\hline $\begin{array}{c}\text { Occupancy } \\
\text { Specialist }\end{array}$ & Female & White & $\begin{array}{c}2.5 \text { (S8) } \\
10 \text { (PHA) } \\
\end{array}$ & $\begin{array}{c}\text { Rural } \\
\text { County }\end{array}$ & 96 \\
\hline $\begin{array}{c}\text { Occupancy } \\
\text { Specialist }\end{array}$ & Female & White & $\begin{array}{c}20 \text { (S8) } \\
30 \text { (PHA) } \\
\end{array}$ & $\begin{array}{c}\text { Rural } \\
\text { County }\end{array}$ & 96 \\
\hline $\begin{array}{c}\text { Occupancy } \\
\text { Specialist }\end{array}$ & Female & White & 9 & $\begin{array}{c}\text { Rural } \\
\text { County }\end{array}$ & 96 \\
\hline $\begin{array}{c}\text { Special } \\
\text { Programs } \\
\text { Coordinator }\end{array}$ & Female & Asian & 2.5 & $\begin{array}{c}\text { Rural } \\
\text { County }\end{array}$ & 96 \\
\hline $\begin{array}{l}\text { Occupancy } \\
\text { Specialist }\end{array}$ & Female & Asian & 13 & $\begin{array}{c}\text { Rural } \\
\text { County }\end{array}$ & 96 \\
\hline
\end{tabular}




\begin{tabular}{c|c|c|c|c|c}
$\begin{array}{c}\text { Intake } \\
\text { Specialist }\end{array}$ & Female & $\begin{array}{c}\text { White } \\
\text { Hispanic }\end{array}$ & -- & $\begin{array}{c}\text { Rural } \\
\text { County }\end{array}$ & 96 \\
\hline $\begin{array}{c}\text { Housing } \\
\text { Quality }\end{array}$ & Female & Asian & -- & $\begin{array}{c}\text { Rural } \\
\text { County }\end{array}$ & 96 \\
$\begin{array}{c}\text { Standards } \\
\text { Inspector }\end{array}$ & & & & & \\
\hline $\begin{array}{c}\text { Housing } \\
\text { Quality }\end{array}$ & Male & White & 25 & $\begin{array}{c}\text { Rural } \\
\text { County }\end{array}$ & \\
$\begin{array}{c}\text { Standards } \\
\text { Inspector }\end{array}$ & & & & & \\
* Section 8 Project-Based Rental Assistance & & & &
\end{tabular}

$(\mathrm{PHA})=$ years of experience in Public Housing Authorities and/or Housing Policy (S8) = years of experience in that particular position

\section{Data Analysis}

I utilized a recording device to document and store interviews. After the scheduled time devoted to fieldwork was exhausted, I manually transcribed the fifteen interviews, and proceeded to analyze them using NVIVO 12 software. Besides the interviews, I coded and analyzed my handwritten fieldwork notes, photographs, audio follow-ups, and several institutional documents that PHAs and Section 8 HCV Program's administrators gave me while I visited the field. I created analytical nodes following the theoretical structure of the dissertation and the qualitative research question. Specifically, I based the nodes construction on the semi-structured interview questionnaire previously explained in this chapter. Nonetheless, before proceeding to report fieldwork results, I first need to report on silence.

\section{Results and Discussion}

\section{Reporting on Silence: An Archeology of Rejection}

Environmental circumstances of a given policy determine the openness of those who implement it. The discursive trends (Conners, 2017) that legitimized housing policy 
have changed from positive to negative within the last three decades (Garshick Kleit \& Page, 2008). Public housing programs stopped receiving reputational, financial and political support from legislators (Garshick Kleit \& Page, 2008: 34), the federal government (Cunningham, 2003: 97), the media (Semuels, 2015), and the population (Cunningham, 2003: 96). If housing policy in this nation has been systematically "dismantled" (Goetz, 2012:452), one would understand that policy implementers at low and standard performance PHAs identify a threat in a research invitation. How does this current state of affairs reflect on fieldwork access and the qualitative research?

I entered the field fully conscious of the difficulties posed by my topic. Not only was I asking about the mysteries of the Black Box of decision-making and implementation process; but I was further categorizing such actions and decisions according to values. In an attempt to anticipate the effect of these conditions, I initially followed a key informants' strategy (Payne \& Payne, 2004). UCLA and FIU housing and PA scholars, and a HUD managerial level practitioner introduced me to several Public Housing Authorities directors and managers. This strategy seemed promising at the very beginning when I received enthusiastic email responses from PHAs' practitioners. Shockingly, after the initial introduction, the effort diluted in a single interview. I will illustrate the situation using an example.

In February of 2017, one of my contacts linked me via email with a nearby PHA's executive director. My contact and I explained the content of my dissertation research and the purpose of the interview. The director's assistant scheduled a telephonic appointment for middle March. I was both, surprised and pleased on the promptness of the process and exchanged all the necessary documentation, including the written consent to be signed 
before the telephonic appointment. I did not receive the signed consent, and as the meeting evolved, it turned clear that the PHA's director did not have in mind to conduct an interview. He introduced me to some of his staff members, assistants, and HR professionals. They would "study" the possibility of allowing me to develop my research within his Housing Authority. I was formally assigned to a liaison person, to whom I will call Mr. X.

Mr. X explained that my petition would be studied by the PHA's General and Labor Counsel, in the meantime, I could contact him to receive updates on the status of my request. I emailed Mr. X three times asking for updates, such emails are dated at the end of March, and the middle and end of April. Mr. X finally replied on May $10^{\text {th }}$ of 2017, explaining that after informing to his Section $8 \mathrm{HCV}$ program's workers on the "opportunity to volunteer" in the study, unfortunately, they had shown no interest in participate in the research. He kindly apologized for "any inconvenience this may cause," and I knew that the door was closed. With similar failures contacting other Public Housing Authorities, I started to realize that the strategy of looking for specialized informants through equally specialized and highly connected contacts was not guarantee of success.

From June to August, I put in place a random and repetitive exercise of callings and emails. According to my institutional email browser, I sent at least sixty emails to Public Housing Authorities across the country. I sat down every day at my desk with the goal of calling no less than twelve to fifteen housing authorities. I purposefully chose those of different performance levels so I could satisfy my comparative hypotheses of bureaucratic vs. democratic values. On July 12th, 2017 I wrote in my fieldwork notebook: 
"Having started the telephone calls I have noted how difficult it is to reach lowest score PHAs. Disconnected telephones, a receptionist that does not have a clue anddoes [sic] not care and a long, long etc.!"

I came as far as receiving several positive responses that were withdrawn as soon as I sent them the Informed Consent to be signed. Just to illustrate my point, in an email dated at the end of July, I found myself replying to an enthusiastic Eligibility and Occupancy Director. She had reached me on the phone five minutes earlier and agreed to conduct the interview. After emailing her the consent, the informational letter, the IRB approval, and the questionnaire (as she requested), she replied: "Hi Melissa, We will not be participating in the research. Thank you" I questioned myself about some miscommunication caused by the documents. Maybe I was scaring practitioners away with my formalities.

I went through the documents with one of my committee members experienced in qualitative research, and a fellow student who had just finished the qualitative portion of her dissertation. They both agreed that the paperwork was acceptable and did not appear threatening. My committee member suggested that perhaps my approach was too formal, strict. We decided to relax the tone of the emails and being more amicable and human. In an undated entry of my fieldwork notebook, I enumerated an "Interview Strategy Approach" list, based on my committee member's advice. The list includes points such as:

"10. BE SHAMELESS! In begging them and giving them a reason to want to cooperate.

11. Sounding like a formal researcher won't win any hearts" 
Despite the shift in the strategy, I did not receive any further responses. Another member of my committee suggested a "Show up" strategy, under the assumption that it may be difficult to say no to a person that has come all the way to the venue. I visited three Public Housing Authorities in Florida on October 10th, 19th, and 27th. I was able to interview one Section 8 HCV program's director. Simultaneously, I continued with the other strategies mentioned above, of calling, emailing and reaching PHAs staff through common contacts. One of these Florida visits brought a slight clarity on the rationale behind the unenthusiastic Housing Authorities' response to my research. The events occurred as follow:

At the end of September, one of my contacts linked me to another executive director from a nearby PHA. I guessed that because of the importance of my contact's contact, the process of scheduling the interview had been, again, prompt and smooth. On September 29th, the PHA's Communications and External Affairs Manager scheduled the interview, adding a "We would like to get the questions ahead of time" to her email. As I expected, the Manager canceled the interview shortly after I emailed the questionnaire, stating that the Executive Director was "still dealing with the post-Irma issues." Later that week, due to my "Show up" strategy, I visited the same local Section $8 \mathrm{HCV}$ program facilities where a reluctant clerk made me wait for another employee. Coming out from the enclosure facilities, the staff member handed me a yellow memo with a name while indicated me that the program's staff did not have the authorization to participate in studies. The name in the memo would authorize the participation in the research upon my request. The name was the same Communications and External Affairs Manager that had scheduled and then canceled me right after I emailed the questionnaire. I called the number that joined the 
name that same day, October 10th of 2017. I wrote my impressions of the call in my fieldwork notebook under the memo stuck to the page:

"Went to Section 8 [mention of the locality]

Was given the contact of [Communications and External Affairs Manager] - Things are PRETTY BAD. They really don't want to talk. She implied that the questionnaire was 'unapropriated' [sic] since Section 8 staff can, and I quote, "talk about what the program is about but NOT about what do they think or how do they feel". She promised to come back to me - I don't think she will. She also expressed a lot of concern about being oversaw [sic] by HUD."

This hint of clarity brought to the table the possibility of abandoning the research interest on unresponsive standard and substandard performance Public Housing Authorities while focusing on cooperative high performers. I contacted previously interviewed practitioners from Californian high-performance agencies that then operated as key informants (Payne \& Payne, 2004) and partially opened the field. This change impacted the research by reducing the qualitative hypothesis, from:

A more democratic-centered set of public values and attitudes will coincide with positive policy performance and higher levels of poverty/race desegregation, and housing/ neighborhood quality. On the other hand, an orthodox/NPM/domination-oriented set of public values (Client/Customer/subject types) will coincide with negative policy performance and lower levels of poverty/race desegregation, and housing/ neighborhood quality.

To: 
A more democratic-centered set of public values and attitudes will coincide with positive policy performance and higher levels of poverty/race desegregation, and housing/ neighborhood quality.

I account for the outcomes of this ethnographic exploration in the rest of the chapter.

\section{High-Performance PHAs Administrators' Values and Attitudes towards Citizens during the Implementation Process of Section 8 HCV Program}

Analyzing Administrators' Interpretation of the Notion of Public Service Values

As stated before, I purposely included the first question of the semi-structured interview questionnaire: "In your opinion, what are the main values that guide your work at the Section 8 HCV Program?" The intention was to promote a self-reflective exercise among public administrators on the values that they utilize to implement Section $8 \mathrm{HCV}$ program, and in general, the way they do their jobs. With an open question, I attempted to avoid creating an immediate bias by providing specific values' names. This question also allowed public administrators to discuss their qualities, temperament, and personality traces, along with customized methods and practices applied on their day to day duties. Such reflections were not distant from the original notion of public service values as "ideals, coined as principles to be followed when producing a public service or regulating citizens' behavior, thus providing direction to the behavior of public servants" (Andersen et al., 2012: 293). Later, while conducting the data analysis, I utilized the dissertation's theoretical structure to align administrators' expressions with specific values.

Public administrators' spontaneous responses to the question of their values align mainly with what Frederickson (1989: 96) calls the "democratic values," where equality, 
freedom, social responsibility, and the general welfare prevail. There is a common awareness of what Section $8 \mathrm{HCV}$ program's implementers invariably call "the people," their needs, and the different ways in which the program may assist them. An Administrative Analyst reflects on the structurally unequal socio-economic situation of the citizens that the program serves:

"People we're helping, we are helping the neediest people, the neediest segment of our population is the homeless. In many cases, we are kinda the last resource for them, you know in terms of getting them housed."

This awareness on the variations of social and economic conditions (Frederickson, 1997: 37) within the general population and the identification of those segments that most urgently demand governmental actions locates social equity at the center of the discussion. Citizens, or "the people" are the starting point of the conversation on public service values, and Section $8 \mathrm{HCV}$ program implementers intuitively formulate the basic questions of social equity: [this program is] "well managed for whom? Efficient for whom? Economical for whom?" (Frederickson, 1997: 37). A program's director provides her response to the question on public service values introducing a "for whom"/social equity statement:

"The main values? The quality of life, that people have, you know, their living conditions, you know the basic needs that we all have, and food, shelter, those are too the basic needs, so being able to help with that."

After locating public service values as a social equity, or "people in need" matter, Section $8 \mathrm{HCV}$ program's administrators discuss their role, orientation, personalities, and actions towards the satisfaction of people's necessities. A Housing Quality Standards 
Inspector and a Special Programs Coordinator share their views on how their values and character reflect on the program:

"I have always been concerned about trying to get people back to a comfortable or standard lifestyle so I'm going into the houses with the impression of that is people who has had problems and people that is in a tough situation. My first thing is to try to calm them down, defuse it, so I go in with a friendly demeanor, I "kill them with kindness" is kind of my motto, so I'm very concerned about keep people at a calm level, a level where I can communicate with them."

"So one of the values that I was kinda instilled on and that matches my personality and my background was to improve people to be self-sufficient so that they could be less reliant on public assistance and that they could focus on other things, education, you know increasing economic... earning income, especially a job and things like that, depending on the individuals that we look at, health plans, health goals, credit scores, things like that just so that they can become more healthy and have more sense of a wellbeing status.”

Not all interviewees invest themselves exclusively in social equity and democratic values. Four of them express a twofold interest, and practice both, democratic and bureaucratic values. These public servants give importance to the legislation and policy regulations while attributing equal relevance to the satisfaction of citizens' needs. An Occupancy Specialist equates the importance of complying with the Program requirements with the personal satisfaction that comes from providing housing to low-income families: “(...) we are helping low-income families so, who is low-income and qualify and as long as they follow the rules they are gonna be fine, and I, to me I feel we do 
good for the public because we are helping a lot of low-income families with the Section 8 , a lot of families cannot afford the rent, so I think that the value of having a roof over your head especially like in winter and it's cold and raining, it's pretty good."

A final group of three Section $8 \mathrm{HCV}$ program's implementers aligns its selection with the set of bureaucratic values of efficiency, accountability, and political neutrality. An Intake Specialist's preference for neutrality emerges as she explains the irrelevance of her beliefs when applying the regulation:

"The values that guide my work are pretty much based upon what the rules and regulations of the program are, so what I feel is irrelevant (laugh), so you know, I have to go by whatever it is that the rules and the regulations of the program go by."

In the meantime, accountability is the major guidance and preoccupation of a

\section{Section $8 \mathrm{HCV}$ program's Assistant Manager:}

"As far as it being a public agency, you know this is... our program is federally funded so our dollars and stuff come from the federal government, as far as running the program and as far as the assistance goes that we provide on behalf of our tenant. So, it's an obligation because we have tax dollars, you know this is not our money or anything, (...) we have an obligation to do the best we can because these are tax dollars so I come in here and always try to make sure that you know, we are very prudent, very prudent with the money and that we are making good, sound decisions because, again this is public money, and so you know we [are obliged to do] the right thing by." 


\section{The "Balancing Act," or the Complexities of Selecting a Unique Set of Values}

This dissertation accompanies Frederickson (1997: 31) in his hypothesis that one specific set of values, usually bureaucratic ones, are at the top and "have a lock" on public administrators' preferences and actions when implementing policy. This dominant set of values influences the extension and quality of services delivered by policy implementers to citizens via administrative discretion (Watkins-Hayes, 2009: 59). On the other side of the theoretical spectrum lies Montgomery Van Wart (1998). Van Wart advocates for a legitimate competition of values, where the selection of the "best" values "must be made within specific context" (Van Wart, 1998: 255). To my surprise, neither Frederickson nor Van Wart coincided with Section 8 HCV program administrators' responses.

\section{Addressing the Importance of Bureaucratic and Managerial Values}

I included two questions in the semi-structured interview with the purpose of classifying program's implementers within a particular set of values. In the first question, I encouraged PHAs and Section 8 HCV Program's administrators to select one out of the four possible set of values. Their particular choice would define the behavior of public administrators towards recipients: Client (Efficiency, accountability \& neutrality); Customer (Economy, performance \& entrepreneurship); Citizen (Social equity, sovereignty of the people \& participation); and Subject (Control, domination \& power). In the second question, I read out loud the description of two different possible scenarios of administrators' actions. The first case scenario accounts for a more democratically-oriented decision; while the second scenario aims for a more bureaucratically-oriented choice.

As first responses were flooded with democratic-oriented references and constant mentions of "the people," I expected similar positions when it came to a more specific 
values' selection. Nonetheless, PHA and Section $8 \mathrm{HCV}$ program administrators delivered answers of complexity only comparable with the decisions that their jobs entangle.

When selecting among the different values' trios and locating themselves in a particular end of the public administrators-recipients' rapport typologies, a vast majority of Section $8 \mathrm{HCV}$ program's administrators (eleven interviewees) opted for the 'Client' perspective, choosing the values of efficiency, accountability and neutrality as the main guidance of their work. A program's Managers conceptualizes his selection:

"So, the neutrality is as I mentioned, we don't have a lot of discretion so we're basically just following the rules and we're looking at the facts, you know, if someone is making too much money every year, so they can't come to the Program, it doesn't matter if they are yellow, black or purple. Efficiency, I tell my staff that that's the way we can provide customer service in this type of Program is by being efficient, so when we do paperwork to process it as quickly as possible and as correctly as possible so that we can get people housed onto the Program in a timeline manner. And then, the other... what is the other point in there? Neutrality, efficiency and...? (Interviewer: And accountability, yeah). And accountability, so yes! Because we are a federally funded program we have to be held accountable on how we do our calculations, how we maintain our files, and so we are audited on a regular basis, both externally and internally."

Most Section $8 \mathrm{HCV}$ program's public servants considered the utilization of these values as necessary tools for conducting a clean and proper operation. A sense of compliance with their duties and responsibilities prevails when caseworkers reflect on the quotidian practice of managerial/bureaucratic values. An Occupancy Specialist explains: 
"Well, everything is on a deadline, you have so many cases a month that you have to get completed, so you have to make sure that the clients get their paperwork in and when they need assistance you have to try to help them to get it in, make sure that they have provided everything we need to calculate everything correctly and just be as accurate as possible with, you know, and get everything done in a timely manner by the deadline, as efficient as possible."

Three of the interviewed administrators selected the set of democratic values that include social equity, sovereignty of the people and participation. A Special Programs Coordinator elaborates on her selection, and "the people" as a subject reemerges: "HUD does try to create these programs so that there could be more... I mean if you read in to the background of why these programs existed was to provide people, you know, take for example with the HUD-VASH program, the homeless vet, the goal of that program is to stabilize housing, once you stabilize housing, not just for homeless vets but for low-income individuals, you then, with the hope that they can then focus on other things, because housing is such an important factor in the health and well-being of people that without that they can't really focus on "oh, I should go get a job! I should go and get to school!" and so, once you stabilize that and hopefully eliminate that stress, you then can provide them a sense of power to go, or empowerment to go and achieve things that they normally wouldn't be if they were currently homeless or they have to stress about that situation, and I have seen that when some client, once that you stabilize housing for them then they can focus on other issues in their lives so that they could be self-sufficient." 
Only one administrator, at the managerial level, selected the 'customer' rapport associated with the values of economy, performance, and entrepreneurship. Such preference becomes understandable in the light of his role of executive director. Since the congressional approval of the Quality Housing and Work Responsibility Act, Public Housing Authorities experienced an expansion in their scope of action. Such changes include increased flexibility (Garshick Kleit \& Page, 2008: 38, 2015: 624), and a growing need of a search for resources and strategic alliances with both, public and private partners (Bingham \& Kirkpatrick, 1975: 66; Garshick Kleit \& Page, 2015: 625). The PHA's Executive Director illustrates the case:

"I think entrepreneurship is really required in today's day and age because the reality is we are facing a decline, a flat decline in federal budget so we have to be very creative about what we do, and in this day and age where our solutions usually revolt around the provision of housing and supportive services, we have to seek partnerships to provide the supportive services, so it invites a whole spirit of camaraderie given the special needs on target population, putting together special programs, special relationships with service providers on an entrepreneurial spirit by the way they are serving the various populations that we work with."

Curiously enough, the 'subject' category of public service values (Control, domination, and power) spawned a humorous reaction and amused rejection among PHA and Section 8 HCV program's administrators. From a "Well is not that one! Of course! (Laugh) Not that one! Never!" of an Occupancy Specialist, to a "And control, and domination, and power, not quite sure what that one would mean, I have none of them! 
(Laugh)", of another Intake Specialist, this choice seemed strange to the workers' imagination.

Navigating Between Bureaucratic and Democratic Values

As stated before, I included a second question related to the selection of one specific set of values. This question consisted of a description of two different possible scenarios that demanded Section $8 \mathrm{HCV}$ program administrators' actions. The first scenario accounts for a more democratically-oriented choice; while the second one aims for a more bureaucratically-oriented decision.

Previously, when PHA and Section 8 HCV program's workers had to pick a single option of values' trios among the four possible administrator-recipient's rapports of 'client,' 'customer,' 'citizen,' and 'subject,' interviewees expressed nonconformity towards the exclusivity of these options. Through elaborated explanations, they provided choices that reached two or more categories of values simultaneously, proposing combinations of public service values selections that accounted for a far more complex reality than the questionnaire had predicted. When asked to choose, one Occupancy Specialist reflects on this simultaneity of values:

"I would say it's a mixture of the first two [bureaucratic and democratic values' selections]. You know, you have to be efficient, but we have to do it without losing perspective of the client so. I would say, probably number one, with a mixture of two. But number one, probably."

A Section $8 \mathrm{HCV}$ program's director finds herself navigating between both, the managerial and the democratic sets of values: 
"Between number two and number three. (Interviewer: Social equity, sovereignty of the people and participation; and economy, performance and entrepreneurship?). But and again you have to consider budget, so that's where number three place into number two."

A Housing Quality Standards inspector provides the key to understand this back and forward exercise. The inspector makes a distinction between the different scenarios and audiences for each set of values' selection. Democratic values such as social equity, sovereignty of the people, and participation aim towards "the clients," or recipients of the program. Meanwhile, the bureaucratic choice of public service values that includes efficiency, neutrality, and accountability points towards organizational duties and responsibilities:

"I would have to say, it would have to be selection one and two, a little bit of one and two. I think for one it's more for me being efficient, but I think that when it comes to the clients and going out on the field I'm more empathetic to the second category, you know I value what their opinions are, so it's one and two."

This PHA and Section $8 \mathrm{HCV}$ program administrators' tendency to make more sophisticated uses of different sets of public service values simultaneously, and towards a variety of audiences, intensified along the case scenarios' responses. Six of the interviewees opted for solving the case through the use of a democratic values approach. Other six implementers reflected on the navigation of both, democratic and bureaucratic values. A reduced group of three public servants turned to a rigorous bureaucratic perspective. Coincidently, two out of these three workers deal with the strictest segments 
of the policy implementation process: Housing Quality Standards inspections, and eligibility.

The democratically-oriented selection of values cares for the abidance of policy regulations, HUD and Housing Authorities' rules. In the following exchange with a caseworker, she establishes the precise limits of their actions within the case scenario before opting for the more lenient response. She assures explicitly that her actions will not contradict eligibility requirements, which is by far, the strictest stage of the Section $8 \mathrm{HCV}$ program implementation process and the one that allows near zero levels of discretion:

Caseworker: No, correct, so is it referring to what? You help the client even though they can't really qualify for it? Or which you go by the book?

Interviewer: no, if they have already qualified but they still need more paperwork or more, in order for them to find like a proper...

Caseworker: The unit?

Interviewer: Yeah

Caseworker: Do I help beyond that or I...? Or I say "Let me ask and make sure" (laugh)

Interviewer: Exactly... or you say "these are the rules"

Caseworker: Correct

Interviewer: "you don't have this paper" or, you know... "You don't have this" ... "you have to fill this requirements, I'm sorry but I cannot help you"

Caseworker: “so, it's still number one, regardless. It's still number one. The one I go by, because we are by the book, but being [case] number one you can also be by the book because you can provide the guidance and the resources that they need. If 
I can't give a decision because it's not up to me to give a decision I give the clients the tools to request what is available for them through the supervisor, the management, because it's not "your voucher is gonna expire today so if you don't bring it by five o'clock that's it", No."

There is a cohabitation of the democratic and bureaucratic perspectives. A utilization of high levels of discretion is present too, in caseworkers that do not identify themselves exclusively with one case scenario. Two different Occupancy Specialists navigate the combination of values that entails their response:

"Somewhere in between there. I'm a rule follower, these are the rules, but we have policies and procedures to try to be lenient in certain situations, there has to be a precedent and yes, we do... it's a case by case situation, it's definitely a case by case... I would never use the word "leniency", just because we do have to treat everyone the same, we can't just be lenient with this family and not lenient with the other family so, but if we set a precedent is like "in this situation we can do something extra" so, in this situation "ok, we have done it for this family in this situation so we can do it for this family in this situation," but we still have to follow the rules and the regulations."

"Try to be as lenient as possible within the rules. So if we are able to extend, or help them in any ways and not being in violation of anything, yeah, that's the route. I'm not real strict! (Laugh) on people or anything, if usually I can do anything to help within what we are able to do for them."

Operative levels of the program tend to respond from a day-by-day experience to the case scenario question. Meanwhile, the managerial level produces a more elaborated 
discourse on the rationale behind the simultaneous approach to democratic and bureaucratic values during Section $8 \mathrm{HCV}$ program's implementation process. In her answer, a program's director points at what seems to be the problematic knot of values cohabitation. The simultaneous use of values sets is possible, as bureaucratic-oriented policy and regulations provide room for democratic values utilization. The catch lies in the scope of individual administrative actions. "Running the extra mile" (Marr, 2016) reveals itself as the starting point of the discretion needed for exercising the democratic set of values and approach program's recipients as 'citizens':

"I will work within the guidelines to my best capability. We are required to work within the core of federal regulations. Now, this is a human industry, so, I think part of that also entails going the extra mile. It doesn't mean bending the rules, it doesn't mean breaking the laws, it simply means working with people. So, there have been administrations, not only here, but in other agencies that I have been, that the administrator was by the book. It's not by the book always, it's not something that you read and you implement, because, it's the human factor. So, you're able, and you have to be able to remain within the regulations and the regulations generally do apply because they give you guidance, more than just strict rule books, and they also allow you to run your program with a little bit of flexibility because it's a guideline and not a law. But, you know, some people see it as "You know, that's the way it is, so that's how it's gonna be done, and I don't care what the circumstances are". That's not how I ever implemented anything, I have always tried to adhere to the policy. However, had that policy worked with the intent that it was designed? To guide it." 


\section{A Balancing Act}

Frederickson (1997) and Van Wart (1998) fall short when interpreting public service values utilization during Section $8 \mathrm{HCV}$ program's implementation process. A dominant bureaucratic set of values and its efficiency fever (Frederickson, 1997) does not marginalize the delivery of services under democratic values. Contrariwise, the Section 8 worker recognizes the "duty and the obligation to deploy his [or her] efforts on behalf of the less advantaged" (Frederickson, 1997: 42):

“(...) if your development is like disabled and elderly I don't know what else they can do, they have a limited amount of income, is not like they can even go to school to get help with education or jobs or anything like that, there is some people that they are just not capable of obtaining employment."

Neither is there a "reachable gestalt" (Van Wart, 1998 in Molina, 2015: 49) that allows public service values to circulate by selection, depending on specific context to eventually let the "best" values be "widely maintained or adopted" (Van Wart, 1998: 255).

In the particular analysis of Section $8 \mathrm{HCV}$ Program, public administrators identify policy stakeholders and their demands. Such demands can be either democratic, bureaucratic, or managerial. Next, implementers comply with their different duties and responsibilities by simultaneously utilizing various sets of public service values. The selection of values depends on the situation and the audience (See Figure 6 below). 
Figure 6: The Balancing Act

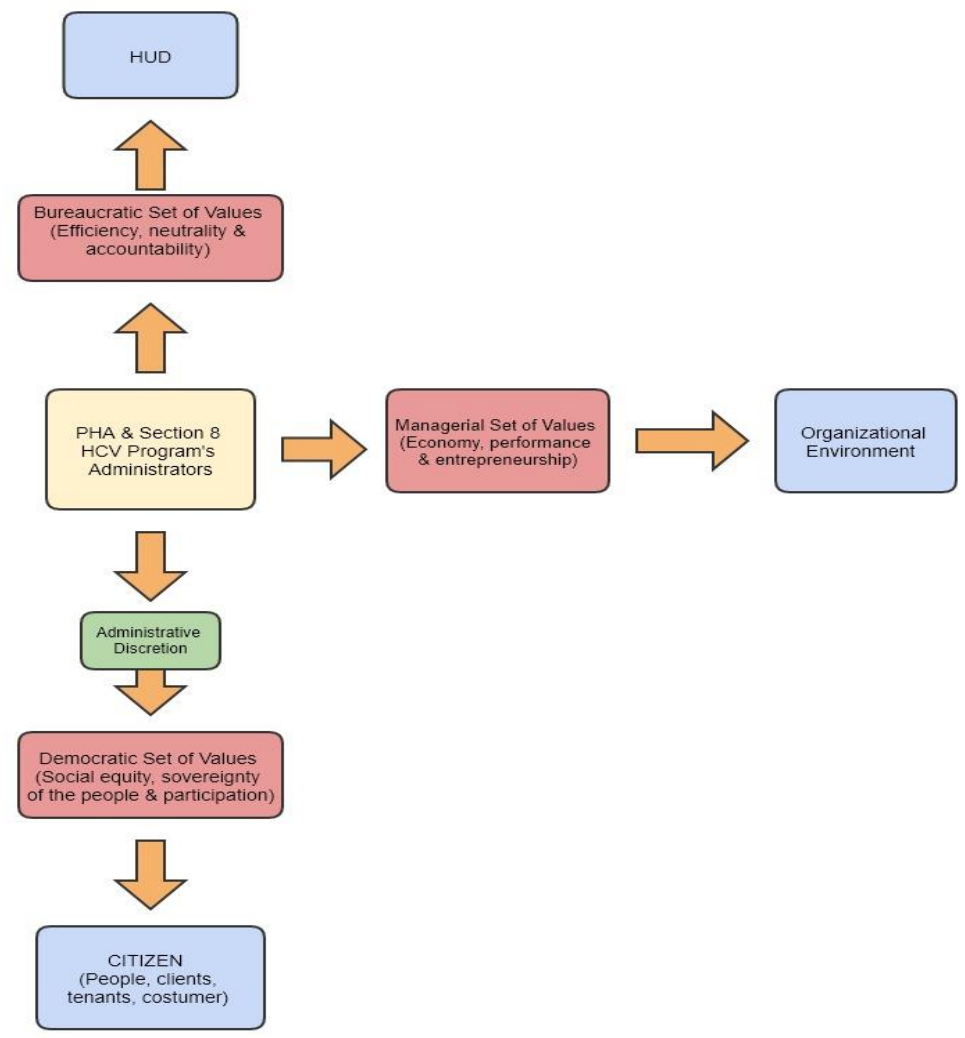

Back to Frederickson, it is important to concede that the application of democratic values demands an extra effort from public servants to make. The utilization of bureaucratic values seems to be mandatory as the agency is formally accountable to HUD and subject to penalties. The use of democratic values appears to be optative, as citizens have fewer accountability resources. In the case of high-performance Public Housing Authorities and Section $8 \mathrm{HCV}$ programs, public servants have naturalized and institutionalized running the "extra mile" needed by the use of democratic values. Such behavior may count as a differentiator factor for achieving high-performance, as Chapter 4 explains how environmental and organizational conditions equally affect both, agencies and policy. In the following exchange, an Occupancy Specialist tells me about one of the 
many ways she assists citizens beyond her organizational duties. She also responds to my question for the "extra mile" (Marr, 2005: 101):

Occupancy Specialist: "I have one person that was late getting paperwork in, I mailed twice and for some reason she still isn't getting the mails, not able to drive to come to [town] to pick it up so that I reached for one of our inspectors who is going to be in the area and can actually hand deliver the paperwork to her, so she can get it, so we can get everything completed for her continue the occupancy and not be having taken through termination because she wasn't getting the things turned back in. So that just whatever we can help, you know kinda hold their hand and try to get stuff in, if they don't understand, they will come in and I go through the paperwork with them, help them fill it out, answer questions that they don't understand on the forms... yeah, just do anything that we can within our power to try to help them through the process if they are not able to on their own."

Interviewer: And, only to ask, this may seem like a rhetorical question but, you don't have to do that right? You don't have to... like, but you do it. Why do you do it?

Occupancy Specialist: “Because we don't wanna terminate people off the Program for something silly. You know, they are not breaking the rules, they are just maybe having a hard time, especially the elderly, you know, these persons unable to drive to come in. No, it's not a requirement that we do it but it's... for disabled and elderly especially, I think, you know, they may need an extra help than an able-body person. But still even the able-body people, they need help just with paperwork, 
you know, just it seems silly to go through a whole termination just because they can't get the paperwork (loud laugh) on time, you know."

PHA and Section $8 \mathrm{HCV}$ program's administrators interviewed for this dissertation displayed high levels of professional and emotional investment in the utilization of democratic values to consciously address social deprivation (Frederickson, 1997: 38). Nonetheless, two external elements turn the simultaneous utilization of democratic and bureaucratic sets of values into what one of the interviewees calls "a balancing act." These elements are limited funding and HUD regulations. An assistant Manager and a Supervisor illustrate the limits of the norm, especially in eligibility matters.

"I think it is a balancing act, you know there is never one thing that you just wanna lean on so much to work as guide every day, you know, you may come and you may hear an extremely sad story and you may wanna do everything in your power to help out a particular participant, right? But if it's gonna break the rules or whatever it is you try to do, if it's gonna break the rules and regulations, you know, unfortunately, you can't do that. You can help them as much as you can, but within reason as well. So, it's a balancing act."

"So we can't do that, I mean, we will try to assist them as much as we can but if documents submitted suggested that they are not eligible, unfortunately they will not be eligible even, you know, as sad as it is I have had to say someone is not eligible because of 50 dollars, you know, 50 dollars over the income limits, unfortunately means 50 dollars over the income limits, no way, no matter how you see it, how you calculate it, it's 50 dollars and I have to accept that. So that's a little harder and that's a little strict for me. But, certainly in other things I'm more lenient 
and I can see, you know, us being able to help them more, but unfortunately not with eligibility."

Budget is another controlling element of administrative discretion and the exercise of democratic values. In a way, the due process actions and bureaucratic compliance guarantee the necessary funding to ensure democratic actions and citizens' assistance. An Occupancy Specialist reflects on the matter:

"[I] try to help them in as much as I can while staying within all the rules because there are certain things that, you know, we have to follow, in order to receive funding, you know, we are a high performer so we do everything we can correctly to keep receiving all the funds to help as many people as we can."

\section{Where Are These Values Coming From?}

Celeste Watkins-Hayes defines "professional identities" as "relatively stable and enduring constellations of attributes, beliefs, values, motives, preferences, and experiences that individuals use to define themselves in an occupational role (Schein 1978; Ibarra 1999 in Watkins-Hayes, 2009: 26). The semi-structured interview explores the elements comprised in the organizational ethos of Section $8 \mathrm{HCV}$ program's implementers by including two questions: "Do you feel that your values' trio selection is an autonomous one?" And "Do you think your PHA's values are the same as yours?"

Ten PHA and Section $8 \mathrm{HCV}$ program's implementers recognize either partial organizational influence (four respondents) or full institutional guidance (six respondents) on the ways they select and utilize public service values during policy implementation. Five public servants coincide in recognize their private milieu and family upbringing as the origin of their values' preference. One of such servants recognizes her 'evolution,' from a 
more conservative and bureaucratic approach to a more social equity and democratic oriented perspective:

"I have a totally different perspective than when I started working here, when I first started working here I wasn't familiar with the clientele and the individuals I'll be working with and I really changed and softened up in saw the hardship that a lot of the families go through here, and so I definitely evolved, that's the best word I can say, so I am much more compassionated, much more understanding (...). My dad told me, my dad is a very conservative individual and he is not happy about how liberal I become lately (laugh), and he is like "working for the government has made you liberal" and that's true, because he doesn't see what I see, he doesn't see the undocumented, Hispanic individual who was brought here at three years old and she can't do anything, because her parents are dead now, she doesn't even know Spanish really, this is all she knows, and she is scared she can't...we can't even pay rent for her, you know, he doesn't... people don't see what we see here.”

\section{Political Neutrality and Technical Expertise as Source of Administrative Discretion}

In Chapter 2, I introduced seven hypotheses on the political neutrality of public administrators: 1 . the principle of political neutrality is an ideal, impossible to accomplish in the reality of public administrators (Friedrich, 1940: 3). 2. Public administrators do exert administrative discretion in their daily decision-making and implementation processes (Friedrich, 1940: 7; Svara, 2006: 122; Lipsky, 1980). 3. Due to the impossible applicability of the principle of political neutrality in real scenarios, administrators replace neutrality with a more reachable value. 4. Public servants use technical expertise as the proxy for political neutrality (Dahl, 1947: 1). 5. Administrative discretion is justified by 
administrators' technical expertise (Dahl, 1947; Foucault, 1980). 6. Public Administrators' 'expertise' is founded not exclusively in technical knowledge but in political (citizenship), social, and cultural constructions of identities (socio-economic status, race, gender, background) (Forester, 1984: 26). 7. This impacts policy outputs (Habermas, 1973, in Fischer, 1993: 166). I will provide qualitative evidence that either support or refute the hypotheses mentioned above.

Notion and Scope of Political Neutrality According to Section 8 HCV Program's Implementers

Contrary to my initial theoretical proposition, PHA and Section 8 HCV Program's administrators endorse the validity of the principle of political neutrality. Section 8 workers consider this traditional public service value achievable in its full extension. Neutrality is regularly practiced by the program's implementers when interacting with recipients. How do Section 8 HCV program's implementers elaborate the notion of political neutrality? The response to that question would be: precisely as PA scholars present the notion within the academic field. (Finer, 1941; Kernaghan, 1976; Overeem, 2005). Whether it has to do with elected officials or citizens, Section 8 public servants agree that they "do not have personal feelings or interests involved" (Beck, Jorgensen \& Bozeman, 2007: 372) in the implementation of the program. When the rule and only the rule mediates the public administrator-citizen rapport, the regulation always wins. Expressions such as "You have to be impartial, you can't be someone that is biased across the board," "You can't be biased on who you're helping," or “(...) you don't pass judgement, that's not what we're trying to do, we are trying to assist" are fairly common among the group of fifteen interviewees. When asking a supervisor to expand on his concept of neutrality, he explains: 
"Yeah. Not being biased. Go in there and assist whoever it is you're assisting the same way you assisted the person before you and the person after, you can't go in there because the person before you lied to you thinking that this new person is gonna lie to you about the same thing or about something different. Everyone's case is differently, you have to give them a chance to tell you what it is and assist them to however you can."

Section $8 \mathrm{HCV}$ program's practitioners enumerate various sources of apprenticeship of political neutrality. Eight practitioners indicate some organizational resource as the basis of their ability to make impartial decisions in front of program's recipients. Both operative and managerial level workers mention several pieces of training that, though not explicitly related to neutrality, count as a resource to address impartiality in the decision-making process. "Discrimination classes," "How not to judge at the moment," "Fair Housing training," "customer service," and "how to deal with difficult people" are some of these training. Experience, information, the resolution of similar cases in the past, team work and the support of fellow staff members, and formal education are other valid sources of neutrality.

Four program's implementers coincide with elaborating neutrality as a personal trace of character, individual quality of their personalities, or skill acquired outside the organizational environment. In this regard, a PHA executive director expresses his view:

"No! No one teaches you how to be neutral, in fact, the greatest source I find in American politics and in this idea in surrounding neutrality is this idea that... we don't give our leaders a good ethics and morals training, I happen to get a really good ethics and moral training but it wasn't in the United States and I had to go a 
long way to get it and it is one of the most valuable foundational stones upon which I stand because it is only with a really highly developed personal philosophy and a highly developed ethics and morality that you can exercise neutrality. And so, NO! We don't get educated in this so you're really hoping that when you're hiring a director for any given agency that they bring with them those values and that expertise."

The politics-administration dichotomy prevails. The separation between elected and appointed officials and the hierarchical relationship between policy creation and execution (Finer, 1941) remains untouchable over the years. A Special Programs Coordinator reflects on the extension of her discretion to modify Federal mandates:

"There is not a lot of things that I could do that can make a difference, so the only thing I could do is maybe, when it comes to voting for who is in the White House I can look at what their view point is related to HUD and who they are going to elect to be in charge of HUD, I think that's when you can have more of a bigger say in the outcome of Section 8 and the Housing Authority, but other than that, yeah! Once the election is over and whoever is in the White House and the Budget comes down and the policy comes down, we are subject to follow those rules."

\section{Technical Expertise as a Tool for Achieving Political Neutrality}

I had stated that because of the impossible applicability of the principle of political neutrality in real scenarios, administrators replace this public service value with a more reachable one. In this vein, I further hypothesized that public servants use technical expertise as a proxy for political neutrality (Dahl, 1947: 1) and that administrators justify 
their discretion towards policy recipient by applying technical expertise (Dahl, 1947; Foucault, 1980).

The evidence from the interviews' responses and qualitative fieldwork took these hypotheses to a different but equally compelling direction. PHA and Section $8 \mathrm{HCV}$ program's administrators consider neutrality a reachable and achievable value, and technical expertise is not a proxy but the most valuable tool to guarantee impartiality. Implementers keep the disciplinary aspiration of scientism (Dahl, 1947: 1) by following a positivist and rational method to make decisions. Political neutrality is achievable through the expert knowledge and thorough application of the regulation. When asked about neutrality, Section 8 workers emphasize in the importance of being proficient in the norm to reach an impartial decision. After a Section $8 \mathrm{HCV}$ program's Manager defined neutrality as "just being consistent with the enforcement of the rules," he completes his statement providing the best approach to neutrality: "So long as you structure the situation to the regulation. By following the regulations you can maintain neutrality." Another practitioner praises the importance of maintaining uniformity in the application of the rules:

"We are, at least for our agency here, we reference the policy a lot, so that one, it safeguards from the client getting misinformation, so if one caseworker was telling a client something else and then the next day another caseworker was telling something else, it creates a lot of confusion so the standard and the streamline of a policy really helps ensure that we here give the same information to everyone, no matter who they are talking to, and we do have to train the front as well, so they are giving the same information so that does help [to] eliminate a lot of confusion." 
As the regulation reveals itself insufficient in some situations, knowledge by past experiences counts as an essential instrument for achieving neutrality. An HQS inspector provides the most technical example by using water heaters as reference:

"So there are certain things like for example, you'll know what you're supposed to be looking at but you won't know in particular because there are so many different types. I'm gonna use water heaters for an example. There is three or four different types of water heaters, they only teach you the basics, "Turns the water hot", "No leaks". Along the line you learn different things of different systems, where they can fail, where the weak spots are... so, that's what you learn because people are pointing it out, or because you actually see it physically, but you didn't learn it from a book, that's kinda an ongoing thing, so after twenty years or so of doing that, you pick up a whole bunch of different things so it definitely puts you at a total different level than the people that just had their experience straight out of a book or straight out of the classes."

I will address the existence of this room for administrative discretion and its implications for the utilization of democratic values in the next section.

\section{The Parallel Avenue of Administrative Discretion}

I had anticipated that public administrators exert administrative discretion in their daily decision-making and implementation processes (Friedrich, 1940: 7; Lipsky, 1980; Svara, 2006: 122). I further hypothesized that such administrative discretion is endorsed by administrators' technical expertise (Dahl, 1947; Foucault, 1980). What I did not foresee was the possibility that administrative discretion of Section $8 \mathrm{HCV}$ program's 
administrators worked as a vehicle for the provision of democratic values to the most vulnerable segments of the population (Frederickson, 1997: 42).

In the particular case of Public Housing Authorities and the Section $8 \mathrm{HCV}$ Program, a process named "devolution" allows this practice. Devolution is "the rapid deregulation and greater local control in federal social assistance programs" (Congressional Research Service, 2012: 2). Although the cause of many setbacks, predominantly financial ones, devolution facilitates dedicated public administrators in high-performance agencies to incorporate the practice of social equity, participation, and sovereignty of the people, among many other democratic values. They are neutral in front of the regulation because, in fact, the regulation has not been bent, violated, or broken. Instead, the regulation has room for flexibility and adaptation. Public servants utilize this adaptive capacity, not for oppressive purposes, as Foucault (1980), and Alkadry and Blesset (2010) state; but to expand as much as possible the public service values portfolio. Section 8 implementers comply with the New Public Management's high-performance, and economy demands slowly introduced thirty years ago (Goetz, 2012: 457); while refusing to abandon the values of the historical anomaly that brought Public Housing Authorities to life, the New Deal. The managerial and middle level of authority is essential in this action:

"And then, being that I am a supervisor, I am more lenient on how I read what they want me to do, and I assist people how they want, you know, yes, they want you to abide by all the rules, and for the most part we try to, we try to go $100 \%$ of whatever is on there, it's gonna be based on the book, because that's ultimately what we 
wanna do, the Admin. Plan is there for a reason, but a lot of it is vague, and we can read it differently or see differently to be able to assist."

In this case, Section $8 \mathrm{HCV}$ program workers' administrative discretion operates within the regulation. However, there is another variation of discretion that functions on the verge of the policy operation. In many occasions, recipients do not need to capitalize on the flexibility of the regulation, but a push to make it to the rule. This reality reveals the limitations of the policy which does not provide services beyond the issuance of the voucher. Recipients' needs fall beyond merely issuing a voucher and implementer are aware of this reality. Elderly recipients and those with mental and physical disabilities receive informal assistance from caseworkers that help them navigate the simplest tasks within the program. An occupancy specialist provides an example:

"Ok, I have some of my clients that have some mental disabilities that make it difficult for them to do paperwork, and their paperwork is very straight forward, the recertification packet is pretty simple to do, but it's overwhelming for them and so, then I meet with them and I fill out the recertification packet with them, just go over the documentation I may need, I try to... because a lot of our clients are on Social Security, and that information we can pull without stressing them out about having to go find a letter, so yeah, the one on one makes it different for quite a few of my clients. You know, to help them with that paperwork."

I had predicted that public administrators' discretion is founded not exclusively in technical knowledge; but in political (citizenship), social, and cultural constructions of identities such as socio-economic status, race, gender, and background (Forester, 1984: 26). I stated that this hybridization of public servants' administrative discretion impacts 
policy outputs (Habermas, 1973, in Fischer, 1993: 166). I followed Foucault (1980), Alexander and Stivers (2010), and Alkadry \& Blessett (2010) in the assertion that Section $8 \mathrm{HCV}$ public administrators linger stereotypes on policy implementation.

The interviews and participant observation tell otherwise. Section $8 \mathrm{HCV}$ program's practitioners utilize administrative discretion to introduce democratic values in the implementation process. They also locate particular identities, especially elderly and disabled individuals, and reshape the policy by these specific identities' needs and disadvantages as the product of historical inequalities. A Section $8 \mathrm{HCV}$ program Manager explains the lawful modifications made to the policy to address accessibility barriers in African-American households during the strictest phase of the program, eligibility:

"HUD does have guidelines, so, for example HUD would say this is what you can do... so for example for Criminal Backgrounds, you can do steps point two and three and you're allowed to may do them, you have to do step one, and you may do step two, three, and four. So what we typically do is we do the we have to dos, and then where there you have may dos, if it looks like it may be putting a barrier in anyone's individual way, then we don't put that into place. So for example, if someone has been arrested, we don't look at that, but if there was conviction, then we will look at that. Some Housing Authorities are gonna look at... I have looked at some Housing Authorities' policy and procedures manuals and they have three, four, five pages of Criminal History that will disqualify someone, and typically you will find that that impacts people of color, what we have done is we have just done the bare minimum because we realize that (...) the criminal justice system has had this impact upon people of color and if we adopt it as more strict then we will be 
impacting folks that shouldn't be. So, we are fairly progressive in the Housing Authority, and we do follow the rules and so I think what the difference is that... where HUD says you may do something that may be a little more restrictive, we tend not to do that...particularly, in our lookback periods of Criminal History, you know some agencies go five years, seven years, HUD says that you only have to go back three. So that would be, we just do the three."

\section{The Demeanors that Challenge Neutrality}

There are two demeanors, not identities, which challenge Section 8 HCV program practitioners' ability to remain impartial in front of recipients. Firstly, there is the Free Rider demeanor. A recipient that meets the requirements to be eligible but implementers perceive as an individual that may not be as vulnerable and in need as others, such as elderly, disabled, homeless, and working families with children. The most frequent the rapport with recipients, the highest the chances for public servants to face situations where experience indicates an anomaly. An Occupancy Specialist provides examples on these indicators:

"Those are difficult clients for me, because I see so much need, and then I see these people "do they really need the assistance?" you know, they start a job, I raise the rent, they quit the job, when they get actually paid for self-sufficiency, but there is nothing we can do about that. So some of that can be frustrating."

Section $8 \mathrm{HCV}$ program's administrators face these situations by applying the rules exactly the way they would do with any other recipient: 
"You know, some people come in that actually need it, some people don't really need it but want it, and to me, I help them either way, it doesn't affect how I feel or my feelings are not gonna get in the way of me choosing not to help someone because I feel they don't deserve it. No, if you turn in paperwork to me and it shows you're eligible, whether I like it or not, whether you were mean or not to me, it shows that you're eligible and guess what, you will get your voucher, that's strictly all that matters, is whether you're eligible or not. My feelings have nothing to do with actual work or how someone is selected or... it's who is next on the list, who gets selected, are you eligible or you're not eligible, done (laugh)."

The second demeanor that Section $8 \mathrm{HCV}$ Program's administrators find challenging to address by being neutral is what can be generalized as "difficult people." 'Entitled,' verbally abusing, or violent recipients. Despite training, upsetting encounters with recipients demand an extra effort and further preparation. An Occupancy Specialist shares her strategy to deal with these emotionally taxing episodes successfully:

"I try to treat everyone professionally and the same so, we have phone calls, lots of phone calls, whether someone is very angry and agitated I try to be professional and treat them the same as someone who is not, who is doing just fine so. It's just trying to be even, even-tempered and not take anything personal."

When I conducted fieldwork, I observed Section 8 HCV program's inspections routines with a Housing Quality Standard inspector. I waited in the car while the Inspector asked for recipient's authorization for me to join the inspection. During the very first visit, I was waiting in the car while I could clearly see the Inspector kindly speaking with the recipient, which was a mentally disabled woman. She rejected my presence, but also did 
not allow the Inspector into the house. I could clearly hear screams and shouts. I wrote in my fieldwork journal seated in the car as the events occurred and after they passed:

November $30^{\text {th }}, 2017$

Inspections with [Inspector's Name] around 11: 00 am to almost 2:00 pm I wasn't allowed to the inspection by the tenant as she is having a mental breakdown as is also hostile towards [the inspector]. I clearly heard [the inspector] formulating the question "I have a question, I have an intern with me, do you agree to have her at the inspection?" And then I heard a clear and loud NO! [The inspector] is politely asking to come in, I think I hear the tenant screaming leave! This work is utterly stressful. (...) [The inspector], I asked her about concerns about her safety, she said she treats people the same and that when she shows respect and consideration people usually calm down. She is a pro! She calmed the client while conducting the inspection. She [the tenant] has 21 days to correct with the landlord. She got housekeeping requirements write down.

The general strategy is not to take the situation personally, keeping in mind the complicated circumstances of most of the recipients:

"I try to think it is not taking their personality in the situation... into consideration but on what are the facts, you know, they are frustrated and upset because you have not approved their medical allowance, it's just stay neutral, it's not, it hasn't been done because you're naming a person (...), it hasn't been done because the regulation doesn't allow us to take the allowance into consideration." 


\section{Public Administrators' Attitudes towards Section 8 HCV Program's Recipients}

The notion of attitude comprises the cultural patterns (Alexander and Stivers, 2010), as well as psychological and emotional drivers that influence public administrators' approach to the implementation of the policy and its recipients. These elements are not part of implementers' organizational ethos and come from the social environment. The way public servants "think and feel about" (The Merriam-Webster dictionary) recipients influence their behavior and the program's outcomes.

According to Alexander and Stivers (2010: 582), many of these attitudes are undesirable as they reproduce an "adversarial tone" between public agencies and traditionally disadvantaged communities. I already illustrated how in the case of this study interviews, public administrators recognize recipients' identities (Eagan, 2006), not to reproduce "society's customs and conventions" (Alexander \& Stivers, 2010: 582); but to level the institutional disparities in access to the policy, caused by prejudice. In this section, I will provide a thorough explanation of this rather unusual public administrators' behavior.

\section{Life Happens}

Marr (2016) emphasizes the importance of public servants' understanding of poverty. This emotional, psychological and social construct leads practitioners to elaborate a rationale on why recipients seek for the benefits of Section $8 \mathrm{HCV}$ program. On the one hand, if implementers understand that poverty causes are "multiple, interdependent, and operating at different social levels" (Marr, 2016: 223), their rapport with program's recipients will be permeated by empathy and compassion. Hence, the chances to provide a broader spectrum of services will be higher. On the other hand, if practitioners attribute a 
particular responsibility to recipients' identities and/or life decisions, then the public administrator-recipient rapport will change in nature.

To identify Section $8 \mathrm{HCV}$ program administrators' attitudes towards recipients, I included three related questions in the semi-structured interview questionnaire: "What are your thoughts and feelings about people that seek for Section 8 HCV benefits?", "Do you think people could do any different to avoid finding themselves applying for a voucher?" And "In your opinion, which are the factors that take a household in need of assistance to apply for a Section 8 voucher?" Interviewees' responses correspond to what Marr calls "Holism," or a complex and multifactorial understanding of poverty causes. Following the author, this approach “encourages trust between clients and staff” (Marr, 2016: 223).

PHA and Section $8 \mathrm{HCV}$ program administrators interviewed display a compassionate view towards recipients. This view builds on the belief in the unpredictable twists of anyone's fate. For these public servants, life entangles uncontrollable difficulties that encounter some remedy in the program's existence. An HQS inspector shares his reflection:

"Some people, they just get bad cards, they can be doing everything right and they kinda end up in certain situation, I try to keep that in my mind so I try to keep the judgement out of it completely because I don't know where people came from and what their situation is."

The power of this certainty becomes evident when an inspector suggests applying to the program as an anticipatory act of a possible life's calamity:

"I told a lot of people "Hey, you know what, [the City] opened up the waiting list, apply!” they say “I got a job! I don’t need to apply!” I said "Yeah, you don’t need 
to apply now, but you don't know your situation in ten years" your situation can completely change and why worry about that now, just apply, if you don't need it then, then you don't need it, you say 'thanks, no thanks, I'm good, I'm a millionaire now, I don't need Section 8" (laugh), you know, but you don't know, and without assistance you can be in the waiting list for years, decades and not being able to call off the waiting list for many reasons."

This rationale behind poverty and the need of housing unfolds in a variety of answers to the question: What are your thoughts and feelings about people that seek Section $8 \mathrm{HCV}$ benefits? Such answers go from the most rational ones to those mediated by emotion. This contrast is visible in the responses provided by an Occupancy Specialist and a PHA executive director:

“(...) so they came to the program obviously because their income level is such that they need help with the rent, they can't pay all the rent themselves, with their income base. So, definitely where they apply, they are seeking to get that help just so they can survive on [it] on the month-basis."

“Oh My Goodness! Yeah! The people we serve... Oh my! My heart goes out to them! Let me tell you. They live in a world that is very, very difficult. We live in a high-cost area where way many households use way much of their income for rent and utilities, I feel very, very passionate about the importance of social justice and providing these households we serve some measure of economic stability through housing. Oh! My heart goes out to our clients."

In this vein, implementers describe the complexity of the factors that take a household in need to seek for Section $8 \mathrm{HCV}$ program's benefits. Among these factors, the 
most frequently named are physical and mental disabilities, elderly, limited or no income, family disagreements, natural disasters, homelessness, insufficient education, tight housing markets, unemployment, gentrification and increase in the rent-controlled property. When asked if people could do any different to avoid finding themselves applying for assistance, the vast majority of responses were No, starting with an "it takes a lot for a person to actually walk into an agency and ask for help," by a HQS inspector. An Occupancy specialist adds: “(..) anything could happen in life, so you could have a perfect life and then something happens and you find yourself homeless or something, it's just, I don't think it's a decision that people make that could make any different."

\section{Representative Bureaucracy, or a Hypothesis on the Compassionate Rationale}

The representation of interest groups within bureaucratic structures occurs due to the inclusion of a workforce that represents "the very ordinary people" (Rohr, 1986: 48) inside public agencies. Usually, that representation is limited to the identity traces of race, ethnicity, and gender (Bradbury \& Kellough, 2011: 157). However, public administrators' socio-economic identity can be as powerful as the ones mentioned above. The shared experience of poverty and need may influence both, conscious and unconscious acts of correspondence between bureaucrats and population.

Section 8 HCV program's administrators “share core attitudes, values, and beliefs with the social groups" (Bradbury \& Kellough, 2011: 158) that they serve. As voucher recipients, they are socialized in the experience of poverty. A PHA executive director comprises the situation in one phrase: "in our area, we are all poor here."

The vast majority of interviewees (eleven) practice a life-experience-based empathy towards Section $8 \mathrm{HCV}$ program's recipients. Some of the practitioners account 
for a general "share of struggle in life." Others are more specific and describe episodes of their past such as being a young single mother in search of employment while receiving Section 8 assistance, brief periods of homelessness, and a background with a low-income family under welfare assistance, including food stamps. One Intake Specialist reflects on her experience as a young single mother on Section $8 \mathrm{HCV}$ program's assistance:

"I was in public housing myself, so I mean, I've been there, I know what it is like to be a single mom, and you know, I'm grateful for that, I had the opportunity to use the Program, you know, and so... even though it was only like a year (laugh). Yeah, but yeah, I know what it is and so, I can relate."

When questioned if whether this experience influences or not their attitude towards program's recipients, only one administrator responded: "It's why I'm here." Other responses pointed to a null influence of these experiences on the decision-making process. An Occupancy Specialist explains:

"I do connect with a lot of experiences to either my family or my personal experiences, and sometimes I share this with my clients "you know, I understand what you're going through because I have done this, you know, I have been there" or my family, because I like to let them know that I'm a real person too and I have experiences and that that teaches me, but I don't let it make my decisions because the guidelines that we have, they are pretty cut and dry. Yes! I would like to lower the rent for somebody but I can't do that based upon the information that I have, but I can let them know that I understand how they're feeling, you know, and I think that's important to my clients." 
Once again, Section $8 \mathrm{HCV}$ program's implementers subordinate their administrative discretion to the regulation that, as I previously stated, entails levels of flexibility and leaves room for the utilization of democratic values. How can these neutrality/discretion dynamics operate simultaneously? I will provide an explanation in the next section.

\section{Devolution, Democratic Values and Regulations: The Multiple Levels of Discretion}

In Chapter 3, I make a case for public administrators' agency (Frederickson \& Smith, 2003: 41; Waterman \& Meier, 1998: 175). I further hypothesize that public servants' discretion and autonomy shape the implementation process (Allison \& Halperin, 1972: 43) and that implementers interacting directly with the public are prone to introduce 'alterations' to the policy (Winter, 2002 in Bastien, 2009: 666). Some PA theorists display a genuine distrust of public administrators' discretion (Gulick, 1978, in Elmore, 1979: 609). Contrariwise, other scholars understand discretion as "necessary to avoid malfunctions in situations not foreseen by the law" (Bastien, 2009: 667), and essential for programs' adaptation to local conditions (Palumbo, Maynard-Moody \& Wright, 1984 in Matland, 1995: 148).

I depict Section $8 \mathrm{HCV}$ program administrators' exercise of discretion as a complex 'balancing act.' This act is defined by policy devolution (Congressional Research Service, 2012: 2) and the regulation flexibilities that it entails, leaving room for discretionary behavior. Administrative discretion of Section $8 \mathrm{HCV}$ program's implementers is also mediated by the naturalization of the extra mile, and the utilization of bureaucratic values, within, and parallel to the regulation. 
In this section, I break down Section $8 \mathrm{HCV}$ program's implementation process into some of its most critical services and actions to determine the level of administrators' discretion -low, medium and high. I establish the level depending on the amount of flexibility that the regulation allows, public administrators' agency (depending on the need of managerial intervention or not), and if whether or not public administrators utilize democratic values to execute program's implementation actions.

These services are 1 . To apply for the waiting list; 2. Pull out recipients off the waiting list, screen, and being deemed eligible; 3. Housing placement counseling and assistance; 4. To search for a unit; 5. Payment standards; 6. To process approval paperwork (Request for Lease Approval) and PHA and landlord's contract submission; 7. Inspection of the unit; 8. Additional financial assistance for moving and searching costs. I classified the actions and services as follow (see Table 19):

Table 19. Section 8 HCV Program Levels of Administrative Discretion and Actions

\begin{tabular}{l|l|l}
\multicolumn{1}{c|}{ High } & \multicolumn{1}{|c}{ Medium } & \multicolumn{1}{c}{ Low } \\
\hline $\begin{array}{l}\text { Extension of searching } \\
\text { time }\end{array}$ & $\begin{array}{l}\text { Additional Counseling or } \\
\text { Assistance } \\
\text { + Parallel } \\
\text { +Referral to external } \\
\text { service }\end{array}$ & $\begin{array}{l}\text { Additional Financial } \\
\text { Assistance } \\
+ \text { Referral to external } \\
\text { service }\end{array}$ \\
\hline & $\begin{array}{l}\text { Process of Approval } \\
\text { Paperwork (Request Lease } \\
\text { Approval and PHA- } \\
\text { Landlord contract) } \\
+ \text { A lot depends on } \\
\text { landlords and Voucher } \\
\text { holders. }\end{array}$ & $\begin{array}{l}\text { Eligibility requirements } \\
\text { and times }\end{array}$ \\
\hline & & \\
\hline & & Payment Standards \\
\hline
\end{tabular}




\section{High Levels of Administrative Discretion}

\section{Extension of Searching Time}

Once the household or individual is issued a voucher, it is their responsibility to search for, and secure a unit. Due to the multiple hazards of this stage of the process, related to both, the recipient (disability, elderly), and the environment (tight housing market), Section 8 HCV program's implementers assist recipients in the extension of their voucher for them to be able to find a proper unit. An assistant Manager makes a thorough description of the process:

"in our particular agency the initial issue is 60 days to search so once actually they have the voucher in hand, we can request extensions, in general the extensions can go up to 190 days, so we need to provide the reason on whereas you know, tracking why you need the extension, you need to tell us why... so you say things like they don't have the security deposit, you can't find units in a certain area, things of the sort, so we can provide extension to a 190 days. Sometimes, due to extenuating circumstances that clients can go through, so we can take that into consideration and we can actually go to 270 days to search, and that's going to be reviewed on a case by case basis with the extenuating circumstances beyond 190 days, and there is even a Reasonable Accommodation process where you can go above 270 days just depending on what it is, you know, whatever the disability is and how it is affecting your search to find an unit, so we have to look at those on a case by case basis as well."

The operative members of the staff seem to have high levels of administrative discretion to extend the search time. Two resources, extenuating circumstances and 
reasonable accommodation, appear to be the most relevant tools when a recipient's situation approach desperation. According to Brady (1993: 32), "HUD defines extenuating circumstances as those beyond the tenant's control and provides examples: hospitalization, travel for a family emergency, or overseas military duty." Meanwhile, O’Hara and Cooper (2003: 25) invoke reasonable accommodation for individuals with disabilities to be able to ask for changes in the application process. Such as "allowing additional time to submit an application; allowing applications to be dropped off at the PHA by a friend, family member, advocate, service provider, etc.; and conducting home visits to allow an applicant to complete the application."

While interviewees appeal to reasonable accommodation only in extraordinarily difficult circumstances, they seem to utilize only democratic values and extra time towards recipients when assisting them in more simple demands. The common perception among Section $8 \mathrm{HCV}$ program' administrators is that extending the searching time seems to be the most expedited way to guarantee success in housing a recipient:

“The regulation states that it's up to the Housing Authority how much time they wanna give a family. We have a policy in place that they have to request in writing to extend their search time. We have extended it, oh my gosh! I think the record for us was an entire year of searching. And it's terrible right now, the rental market is terrible, the rents are high, we always are extending right now and we keep that in mind, we know that there isn't enough vacancy out there and the rents are climbing and we don't have the funding to cover those increasing rents, so it's more and more difficult for families to find units, so yes! We definitely take that into consideration and give them additional time, case by case but yes!" 


\section{Medium Levels of Administrative Discretion}

Approval Process

The process of approval entails two critical moments. First, the submission of the Request for Tenancy Approval (RTA) by the recipient once she/he has found a unit. And second, the submission of the contract between the Public Housing Authority and the landlord, named HAP (Housing Assistance Payments) contract. According to Section 8 HCV program implementers, the Code of Federal Regulations stipulates times and deadlines for the approval process. A Section $8 \mathrm{HCV}$ program's Manager describes the operation:

"When the recipient finds a unit, they turn in paperwork, the tenant and the landlords allow, so once when we receive it, we will contact the landlord within 24 hours to schedule an inspection, we can take up to 15 days to schedule an inspection, based upon the size of our Housing Authority. HUD has guidelines out there on when you have to schedule an inspection by, and in ours, what HUD mandates is in 15 days. We do try to process, the Request for Tenancy Approval within 24 hours, and typically we can get an inspection scheduled anywhere between 72 and 40 hours of receipt because of the schedules need between the landlords and then, the inspectors, depending on their schedules."

Despite practitioners' efforts in reducing the time that takes to house a family or an individual, there are limits to their administrative discretion on expediting the process. These limitations are associated with the tenant's promptness when turning paperwork in. Above all, it depends on landlords' wish to comply. An Occupancy Specialists reflects on landlords' role in the approval process: 
"Some landlords, they do complete all the paperwork and return with the contract, and you know, copy of lease. Sign everything as soon as possible, then the reduction is, you know, it goes by smoothly, you know, fast. The inspection depends on if the unit if livable or not, if the unit has a lot of things and the landlords are taking their time, it will take time to do that, there is nothing we can really do."

\section{Additional Counseling}

The provision of additional counseling or assistance faces a completely different predicament. Formally, it does not exist as a service. Public Housing Authorities and Section $8 \mathrm{HCV}$ program's administrators do not have the expertise, resources or time to conduct this action. And nonetheless:

"Well, again, it's a human field. I mean, we're dealing with people's homes, so, you can help to get some counseling, on some level if you get someone here that is obviously needing a little bit of guidance, so you try and keep it to minimum; but, I'm not gonna sit here and watch somebody make a huge mistake and not say "Hey! Wake up!"”

Housing Authorities with better resources and more connections partner with organizations that are able to provide counseling to recipients. An Occupancy Specialist and a Special Programs Coordinator reflect on the effects of lacking the provision of this service:

"We are not able to do that here, we don't have the training. We just administer the Program. You know, some people say "I need help!" you mean that as needing help, and we just refer them to other agencies. We don't have the staffing or the 
training for actually being a social worker, so we try to steer them in the right [direction]."

"(...) at the end of the day is always the mental health, you know, you see all these patients that come in, or clients, and they are crying, and they are distressed and they have anxiety and I just try to work with them and not having... I mean, I have talked to, I have thought about the idea of having a mental health therapist here to kinda deal with some of these patients, but again HUD doesn't allow room for that."

\section{Low Levels of Administrative Discretion}

\section{Eligibility}

Eligibility seems to work as the perfect example of the effects of policy devolution (Congressional Research Service, 2012: 2) on regulation, and the limits of implementers' administrative discretion once the managerial level stretches the norm to its maximum. An Occupancy Specialist describes how the Public Housing Authority minimized eligibility requirements while maintaining its allegiance to HUD's mandates:

"We have reduced for eligibility especially, and for termination. We go to the bare minimum of what is put in place by HUD as far as regulations, so we used to be a little, a lot more stringing because we could be but yeah we have reduced like for eligibility we have reduced the criminal background check from five years to three years, the past three years for violent crime and drug activity and then even now we're a little bit more not strict as far as the type of charges they are convicted out so, we have done that."

There is no room for utilization of democratic values or further assistance in this phase. With no exception, interviewees emphasized in the impossibility to intervene in 
eligibility matters. A Supervisor explains: "Regarding eligibility, it's strictly strict. You know, I can't say that I would try to do anything regarding it."

Intake specialists rely on other agencies to screen an applicant's background. Time may vary from the moment a person is pulled out of the waiting list to the moment this person is deemed eligible. Implementers acknowledge recipients' situation and operate in consequence. Not always the process is smooth:

"We can determine eligibility between three days to six months. It's all based on our different situations unfortunately. You know, if someone turns in all their [paper]work, we do the background check, ah, criminal check, I'm sorry, and that gets returned within two days, and we have everything, they can get a voucher in three days. But if for whatever reason the person doesn't turn everything in, they have to go for finger printing, they have to go through the sheriff department and everything, that can potentially take you know, three to six months to get all that paperwork done. So can it be lowered, yeah, it can but due to unforeseen circumstances, sometimes they get just delayed"

\section{Payment Standards}

According to O'Hara and Cooper (2003: 36), the PHA establishes payment standards for the units based on their number of bedrooms. Payment Standards are also based on HUD's Fair Market Rents, an estimate that reflects "modestly priced rental housing costs" in a specific housing market area in the country.

Payment Standards are, as the name indicates, a highly standardized aspect of the policy. They are difficult to modify but not impossible to do so. Extraordinary circumstances in recipients' life mobilize the modification in Payment Standards. Usually, 
a caseworker advocates for a tenant's particular situation while the ultimate decision rests at the Managerial level. It is valid to mention that these decisions are made under delicate funding considerations, overcome only by considerations on democratic values. An Occupancy Specialist narrates a recent case:

"I have a client whose daughter tried to commit suicide and requested that they can extend their voucher so that she can get her own private space so that she can, you know, hopefully mend and not feel so threatened and then I was very grateful that [the Section 8 Manager] actually again, has the final say on the exceptions, the client has to provide a reason, with the funding being so tight, most exceptions are probably not being approved... but I was very grateful that... this is one that we just did last week so, the week before...I'm hoping that this makes a difference in this teenager's life, they provided documentation that I didn't need to see, but it was heartbreaking."

\section{Time on the Waiting List}

The waiting list is the least controllable phase of Section $8 \mathrm{HCV}$ program as Federal resources are the exclusive fund for vouchers. Two events provoke waiting lists to circulate: More funding, and vouchers liberated by recipients that were either terminated or voluntarily left the program. None of such events occur often. By the time I was conducting fieldwork in California, the Federal Government had announced cutbacks to the program, and there was a climate of uncertainty within the agencies. I drafted a brief reflection on my fieldwork notebook: 
Dec $1^{\text {st }} 2017$

"I think - because I just had lunch with [a caseworker], that a lot of uncertainty in the program comes from HUD funding unstability [sic]. [The caseworker] explained me that this year, HUD already cutted [sic] the funds for Section 8 by around $7 \%$ and that may continue. Depending on HUD decisions, the Section 8 will be able to deliver. With this [sic] shortages there is uncertainty on about how many people to serve, second, there may be a situation of lack of funding where the waiting list gets FROZEN. After that, the worst case scenario would be a WAIVING in the program, meaning starting to reduce the number of vouchers (Very BAD)."

Despite its lack of mobility, PHA and Section $8 \mathrm{HCV}$ program's implementers have developed strategies to activate the waiting list to the best of their abilities and serve their community using limited resources. Managerial level workers shared two of these strategies. On the one hand, there is the introduction of preferences in the waiting list according to the needs of the vulnerable populations surrounding the PHA's area:

"We have a veteran preference, you know, people who are veterans get our preference on the waiting list. For those, so two people apply the exact same day or something, one is a veteran, the veteran will get selected before the other person. Let's say for example, residential preferences, oh excuse me, jurisdictional preferences, people who actually reside in our jurisdiction get a preference over those who don't. So, if somebody, you know, we have a huge geographical jurisdiction, but, somebody in [the] County jurisdiction is on the waiting list, and somebody from New York apply to the waiting list, the person who is in [the] 
County jurisdiction is gonna get preference over, and selected over the person who lives in New York. So, our preferences on the waiting list are taken into account.” On the other hand, the second strategy consists in switching the waiting list to a lottery style list. This system seems to benefit the population by providing citizens with a more rapid and precise response to their question for the chances of getting selected for a voucher:

"We reduced our wait list so what we used to do was open up our wait list, we usually take 4500, 5000 applicants and then that wait list would last for three, or four, or even five years. By the time we got to the year three to five, we couldn't find most of the applicants and it became a sort of an exercise of futility, so we got to a system now where we open our wait list yearly, giving folks a better opportunity in the community and we pick only... we do a lottery with our annual opening. Our last time we opened last year, we got 5500 applicants, we did a random drawing and drew 1200 from that group in order to establish our final wait list pool for this year. We will open up the wait list again this fall, which allows a whole fresh batch to come in, so our wait list is being renewed a lot more frequently than it used to be and that really helped our ability to find households. They don't tend to disappear over a year as much as they do over a three or four year period of time."

Aside these strategies, the most pressuring and invaluable waiting list's mobilizer is funding. 


\section{Additional Financial Assistance}

A regular worker struggles to put together move in costs, deposit, and the first month of rent monies. It is not hard to imagine an unemployed, elderly, or disabled Section 8 recipient trying to meet these requirements from a landlord that has accepted his/her voucher. Public Housing Authorities and Section $8 \mathrm{HCV}$ program's implementers are aware of such circumstances. Unfortunately, due to the limited resources of the program, they cannot provide those much-needed services. As in the case of counseling, the only way out is partnering and networking:

"We don't have a move in assistance, we actually provide them with the 2-1-1 number, [the] County resource, and they also can go to the DPSS (Department of Public Social Services), if they are currently receiving GR or CalWORKs, they can also go through them as resource, they have a once in a lifetime move out assistance which could be provided to them. And if they have Social Security and not CalWORKs or GR, then we let them know “you know what, try to speak with your Social Security administration to see if they have any resources for you", but we don't have those move in costs."

\section{The Limits of the Administrative Discretion and the Signature Outcomes of the Program}

The Section $8 \mathrm{HCV}$ program builds its rapid and sustained growth on its promises of outcomes improvement regarding neighborhood and unit quality, and race and poverty desegregation (Schwartz, 2010 in Ross, Shlay \& Picon, 2012: 36). Despite the initial optimism around the program's pledge of exterminating traditional public housing diseases, the evidence presents a different and daunting reality. Section $8 \mathrm{HCV}$ program's 
recipients tend to cluster within areas of high levels of poverty and racially segregated communities. According to Varady (2010: 392), "without especial geographical requirements and intensive counseling, vouchers recipients generally do not move to lowpoverty suburban neighborhoods."

HUD mandates portability actions with the purpose of promoting vouchers mobility towards more prosper and racially desegregated areas across the country. Public Housing Authorities comply with portability by explicitly presenting it as an opportunity to new voucher holders. PHAs devote exclusive staff to serve port-in, or recipients coming to a jurisdiction with other PHA's voucher; and port-out recipients, or those that port to another area with a local PHA's voucher. Agencies act in tandem with other Housing Authorities to either absorb, which means taking the voucher as its own; or bill for the incoming voucher. An Occupancy Specialist in charge of assisting port-in and port-out vouchers' recipients explains the ropes of the process and how it works the same that with regular Section 8 local recipients:

"We really don't care where they are going. Regardless of where they are going we will port them out, whether billing or absorbing, we will port them out. Port in depends on what other Housing Authority, some Housing Authorities will not port out unless other Housing Authority is absorbing. If they are not, they won't port out. And when people come here, that's really easy and simple, that's how I look at it because the minute I get the portability to port in, I send notification to the tenant to contact me for intake appointment. Once we schedule the intake appointment at that time I issue them a voucher and the Request for Tenancy Approval to start looking for places. So I feel like in our Housing Authority is pretty 
much easy and simple, and all the rules, pretty much a lot of rules are pretty much the same."

Despite this positive account, portability may be creating a new set of problems for Public Housing Authorities. Affordable housing scarcity is a reality nationwide. However, structural measurements such as increasing housing policy budgets and developing affordable housing are not being implemented. Hence, portability is falling into distortions to satisfy the desperate need of housing of vulnerable population. An Occupancy Specialist reflects on the "shopping" practice:

"The hard thing that we see especially these days are they are shopping around, they are just trying to... Well! No, that's not true either! Because if you think about it people shop around, because you know Section 8 is throughout the United States, anybody, and so we have people applying from New York, applying here, and then they are trying to get it back to New York, which I understand, the reason why they are shopping for is because they need it, so now that I think about it, no one would be applying for this if they didn't need it."

These practices may hurt Public Housing Authorities, especially those located in rural settings with low Payment Standards:

"Well, what happens then is "ok, we approve the Reasonable Accommodation, they are a disabled household, you need to stay where your doctors are" and then that Housing Authority bills us 2000 dollars for rent for that family, when it would costs us 500 dollars here. So that's one of the problems that we are facing right now. Most Housing Authorities are billing because they just can't afford it, and we can't afford it either but they have the right to do it." 
Can Section $8 \mathrm{HCV}$ program fulfill its promises of neighborhood and unit quality, and race and poverty desegregation? Public administrators respond to these questions. Neighborhood and Unit Quality

There are two opposite perspectives among interviewees on neighborhood and housing quality within Section $8 \mathrm{HCV}$ 's recipients. On the one hand, practitioners recognize the difficulties to find decent, affordable, and well-maintained housing. Landlords in less desirable areas have the advantage of price and availability. Sometimes, this availability and willingness to take vouchers play against quality conditions as landlords bet for the bare minimum to comply. Implementers on this side of the spectrum express their low discretionary power towards this problematic situation:

"You know we don't have any room here to kinda help with that. Unfortunately we are stuck with the landlords that are willing to rent to Section 8 and some of them are slum landlords, they just meet the minimum housing standards for our needs."

On the other hand, a number of Section $8 \mathrm{HCV}$ program's implementers praise these Housing Quality Standards and inspections as a guarantee of decent living conditions for recipients:

"I think the housing quality inspections are very important in that we can assure for those residents that they have got a decent, safe and sanitary unit, with life safety feature functions, windows lock, doors lock, there is not hazards in the unit, that's really important, in fact, ironically, in [a nearby city] here, which is a very challenged community here, in [the city], the city managers keep telling us they like our housing, they like the Section 8 program because is typically the best housing in their community, because specifically of the quality controls that go 
alone with us, (...) and our involvement in the three party agreement with the landlord and the tenant. It just makes a better outcome."

\section{Race and Poverty Desegregation}

Communication and information seem to be the most powerful tools to guide Section $8 \mathrm{HCV}$ program's recipients to concentrate their search on low-poverty and racially desegregated neighborhoods. The Vouchers' briefing is the best opportunity to address the topic, present portability as a valid option, and provide the necessary information. A Section $8 \mathrm{HCV}$ program's Manager explains the content of the talk:

“(...) when we do our voucher presentations we do provide local maps divided amongst Census Tracts and poverty areas, we provide maps and so where social services are available, transportation lines are available so hopefully... and we do encourage people and we do talk to folks about the benefits of living in less poor neighborhoods such as, perhaps schools, opportunities for employment and better outsides too, and social services..."

Following the Manager, another critical task lies in alluring landlords to the Section

8 program through the presentation of its benefits and conditions:

"Well, first, we do outreach to landlords outside of poverty areas to encourage them to lease up to Section 8 participants, we do regular presentations at local property owners' association regarding housing quality standards and inspections standards."

This informational task has a limit as HUD forbids Section $8 \mathrm{HCV}$ program and PHA staff to 'stir' recipients towards a particular development, area, or landlord. Implementers take this warning very seriously, and many of them prefer to comply with 
HUD's requirement than risk misinterpretation by recipients' part. A program's director explains:

“I can't tell you how many times our voucher holders: "I can’t find anything, would you please help me!" No, we cannot. That's one sure way to get in trouble, and deconcentration, you know, you got all these big words that really do mean something. Stirring is huge, we don't want to stir, you know, we really have to be careful there."

PHA and Section $8 \mathrm{HCV}$ program implementers support literature on recipient households' preferences (Deng, 2007: 22). Voucher holders stay within areas nearby their support circles of family, church, and other social connections. An HQS Inspector introduces a brilliant perspective about the discrepancies between policymakers and recipients on the notions of quality, safe, and healthy:

"I think that, you know it goes back to what previously where we talked about tenants and where they choose to live. They choose to live because of familiarity, or accessibility to resources around them. I think that just thinking in the community that I live in, that I go in in inspects, you know a lot of families, they choose to live in the South Side area because the low-income clinic is there, because their families are there, because the schools are there, it's just walking distance, you don't have to drive, if they move with their kids to another location, they are gonna have to drive to the clinic now, they are gonna have to ride the bus to the clinic. And also taking to account, what I consider quality, or safe, or healthy, they may see, tenants may have a different perception, you know they feel comfort, they feel safe in that environment rather than moving them to Downtown, where the homes 
are bigger and nicer but they have no idea, you know? Houses are more scattered and you don't know your neighbors. So I think, tenants' definition of what's safe and healthy is different from what an outsider's perception is."

\section{Obstacles to Section 8 HCV Program}

Section $8 \mathrm{HCV}$ program's administrators mention four specific obstacles to the program. I organize them by the frequency with which implementers name them when responding to the question: "What would you think is the main obstacle for the Section 8 HCV program's complete success in your area? These obstacles are funding; tightness of local housing markets; limits to recipients' services delivery; and landlords' attitudes towards the program and voucher holders.

\section{Funding}

The funding game is an expression of the tensioning relationship between HUD and Public Housing Authorities across the nation. PHA and Section 8 administrators seem both, constrained and disheartened by HUD's unpredictable determinations to reduce the program's budget. This uncertainty transpires in every interview, not only in this section's question but along the whole dialogue. The exclusivity of the funding source places PHAs' managerial level in a position of permanent discomfort, trying to anticipate every movement from HUD to avoid traumatisms in the Program. An Assistance Manager explains his strategy:

"I always have this speech of, you know, that you have to be prudent, that you're always forecasting, you know, projecting, you never just wanna just come at this day $(. .$.$) , you always have to look into the future, and make sure that you always$ 
gonna have enough funding and that you're not on some collusion course, you know, in few month or in a year or something like that."

HUD's capacity to deliver (or the lack of it) affects every aspect of the Section 8 HCV program's implementation process. It interrupts the ability to pull people out of endless waiting lists and limits the local competitiveness of Payment Standards. HUD cutbacks also hold the delivery of new and issued vouchers and force workers to leave their posts in times of extreme crisis. Implementers face emotional stress linked to job insecurity and the limitations in the distribution of services to recipients. Sometimes, HUD's will is inscrutable, forcing both, Section 8 implementers and voucher holders to interact in an environment filled with uncertainty:

"Right now with the new administration unfortunately we were put on hold, marked as a shortfall agency, we had to suspend all my vouchers and all my pending applications since April, so it sucks for us because now I have 130 families that were in the process of getting their Section 8 voucher and then I have another 145, I believe, families that already had their vouchers since April... you know, a little bit before April, and they can't get a house until the suspension is lifted. You know, whether it's political, whether it's budget related, it all comes from HUD, it has to do maybe with the new administration? Cutbacks, and everything, because we were such a high performing Housing Authority, we didn't have any leeway because we were so good that we... you know, we were punished for it. So we are still waiting because of that."

Policy flexibility and devolution (Congressional Research Service, 2012: 2) are allowing PHA and Section $8 \mathrm{HCV}$ program's managerial level to consider alternative ways 
of meeting housing needs within their jurisdictions. A PHA executive director explains how they "are now moving to project-based vouchers because we're trying to capture housing opportunity." Most of the times, such housing opportunities entail strategic alliances with the private sector (Garshick Kleit \& Page, 2015: 621).

\section{Tightness of Local Housing Markets}

Interviewees concur with scholars when affirming that market tightness is one of the most challenging obstacles to overcome by voucher recipients (Austin Turner, 2003: 1; Deng, 2007: 22; Ross, Shlay \& Picon, 2012: 39; Williamson, Smith \& Strambi-Kramer, 2009: 121). Unlike scholars, public administrators reveal the role of low Payment Standards in a market-oriented environment in the midst of a national housing crisis. An Administrative Analyst pictures the reality that Section $8 \mathrm{HCV}$ recipients face on a daily basis:

"We have a case worker with them, to help them with the paperwork, there is already a waiting list with 25 people for that unit and now we are gonna tell that landlord "hey, we know you can get far higher than the Fair Market Rents for your unit in the open market but, hey why don't you actually help our client and we are gonna pay you less" and think our client is dealing with other issues, as you know, special needs."

On the flip side of the coin, according to implementers, the increase in Payment Standards by Public Housing Authorities encourages landlords to raise rents, in a circle that never ends. An Occupancy Specialist explains:

"But it's a double edge sword, it would be great if we have the funding to increase our Payment Standards to coincide with the rent; however, every time we increase 
the Payment Standards the community finds out and the landlords increase the rents so it's kind of a double edge sword but it would be nice to have the funding so people really, truly can get safe and decent housing as opposed of whatever they can afford in the bad part of town."

\section{Limits to Recipients'Services Delivery}

Section $8 \mathrm{HCV}$ administrators address housing needs as the tip of an iceberg compressing various necessities. The program's target population is frequently affected by both, mental and physical disabilities, unemployment, educational deficits, elderly, and abandonment, among others. Not too many years ago, Public Housing Authorities were able to assist Section 8 and public housing recipients in a more holistic fashion (Bingham $\&$ Kirkpatrick, 1975: 68). Nonetheless, when the discursive approach (Conners, 2017) and the federal support to the American housing policy started to faint in the decade of 1980s (Garshick Kleit \& Page, 2008), these services vanished as well.

Today, only Public Housing Authorities with ample resources such as expertise, motivation, time, personnel, organizational networking, and a democratic set of values, can compete for HUD's scarce resources that allow assistance provision beyond the voucher. Initiatives such as HUD-VASH, and the Family Self-Sufficiency Program function under the assumption that an integral service is an anomaly. The commitment to help vulnerable recipients to return from whichever hardship they are facing entails more than issuing a voucher. A caseworker explains:

"We house, but there is more than they need that just housing. Sometimes you just need a caregiver, sometimes is not a living aid, sometimes they just need somebody to help them with their computer stuff, like paying their bills or something, so you 
know that the elders get abused more, you might see it in the way that they come and present themselves. Some of them probably are not cleaned. So it's how you see them when they come, it's like "what else is there for them."

In the specific case of recipients' attempts to meet Section $8 \mathrm{HCV}$ program's requirements, there is information and skills that deprive households of securing a unit. An Occupancy Specialist enumerates recipients' setbacks that would demand to address the situation through a whole different set of services:

"I know a lot of people have a hard time successfully getting into the unit because maybe they have a bad credit rating, or they don't have money for deposit, or they have no credit at all and they have to have a co-signer, usually it's something in regard to them being proved by the landlord's check."

Landlords' Attitudes towards the Program and Voucher Holders

Once again, Section $8 \mathrm{HCV}$ program's administrators coincide with housing scholars in stating that not every landlord in the nation is cooperative towards voucher recipients (Beck, 1996: 159). Two motivations operate behind this negative approach: discrimination and profit. Landlords distrust in Section $8 \mathrm{HCV}$ program's recipients has to do with racial and ethnic discrimination, but also with the validation of prejudiced images of voucher recipients. A Section 8 Director discusses landlords' apprehensions about the program and its beneficiaries:

"They have this mindset of “Oh! They're gonna trash my unit, and I never gonna get paid for the damages and..." that may be true but could be true for a rate market person too. So you have to police your lease, you have to screen, you have to monitor your property, you know, those are things that you have to do." 
Furthermore, in this particular moment of the housing market landlords do not feel the allure of Section $8 \mathrm{HCV}$ program's benefits. The rental tightness is allowing them to profit greatly through the open market renters. An experienced Administrative Analyst explains how these cycles of landlords' interest and disinterest in the program come and go:

“There are other times, Melissa, where the market [let's] say, it's the opposite. We have landlords begging down our door that want those Section 8 tenants because they have vacant units and they are willing to take our clients because if that person loses their job it doesn't matter, the Housing Authority, the Section 8 Voucher will pay the Fair Market Rent... up to the Fair Market Rent for that unit. So, that's just not what we are dealing with now, I mean, there is that challenge of the tight market, there is the challenge of right now, and pretty much every year." 


\section{Chapter 7: Conclusions}

Research Structure

This dissertation explores public service values in the light of performance. I examined how public administrators' values and attitudes towards policy recipients shape implementation and influence organizational and program performance. I selected the Section 8 Housing Choice Voucher Program due to its ambiguous results as a policy (Deng, 2007: 22; Devine et al. 2003; Galvez, 2010: 6; Newman \& Schnare, 1997: 726; Pendall 2000; Varady, 2010: 402). Section $8 \mathrm{HCV}$ program assists low-income families, elderly and disabled people to afford decent, safe, and sanitary housing in the private market.

My main research hypothesis claims that environmental and organizational factors impose a toll on organizational and policy performance, and that public administrators' values and attitudes towards recipients buffer some of these effects.

In Chapter 1, I introduced the research problem by pointing to the American housing policy failure in delivering housing and neighborhood quality to vulnerable citizens (Newman \& Schnare, 1997: 726). The Section 8 Housing Choice Voucher Program failed as well, in the attempt to meet its signature outcomes, named voucher holders' mobility, and poverty and minority desegregation (Varady \& Walker, 2000; Varady, 2010: 402; Deng, 2007: 22). Do public administrators' values and attitudes play a role in this policy failure? To answer this question I developed one research question and two operative ones:

Do values and attitudes applied by public administrators to the implementation process of Section 8 HCV program influence recipients' access to high quality, affordable, non-racially segregated and non-poverty concentrated homes? 
If, and to what extent, do organizational and environmental conditions, such as demographics and political preferences of communities, economic factors, and racial disparities affect public organizations ' performance?

Do public administrators' preferred set of values and attitudes coincide with either positive or negative organizational and policy performance at the Section $8 \mathrm{HCV}$ Program?

I attached several hypotheses to these questions: 1. Public Housing Authorities and Section 8 Housing Choice Voucher Program nationwide display dissimilar performance that results in recipients' differentiated access to quality, affordable, non-racially, and nonpoverty concentrated homes. 2. Such performance disparities are correlated to environmental, organizational, and policy factors and these factors impact both, PHAs and Section $8 \mathrm{HCV}$ performance. 3. An implementers' democratic-centered set of public values and attitudes will coincide with positive policy outcomes regarding poverty/race desegregation and higher levels of housing and neighborhood quality. Conversely, an orthodox/managerial/domination-oriented set of public values will coincide with negative policy outcomes.

Chapter 2 accounts for the literature review. My main conceptual avenues are the normative notion of public service values in public administration, and the difficulty in linking them to administrators' behaviors and the realities of policy implementation and outcomes. I also included organizational performance as "a socially-constructed concept (Brewer, in Boyne, Meier, O’Toole Jr., \& Walker, 2006: 35), and brought attention to the unexplored questions on performance measurability when addressing democratic values such as "equity, democracy, participation, and citizenship" (Talbot, 2010: 49). I further 
questioned the apparent incompatibility between democratic and bureaucratic values when pursuing and measuring performance (O’Toole \& Meier, 2011: 2). Finally, I connected Section $8 \mathrm{HCV}$ program's Administrators to the values and attitudes that may influence performance and policy outcomes by the use of "discretionary administrative practices" (Tegeler, Hanley \& Liben, 1995: 467) towards recipients.

In Chapter 3, I introduced the operative questions, those that helped me to develop the research, with their correspondent hypotheses. In the theoretical framework, I utilized theories of bureaucratic politics and the Principal-Agent Model to build a public administrator full of agency (Allison \& Halperin, 1972: 43; Frederickson \& Smith, 2003: 41). In the same vein, I included the street level bureaucracy theory (Lipsky, 1980) to address public administrators-recipients rapport and bureaucrats' high levels of administrative discretion. I also developed the four typologies of public servantsrecipients' rapports by theoretical and historical moments of the PA field: Bureaucratic, democratic, managerial, and the critical theory inquiry to political neutrality.

Chapter 4 comprises the research design. I described the two consecutive and interdependent stages of the study. In the first stage, I used quantitative techniques to determine how environmental factors impact PHAs' organizational performance and Section $8 \mathrm{HCV}$ program's outcomes. In the second stage of the study, I utilized a qualitative approach to determine the most predominant sets of public values and attitudes among Section $8 \mathrm{HCV}$ program officials.

\section{Findings}

Chapter 5 and Chapter 6 contain the research findings. Chapter 5 addresses the environmental and organizational influencers of performance in Public Housing 
Authorities and Section 8 HCV programs' outcomes nationwide. The main hypothesis of this quantitative portion of the research is that environmental and agencies' structural factors impose a toll on organizational and policy performance and outcomes. The results support the hypothesis that organizational and environmental factors impose a toll on organizational and policy performance (Smith in Boyne, Meier, O’Toole \& Walker, 2006: 87). In the first model, demographic and socioeconomic characteristics of communities partially explain organizational PHAs' performance. In Model 2, the OLS regression confirms that environmental influencers, such as a tight housing market, influence Section $8 \mathrm{HCV}$ program's hardly controllable structural factors, pressuring both, program's resources and performance (Deng, 2007: 22; Austin Turner, 2003: 1; Ross, Shlay \& Picon, 2012: 39; Williamson, Smith \& Strambi-Kramer, 2009: 121). The third model also confirms that environmental, organizational, and Section 8 structural factors impact poverty segregation levels on Section $8 \mathrm{HCV}$ program's recipients. Finally, Model 4 not only endorses the hypothesis that environmental, organizational, and Section 8 structural factors influence minority segregation among voucher holders, but displays some institutional responsibility in Section $8 \mathrm{HCV}$ program's recipients' levels of minority segregation (Tegeler et al., 1995: 467; Turner, Popkin, and Cunningham in Austin Turner, 2003: 3).

Chapter 6 accounts for the findings of the qualitative portion of the research. I addressed public administrators' discursive devices towards citizens regarding values and attitudes, paying special attention to neutrality and the capitalization of their technical expertise as a source of discretion (Foucault, 1980). Next, I examined the rationale behind their attitudes (Alexander \& Stivers, 2010; Alkadry \& Blessett, 2010; Marr, 2016), and the 
set of public service values utilized by Section 8 workers while implementing the Program. I studied policy implementation process and Section 8 workers' administrative discretion. I further explored practitioners' perceived impact on Section 8 HCV program's signature outcomes: housing and neighborhood quality, and poverty and race desegregation. Finally, I included administrators' perception of the program's most significant obstacles.

Due to the impossibility of contacting with low and standard-performance PHAs' interviewees, I had to narrow my initial hypothesis from: A more democratic-centered set of public values and attitudes will coincide with positive policy performance and higher levels of poverty/race desegregation, and housing/ neighborhood quality. On the other hand, an orthodox/NPM/domination-oriented set of public values (Client/Customer/subject types) will coincide with negative policy performance and lower levels of poverty/race desegregation, and housing/neighborhood quality.

To: A more democratic-centered set of public values and attitudes will coincide with positive policy performance and higher levels of poverty/race desegregation, and housing/ neighborhood quality.

Qualitative findings turned out to be quite surprising. Firstly, I expected that my research evidence would support Frederickson's (1997) claim that a dominant bureaucratic set of values marginalizes the delivery of services under democratic values. In opposition to Van Wart's "reachable gestalt" (1998 in Molina, 2015: 49). Instead, I found that highperforming PHAs and Section $8 \mathrm{HCV}$ program's administrators identify policy stakeholders and their demands. Such demands vary and can be democratic, bureaucratic, or managerial. Then, implementers develop strategies to comply with their different duties by simultaneously utilizing various sets of public service values. The selection of values 
depends on the situation and the audience. In Frederickson's favor, the use of democratic values demands a deliberate extra effort by implementers' part.

Contrary to my initial theoretical proposition, PHA and Section 8 HCV Program's administrators endorse the validity of the principle of political neutrality. Section 8 workers consider this traditional public service value achievable in its full extension. Also contravening my initial hypothesis, technical expertise is not a proxy but the most valuable tool to guarantee neutrality.

Section 8 implementers' administrative discretion works as a vehicle for the provision of democratic values to the most vulnerable segments of the population (Frederickson, 1997: 42). In the case of PHAs and Section 8 HCV Program, policy "devolution" allows this practice. The neutrality of the regulation and the practice of democratic values through implementers' administrative discretion cohabits harmonically as regulation's flexibility provided by devolution prevents it to be bent, violated, or broken. Public servants utilize this "superpower" to expand the public service values portfolio and include democratic ones in their quotidian rapports with recipients. As I expected, Section $8 \mathrm{HCV}$ program's administrators are not neutral towards recipients' identities (Eagan, 2006). Unexpectedly, they use this information to address recipients' historical vulnerabilities and level the policy field in recipients' benefit. One of the rationales behind this behavior may be related to a shared socio-economic identity between workers and voucher holders that encourages conscious and unconscious democratic-oriented actions of bureaucrats towards population (Bradbury \& Kellough, 2011: 158).

The qualitative portion of the research reveals the limited or null discretionary power of public administrators over Section $8 \mathrm{HCV}$ program's signature outcomes: 
neighborhood quality, and overall, poverty and race desegregation. Housing Quality Standards and regular inspections can guarantee safe, decent and affordable housing for voucher holders; nonetheless, that is as far as the program goes due, in part, to the scarcity of funding to increase Payment Standards and housing market dynamics that do not allow recipients' mobility and distort portability strategy. Recipients also have a say in their location and living conditions. In this vein, David Varady (2010: 391) makes an important policy recommendation by claiming that "Efforts to maintain, and expand, the voucher program should be based on the program's proven ability to provide decent and affordable housing rather than on unproven claims that it promotes poverty deconcentration and family self-sufficiency.”

Section $8 \mathrm{HCV}$ program administrators are in sync with the quantitative portion of this dissertation. Implementers responses to the question about the most pervasive and harmful obstacles to the program, namely funding and housing markets, coincide with two significant environmental and organizational influencers of policy and PHAs' performance.

\section{Contribution, Limitations and Future Research}

PA scholars usually address public service values from a theoretical perspective. This dissertation's contribution lies in addressing highly theoretical topics of the field, such as public service values, the political neutrality of public administrators, and the politicsadministration dichotomy, and translate them to the more material sphere of policy, implementation, and performance.

My research interests lay in examining public service values applied to implementers' administrative discretion in a concrete policy and determine if they affect 
the implementation process and the service delivery to recipients. I also wanted to determine if public servants' attitudes towards citizens influence the amount and quality of assistance. I aspired to make these findings coincide with a more concrete branch of the discipline. I considered Performance. What if, contrary to what scholars claim (O’Toole \& Meier, 2011: 2), democratic values are compatible with high performance? And highperforming agencies had room for social equity, sovereignty of the people and participation? I partially succeeded.

As I hypothesized, there is a coincidence between a more democratic-centered set of public values and attitudes, and a positive organizational and policy performance. There are limitations inherent to these findings. Firstly, as the performance indicator for Public Housing Authorities is randomly distributed between cities and counties, I had to select county seat PHAs' scores and combined them with county indicators. This action produced a mixed dataset that opens the door to focus the study in cities only. Secondly, the behavior of the variable 'Income' needs to be further analyzed as it displays unexpected behavior towards PHAs' performance.

Third, I only conducted qualitative research within high-performance PHAs and Section $8 \mathrm{HCV}$ programs. In consequence, I could not develop the other end of the hypothesis that relates low and standard-performance PHAs and Section $8 \mathrm{HCV}$ programs with bureaucratic, managerial, or domination-related values. There was not possible to make a comparison. Fourth, a majority of Californian PHAs accepted to be part of the study, while only one public administrator at a Floridian PHA acceded to respond to the semi-structured interview. 
The fifth "limitation" has to do with the particular conditions of the selected policy. By the time I defended my proposal, I was aware of the broadly criticized operation of the American housing policy (Austin Turner, 2003; Carlson, Haveman, Kaplan \& Wolfe, 2009; Deng 2007). What I did not know was the historical background that explained these critiques, and the current situation of housing policy as nearly dismantled (Goetz, 2012:452). Housing Policy stands still in an ever-changing neo-liberal world that fiercely attacks any remnant of that political anomaly once called The New Deal (Bingham \& Kirkpatrick, 1975: 65). These elements make PHA and Section 8 HCV program's implementer a one-of-a-kind administrator. They have a particular commitment to the policy and the utilization of democratic values. They also display a remarkable capacity to use devolution in favor of recipients. Devolution, in fact, was introduced to strip PHAs off funding and overwhelm them with responsibilities and duties (Garshick Kleit \& Page, 2015: 621). Public Housing Authorities and Section 8 HCV programs across the country are using the weapons against them to survive. Under the hardest conditions of scarcity, they are finding allies to continue the provision of decent, quality, and affordable housing in their communities. Most of these allies are nonprofit and developers from a private market. How long can they resist? Will they be able to provide for the poorest of the poor under these conditions? (Fraser et al. 2012, in Garshick Kleit \& Page, 2015: 622).

Future research is needed in public service values to continue demystifying their incompatibility. The politics-administration dichotomy demands to be questioned in real life, as public administrators are too, human beings, with interests and preferences. I addressed public administrators' part in policy implementation. I further analyzed the influence of their actions, values, attitudes, and the direction of their discretionary power 
on performance and outcomes. The human factor has been the most neglected element when analyzing housing, or any other policy. This dissertation considers a holistic way to do so. 


\section{References}

Abdo, N. (1996). Sociological Thought: Beyond Eurocentric Theory. Toronto. Canadian Scholars' Press Inc.

Alexander, J. \& Stivers, C. (2010). An Ethic of Race for Public Administration. Administrative Theory and Praxis. Vol 32. No. 42(4), 578-597.

Allison, G. \& Halperin, M. (1972). Bureaucratic Politics: A Paradigm and Some Policy Implications. World Politics. Supplement: Theory and Policy in International Relations. Vol 24. 40-79.

Alkadry, M. \& Blessett, B. (2010). Aloofness or Dirty Hands? Administrative Culpability in the Making of the Second Ghetto. Administrative Theory \& Praxis, Vol. 32, No. 4, 532-556.

Amirkhanyan, A., Kim, H., \& Lambright, K. (2013). The Performance Puzzle: Understanding the Factors Influencing Alternative Dimensions and Views of Performance. Journal of Public Administration Research and Theory, 24: 1-34.

Andersen, L, Jorgensen, T., Kjeldsen, A., Pedersen, L., \& Vrangbæk, K. (2012). Public Values and Public Service Motivation: Conceptual and Empirical Relationships. The American Review of Public Administration. 43 (3), 292 -311.

Andrews, R., Boyne, G., \& Walker, R. (2006). Subjective and Objective Measures of Organizational Performance: An Empirical Exploration. In Boyne, G, Meier, K., O'Toole, L., \& Walker, R. Public Service Performance. Perspectives on Measurement and Management. Editors. Cambridge. Cambridge University Press.

Austin Turner, M. (2003). Strengths and Weaknesses of the Housing Voucher Program. The Urban Institute. Congressional Testimony of Margery Austin Turner, Director, Metropolitan Housing and Communities Policy Center, The Urban Institute, prepared for the Committee on Financial Services, Subcommittee on Housing and Community Opportunity, United States House of Representatives.

Austin Turner. M. \& Kingsley, T. (2008). Federal Programs for Addressing Low-Income Housing Needs. A Policy Primer. The Urban Institute.

Avellaneda, C. (2008). Municipal Performance. Does Mayoral Quality Matter? Journal of Public Administration Research and Theory, 19: 285-312.

Basolo, V. \& Hastings, D. (2003). Obstacles to Regional Housing Solutions: A Comparison of Four Metropolitan Areas. Journal of Urban Affairs. Volume 25, Number 4, 449472. 
Basolo, V. \& Nguyen, MT. (2005). Does Mobility Matter? The Neighborhood Conditions of Housing Voucher Holders by Race and Ethnicity. Housing Policy Debate. Fannie Mae Foundation. Vol. 16: 3-4, 297-324.

Bastien, J. (2009). Goal Ambiguity and Informal Discretion in the Implementation of Public Policies: The Case of Spanish Immigration Police. International Review of Administrative Sciences. Vol. 75 (4), 665-685.

Beck Jørgensen, T., \& Bozeman, B. (2007). Public Values. An Inventory. Administration $\&$ Society Volume 39 Number 3, 354-381.

Beck, P. (1996). Fighting Section 8 Discrimination: The Fair Housing Act's New Frontier. Harvard Civil Rights-Civil Liberties Law Review. Vol. 31, 155-186.

Becker, H.S (1996). The Epistemology of Qualitative Research. In Ethnography and Human Development: Context and Meaning in Social Inquiry. Edited R. Jessor, A. Colby, and R. A. Shweder. Chicago. The University of Chicago Press.

Berg, B. (2001). Qualitative Research Methods for the Social Sciences. Long Beach. Allyn \& Bacon.

Berg, A., \& Ostry, J.D. (2011). Inequality and Unsustainable Growth: Two Sides of the Same Coin? IMF Staff Discussion Note. International Monetary Fund.

Biernacki, P., \& Waldorf, D. (1981). Snowball Sampling. Problems and Techniques of Chain Referral Sampling. Sociological Methods and Research. Vol. 10. N.2, 141163.

Bingham, R. \& Kirkpatrick, S. (1975). Providing Social Services for the Urban Poor: An Analysis of Public Housing Authorities in Large American Cities. Social Service Review. Vol 49. No 1, 64-78.

Box, R. (2015). Public Service Values. New York. Routledge.

Boyne, G. \& Walker, R. (2005). Introducing the "Determinants of Performance in Public Organizations" Symposium. Journal of Public Administration Research and Theory, 15: 483-488.

Boyne, G., Meier, K., O’Toole, L., \& Walker, R. (2005). Where Next? Research Directions on Performance in Public Organizations. Journal of Public Administration Research and Theory, 15: 633-639.

Boyne, G, Meier, K., O’Toole, L., \& Walker, R. (2006). Public Service Performance. Perspectives on Measurement and Management. Editors. Cambridge. Cambridge University Press. 
Brady, K. (1993). Recertification: Navigating the "Extenuating Circumstances" and "Totally of the Circumstances" Standards. Housing Law Bulletin. Vol 45, 31-35.

Bradbury, M. \& Kellough, J. (2011). Representative Bureaucracy: Assessing the Evidence on Active Representation. The American Review of Public Administration 41(2), $157-167$.

Brewer, G. (2006). All Measures of Performance are Subjective: More Evidence on U.S. Federal Agencies. In Boyne, G, Meier, K., O’Toole, L., \& Walker, R. Public Service Performance. Perspectives on Measurement and Management. Editors. Cambridge. Cambridge University Press.

Carlson, D., Haveman, R., Kaplan, T., \& Wolfe, B. (2009). Long Term Effects of Public Low-Income Housing Vouchers on Labor Market Outcomes. Institute for Research on Poverty. Discussion Paper No. 1363-09, 1-46.

Carpenter, D. (2001). The Forging of Bureaucratic Autonomy. Reputations, Networks, and Policy Innovation in Executive Agencies, 1862-1928. Princeton, N.J. Princeton University Press.

Charmaz, K. (2006). Constructing Grounded Theory: A Practical Guide Through Qualitative Analysis. Thousand Oaks. CA. Sage Publications.

Chaskin, R. (2016). Between the Idea and the Reality: Public Housing Reform and the Further Marginalization of the Poor. School of Social Service Administration. The University of Chicago. City \& Community. Volume 15, Issue 4, 372-375.

Clifford, J. G. (1990). Bureaucratic Politics. The Journal of American History. Vol. 77. No. 1, 161-168.

Congressional Research Service (2012). The Use of Discretionary Authority in the Housing Choice Voucher Program: CRS Study.

Conners, P. (2017). Constructing Economic and Civic Values through Public Policy Debate: The Case of the National Housing Act of 1934. Michigan State University. Rhetoric and Public Affairs. Vol 20. No 3, .421-452.

Corradino, S. \& Tran, P. (2005). Public Housing Authorities as Developers: Opportunities and Challenges. Journal of Housing and Community Development, March/April, 33-39.

Cunningham, L. (2003). A Structural Analysis of Housing Subsidy Delivery Systems: Public Housing Authorities' Part in Solving the Housing Crisis. Journal of Affordable Housing \& Community Development Law, Vol. 13. No. 1, 95-121. 
Dahl, R. (1947). The Science of Public Administration: Three Problems. Public Administration Review. Vol 7. No 1, 1-11.

Dahl, R. (1994). A Democratic Dilemma: System Effectiveness versus Citizen Participation. Political Science Quarterly. Volume 109. No. 1, 23-34.

Dahl, R. (2006). A Preface to Democratic Theory. Chicago \& London. The University of Chicago Press.

De Bruijn, H. (2001). Managing Performance in the Public Sector. London and New York. Routledge. Taylor \& Francis Group.

Demir, T., Reddick, C. \& Nank, R. (2015). The Relationship between Public Service Values and Administrative Involvement in Policy Making. Public Organization Review, 15: 79-98.

Deng, L. (2007). Comparing the Effects of Housing Vouchers and Low-Income Housing Tax Credits on Neighborhood Integration and School Quality. Journal of Planning Education and Research, 27: $20-35$.

Denhardt, R. \& Denhardt, J. (2000). The New Public Service: Service Rather than Steering. Public Administration Review. Vol 60. No. 6, 549-559.

Denhardt, R. \& Denhardt, J. (2011). The New Public Service. Serving, not Steering. New York. M.E. Sharpe.

Devine, D., Gray, R., Rubin, L., \& Taghavi, L. (2003). Housing Choice Voucher location patterns: Implications for Participants and Neighborhood Welfare. Washington, DC. U.S. Department of Housing and Urban Development Office of Policy Development and Research Division of Program Monitoring and Research.

Dewitt, J., Kettl, D., Dyer, B., \& Lovan, W.R. (1994). What Will the New Governance Mean for the Federal Government? Public Administration Review. Vol. 54. No. 2, 170-175.

Eagan, J. (2006). Who Are We Dealing With? Re-visioning Citizen Subject from a Feminist Perspective. Administrative Theory \& Praxis. Vol. 28. N. 3, 381-398.

Elmore, R. (1979). Backward Mapping: Implementation Research and Policy Decisions. Political Science Quarterly. Vol 94. No 4, 601-616.

Finer, H. (1941) Administrative Responsibility in Democratic Government. Public Administration Review. Vol 1. No, 4. 335-350. 
Fischer, F. (1993). Citizen Participation and the Democratization of Policy Expertise: From Theoretical inquiry to Practical Cases. Policy Sciences. Democracy and the Policy Sciences. Vol. 26. No. 3, 165-187.

Forester, J. (1984). Bounded Rationality and the Politics of Muddling Through. Public Administration Review. Vol. 44. No. 1, 23-31.

Forester, J. (1989). Planning in the Face of Power. Berkeley. University of California Press.

Foucault, M. (1980). POWER/KNOWLEDGE: Selected Interviews and Other Writings 1972-1977. Edited by Colin Gordon. New York. Pantheon Books.

Frederickson, H.G. (1989). Minnowbrook II: Changing Epochs of Public Administration. Public Administration Review. Vol. 49. No 2, 95-100.

Frederickson, H.G. (1996). Comparing the Reinventing Government Movement with the New Public Administration. Public Administration Review. Vol 56. No 3, 263-270.

Frederickson, H.G. (1997). New Public Administration. Tuscaloosa, AL. The University of Alabama Press.

Frederickson, H., \& Smith, K. (2003). The Public Administration Theory Primer. Oxford. West View Press.

Friedrich, C. J. (1940). Public Policy and the Nature of Administrative Responsibility. Public Policy. 1, 3-24.

Galvez, M. (2010). What Do We Know About Housing Choice Voucher Program Location Outcomes? A Review of Recent Literature. What Works Collaborative.

Garshick Kleit, R. \& Page, S. (2008). Public Housing Authorities under Devolution. Journal of the American Planning Association. Vol. 74. No. 1, 34-44.

Garshick Kleit, R. \& Page, S. (2015). The Changing Role of Public Housing Authorities in the Affordable Housing Delivery System. Housing Studies. Vol 30. No 4, 621-644.

Goetz, E. (2012). The Transformation of Public Housing Policy, 1985-2011. Journal of the American Planning Association. Vol. 78. No. 4, 452-463.

Golden, M. (1998). Interest Groups in the Rulemaking Process: Who Participates? Whose Voices Get Heard? Journal of Public Administration Research and Theory. Vol 8. No. 2, 245-270.

Gomez Garcia, M. (2004). Crimenes de Odio en Estados Unidos. La Distincion Analitica entre Excluir y Discriminar. Debate Feminista. Ano 15. Vol. 29, 158-186. 
Grigsby, W. \& Bourassa, S. (2003). Trying to Understand Low-Income Housing Subsidies: Lessons from the United States. Urban Studies. Vol 40, 973-992.

Härtung, J., \& Henig, J. (1997). Housing Vouchers and Certificates as a Vehicle for Deconcentrating the Poor: Evidence from the Washington, DC Metropolitan Area. Urban Affairs Review. Vol. 32. Issue 3, 403-419.

Heckman, A. (2012). Desperately Seeking Management: Understanding Management Quality and Its Impact on Government Performance Outcomes Under the Clean Air Act. Journal of Public Administration Research and Theory, 22: 473-496.

Jackson, M.W. (1987). The Eye of Doubt: Neutrality, Responsibility, and Morality. Australian Journal of Public Administration. Volume 46. Issue 3, 280-292.

Kamensky, J. M. (1996). Role of "Reinventing Government" Movement in Federal Management Reform. Public Administration Review, Vol. 56. No. 3, 247-255.

Kernaghan, K. (1976). Politics, policy and public servants: political neutrality revisited. Canadian Public Administration. Volume 19. Issue 3, 432-456.

Kettl, D. (2005). The Global Public Management Revolution. $2^{\text {nd }}$ Ed. Washington. D.C. Brookings Institution Press.

Kim, S. (2004). Individual-Level Factors and Organizational Performance in Government Organizations. Journal of Public Administration Research and Theory, 15: 245261.

King, P. (2000). Housing Equality and Neutrality. Journal of Housing and the Built Environment, 15: 115-130.

Lee, S. \& Whitford, A. (2012). Assessing the Effects of Organizational Resources on Public Agency Performance: Evidence from the U.S. Federal Government. Journal of Public Administration Research and Theory, 23: 687-712.

Lens, M., Ellen, I., \& O’Reagan, K. (2011). Do Vouchers Help Low-Income Households Live in Safer Neighborhoods? Evidence on the Housing Choice Voucher Program. Cityscape. Crime and Urban Form. U.S. Department of Housing and Urban Development. Vol 13. No. 3, 135-159.

Levitan, D. (1942). The Neutrality of the Public Service. Public Administration Review, Vol. 2. No. 4, 317-323.

Lindblom, C. (1977). Politics and Markets. New York. Basic Books. 
Lipsky, M. (1980) Street-Level Bureaucracy. Dilemmas of the Individuals in Public Services. New York. Russell Sage Foundation.

Lowi, T. (1979). The End of Liberalism, 2nd edition. Boston: Norton.

March, J. \& Sutton, R. (1997). Crossroads-Organizational Performance as a Dependent Variable. Organization Science 8(6): 698-706.

Marini, F. (1971). Toward a New Public Administration. Scranton. Chandler Publishing Company.

Marshall, M. (1996). Sampling for Qualitative Research. Family Practice. Vol 13. N. 6, 522-526.

Marshall, C. \& Rossman, G. (2011). Designing Qualitative Research. Thousand Oaks, CA. Sage Publications.

Marr, M. (2005). Mitigating Apprehension about Section 8 Vouchers: The Positive Role of Housing Specialists in Search and Placement. Housing Policy Debate. Fannie Mae Foundation. Vol. 16. Issue 1, 85-111.

Marr, M. (2016). Urban Welfare Regimes, Organizational Cultures, and Client-Staff Tie Activation: A Comparison of Transitional Housing Programs in Los Angeles and Tokyo. Journal of Urban Affairs. Volume 38. Number 2, 214-235.

Martin, S. \& Smith, P. (2005). Multiple Public Service Performance Indicators: Toward and Integrated Statistical Approach. Journal of Public Administration Research and Theory, 15: 599-613.

Matland, R. (1995). Synthesizing the Implementation Literature: The Ambiguity-Conflict Model of Policy Implementation. Journal of Public Administration Research and Theory, Vol. 5. No 2, 145-174.

Maxwell, J. (2008). Designing a Qualitative Study. In the SAGE Handbook of Applied Social Research Methods. Edited by Bickman, L. \& Rog, D. Thousand Oaks, CA. SAGE.

Meier, K., O'Toole, L., Boyne, G., \& Walker, R. (2006). Strategic Management and the Performance of Public Organizations: Testing Venerable Ideas against Recent Theories. Journal of Public Administration Research and Theory, 17:357-377.

Meier, K., Favero, N., \& Zhu, L. (2015). Performance Gaps and Managerial Decisions: A Bayesian Decision Theory of Managerial Action. Journal of Public Administration Research and Theory, 25: 1221-1246. 
Molina, A. (2015). The Virtues of Administration. Values and the Practice of Public Service. Administrative Theory and Praxis, 37: 49-69.

Mouffe, Ch. (1993). The Return of the Political. London/New York. Verso.

Moynihan, D. (2005). What Do We Talk About When We Talk About Performance? Dialogue Theory and Performance Budgeting. Journal of Public Administration Research and Theory, 16: 151-168.

Moynihan, D. \& Andrews, M. (2010). Budgets and Financial Management. In Walker, R., Boyne, G., \& Brewer, G. Editors. Public Management and Performance. Research Directions. New York. Cambridge University Press.

Newman, S. \& Schnare, N. (1997). “... And a Suitable Living Environment”: The Failure of Housing Programs to Deliver on Neighborhood Quality. Housing Policy Debate. Fannie Mae Foundation. Vol. 8. Issue 4, 703-741

O'Hara, A. \& Cooper, E. (2003). Section 8 Made Simple. Using the House Voucher Program to Assist People with Disabilities. $2^{\text {nd }}$ Edition. Technical Assistance Collaborative, Inc.

O'Leary, R. (1994). The Bureaucratic Politics Paradox: The Case of Wetlands Legislation in Nevada. Journal of Public Administration Research and Theory, 4 (4), 443-467.

O’Toole, L. \& Meier, K. (2011). Public Management, Organizations, Governance, and Performance. New York. Cambridge University Press.

O’Toole, L. \& Meier, K. (2014). Public Management, Context, and Performance: In Quest of a More General Theory. Journal of Public Administration Research and Theory, 25: 237-256.

Overeem, P. (2005). The Value of the Dichotomy: Politics, Administration, and the Political Neutrality of Administrators. Administrative Theory \& Praxis. Vol. 27. No. 2, 311-329.

Overeem, P. (2006). In Defense of the Dichotomy: A response to James H. Svara. Administrative Theory \& Praxis. Vol. 28. No. 1, 140-147.

Peek, L. \& Fothergill, A. (2009). Using Focus Groups: Lessons from Studying Daycare Centers, 9/11, and Hurricane Katrina. Qualitative Research, 9(1): 31-59.

Pendall, R. (2000). Why Voucher and Certificate Users Live in Distressed Neighborhoods. Housing Policy Debate. Fannie Mae Foundation. Vol. 11. Issue 4, 881-910. 
Peters, G., \& Savoie, D. (1994). Civil Service Reform: Misdiagnosing the Patient. Public Administration Review. Vol. 54. No. 5, 418-425.

Rainey, H. \& Jung, C. (2010). Extending Goal Ambiguity Research in Government: From Organizational Goal Ambiguity to Programme Goal Ambiguity. In Walker, R., Boyne, G., \& Brewer, G. Editors. Public Management and Performance. Research Directions. New York. Cambridge University Press.

Rawls, J. (1973). A Theory of Justice. Cambridge. The Belknap Press of Harvard University Press.

Ringquist, E. (1995). Political Control and Policy Impact in EPA's Office of Water Quality. American Journal of Political Science. Vol. 39. No. 2, 336-363.

Rohr, J. (1986) To Run a Constitution. The Legitimacy of the Administrative State. Lawrence, KS. University Press of Kansas.

Ross, L., Shlay, A., \& Picon, M. (2012). You Can't Always Get What You Want: The Role of Public Housing and Vouchers in Achieving Residential Satisfaction. Cityscape. American Housing Survey. U.S. Department of Housing and Urban Development. Vol. 14. No. 1, 35-53.

Rowley, J. (2002). Using Case Studies in Research. Management Research News. Volume 25. Issue 1, 16-27.

Rutgers, M. \& Van de Meer, H. (2010). The Origins and Restriction of Efficiency in Public Administration: Regaining Efficiency as the Core Value of Public Administration. Administration \& Society 42 (7), $755-779$.

Sabatier, P. \& Mazmanian, D. (1979). The Conditions of Effective Implementation: A Guide to Accomplishing Policy Objectives. Policy Analysis. Vol. 5, No. 4, 481504.

Savoie, D. (1995). What is wrong with the New Public Management? Canadian Public Administration. Vol 38. No. 1, 112-121.

Semuels, A. (2015). How Housing Policy is Failing America's Poor. The Atlantic. $\begin{array}{llll}\text { Retrieved } \quad \text { May } & 2018 & \text { from }\end{array}$ https://www.theatlantic.com/business/archive/2015/06/section-8-isfailing/396650/

Shafritz, J., Ott, J., \& Jang, Y. (2005). Classics of Organization Theory (6th Ed). Belmont, C.A. Thomson-Wadsworth. 
Skowronek, S. (1982). Building a New American State. New York. Cambridge University Press.

Smith, P. (2006). Quantitative Approaches towards Assessing Organizational Performance. In Boyne, G, Meier, K., O'Toole, L., \& Walker, R. Public Service Performance. Perspectives on Measurement and Management. Editors. Cambridge. Cambridge University Press.

Snow, D., Benford, R., \& Anderson, L. (1986). Fieldwork Roles and Informational Yield: A Comparison of Alternative Settings and Roles. Journal of Contemporary Ethnography. Vol 14. N. 4, 377-408.

Stivers, C. (1995). Settlement Women and Bureau Men: Constructing a Usable Past for Public Administration. Public Administration Review. Vol. 55. N. 6, 522-529.

Svara, J. (2006). Complexity in Political-Administrative Relations and the Limits of the Dichotomy Concept. Administrative Theory \& Praxis. Vol. 28. No. 1, 121-139.

Talbot, C. (2010). Theories of Performance. Organizational and Service Improvement in the Public Domain. Oxford. Oxford University Press.

Tegeler, P., Hanley, M., \& Liben, J. (1995). Transforming Section 8: Using Federal Housing Subsidies to Promote Individual Housing Choice and Desegregation. Harvard Civil Rights - Civil Liberties Law Review. Rev. 451. Vol 30, 451-486.

The Economist, (2011). The science of justice. I think it's time we broke for lunch... Retrieved October 2016 from http://www.economist.com/node/18557594

U.S. Department of Housing and Urban Development (2013). AFFH Data Documentation. Retrieved May 2018 from https://www.huduser.gov/publications/pdf/FR-5173-P01_AFFH_data_documentation.pdf

U.S. Department of Housing and Urban Development (2013). Housing Discrimination against Racial and Ethnic Minorities 2012. Retrieved May 2018 from https://www.huduser.gov/portal/Publications/pdf/HUD-

514_HDS2012_execsumm.pdf

U.S. Department of Housing and Urban Development (2015). Housing Choice Voucher Program Administrative Fee Study. Final Report. Executive Summary. Retrieved May 2018 from https://www.huduser.gov/publications/pdf/AdminFeeStudy_2015.pdf

U.S. Department of Housing and Urban Development. Understanding Public Housing Assessment System (PHAS). Lead the Way. PHA Governance and Financial Management. A Training for Board Members and Staff. Retrieved May 2018 from 
https://www.hudexchange.info/onecpd/assets/File/PHA-Lead-the-WayUnderstanding-PHAS.pdf

Van Der Waldt, G. (2004). Managing Performance in the Public Sector. Concepts, Considerations and Challenges. Cape Town. Juta and Co. Ltd.

Van Wart, M. (1998). Changing Public Sector Values. New York \& London. Garland Publishing Inc.

Varady, D. \& Walker, C. (2000). Case Study of Section 8 Rental Vouchers and Rental Certificates in Alameda County, California. Final Report. U.S. Department of Housing and Urban Development. Office of Policy Development and Research. Prepared by: Center for Urban Policy Research Edward J. Bloustein School of Planning and Public Policy. Rutgers, the State University of New Jersey.

Varady, D. \& Walker, C. (2000). Vouchering out distressed subsidized developments: Does moving lead to improvements in housing and neighborhood conditions? Housing Policy Debate. Fannie Mae Foundation. Volume 11. Issue 1, 115-162.

Varady, D. (2010). What should housing vouchers do? A Review of the Recent Literature. Journal of Housing and the Built Environment. Dealing with Living in Poor Neighborhoods. Vol. 25, No. 4, 391-407.

Waldo, D. (1998). Bureaucracy and Democracy: Reconciling the Irreconcilable. In The Enterprise of Public Administration. Novato, CA: Chandler \& Sharp Publishers Inc.

Wang, X., Varady, D. \& Wang, Y. (2008). Measuring the Deconcentration of Housing Choice Voucher Program Recipients in Eight U.S. Metropolitan Areas Using Hot Spot Analysis. Cityscape. A Journal of Policy Development and Research. Vol. 10. No. 1, 65-90.

Walker, R., Boyne, G., \& Brewer, G. Editors. (2010). Public Management and Performance. Research Directions. New York. Cambridge University Press.

Walker, R. \& Andrews, R. (2013). Local Government Management and Performance: A Review of Evidence. Journal of Public Administration Research and Theory, 25: 101-133.

Waterman, R. \& Meier, K. (1998). Principal-Agent Models: An Expansion? Journal of Public Administration Research and Theory. Vol. 28. No. 2, 173-202.

Watkins-Hayes, C. (2009). The New Welfare Bureaucrats. Entanglements of Race, Class, and Policy Reform. Chicago. University of Chicago Press. 
Williamson, A., Smith, M., \& Strambi-Kramer, M. (2009). Housing Choice Vouchers, the Low-Income Housing Tax Credit, and the Federal Poverty Deconcentration Goal. Urban Affairs Review. Volume 45. No. 1, 119-132.

Wilson, W. (1887). The Study of Administration. Political Science Quarterly, Vol. 2. No 2, 197-222.

Yackee J., \& Yackee, S. (2006). A Bias towards Business? Assessing Interest Group Influence on the U.S. Bureaucracy. The Journal of Politics. Vol. 68, No. 1, 128139.

Yin, R. (2009). Case Study Research: Design and Methods ( $4^{\text {th }}$ Edition). Thousand Oaks, CA. Sage Publications.

Young, I.M. (1990). Justice and the Politics of Difference. Princeton, NJ. Princeton University Press. 


\section{Appendix A}

\section{Public Service Values and Disparate Outcomes: The Case of Section 8 Housing Choice Voucher (HCV) program SEMI-STRUCTURED INTERVIEW GUIDE}

To Directors, case managers and front desk public administrators (1 hour)

Interviewer:

Melissa Gomez Hernandez

Date:

Place:

Starting Time:

Interviewee/ Pseudonym:

\section{SECTION A. PUBLIC SERVICE VALUES AND ATTITUDES}

In this section, I will ask you about the public service values and attitudes that, in your opinion, you employ while implementing the Section 8 HCV Program.

Preferred Set of Values

1. In your opinion, what are the main values that guide your work at the Section 8 HCV Program?

2. Among these following values trios that I will read to you, please tell me the one that fits your work the most. Please explain your choice:

a. Efficiency, accountability \& neutrality

b. Social equity, sovereignty of the people \& participation

c. Economy, performance \& entrepreneurship

d. Control, domination \& power

2.1.If possible, please provide examples or real life experiences at the program where you have applied your preferred set of values.

2.2.Do you feel that your values' trio selection is an autonomous one? Why?

3. Case Scenario of Democratic vs. Bureaucratic values: At the end of the day you prefer:

- To adopt a lenient interpretation of the rules to ensure a satisfied household who has found a quality unit in a proper neighborhood, even if involves assisting them with the proper documentation, or recommending an acceptable rationale to justify an extension on the term of their voucher?

Or 
- Do you adopt a strict interpretation of the rules, that is, follow them by the book, don't get yourself involved in time consuming tasks or extra complications, and accomplish your aims only in accordance with the institutional guidelines?

And

- If you apply the lenient interpretation; do you do so with every applicant? Or are you lenient to certain category of applicants only? If that is the case, why?

4. Do you think your PHA's values are the same as yours? Please explain by referring and comparing within the trios already provided.

\section{Capitalization of Technical Expertise as source of Administrative Discretion}

1. How do you define political neutrality of public administrators?

2. Were you instructed about how to be impartial when serving Section $8 \mathrm{HCV}$ Program's recipients?

3. Do you consider yourself impartial in political issues and towards program recipients when executing your tasks?

4. Do you consider political impartiality of public servants reachable in real life?

5. Which criteria/instrument/value do you use to reach the most neutral possible decision?

6. Do you use your expertise and knowledge to reach the most impartial decision? Please provide examples through your experience.

7. Do you think that your expertise and knowledge on Section $8 \mathrm{HCV}$ program empowers you in front of recipients? How?

$>$ Attitudes

1. What are your thoughts and feelings about people that seek for Section $8 \mathrm{HCV}$ benefits?

2. Do you think people could do any different to avoid finding themselves applying for a voucher?

3. (Holism) In your opinion, which are the factors that take a household in need of assistance to apply for a Section 8 voucher?

4. (Flexibility) Do you implement program rules and services according to the diverse circumstances of the recipient household,

Or

Do you apply them in a uniform fashion?

5. Do you feel related in any way to the recipient's experience? Have you been in a similar situation throughout your life?

\section{SECTION B. PERCEIVED SCOPE OF PUBLIC ADMINISTRATORS'ACTIONS DURING THE IMPLEMENTATION PROCESS}

In this section, I will ask you about your perceived scope of action during the implementation phases of the Section $8 \mathrm{HCV}$ program. 


\section{General Actions}

1. Do you think that the following actions make a difference in terms of assuring Section $8 \mathrm{HCV}$ better outcomes (better quality housing and neighborhood, and higher desegregation)?

Please give time to explain those that you personally apply on a daily basis, and how do you think they impact the recipients:

- Reduction of average time for determining eligibility

- Provision of additional housing placement Counseling and assistance.

- Provision of extended time of search

- Reduction of number of requirements

- Exceptions to the payment standard What type of rationale do you typically use to grant exceptions to the payment standard?

- Increase of orientation time and frequency

- Reduction of average Months on Waiting List (per race)

- Provision of recipients additional financial assistance (move in costs/search costs)

- Reduction of approval time average in:

- Request for lease approval (RLA) form.

- Inspection of the unit.

- PHAs \& voucher holder contract submission.

\section{Funding Actions}

2. Does your program seek for alternative sources of funding such as grants and awards?

- Is this action mandatory (by HUD)?

- Why do you think it is important to seek for alternative sources of funding? And why do you and your program do it?

- Does it improve or change Section 8 performance? Please elaborate

\section{Portability Actions}

3. Let's talk about portability. Do you and/or your PHA implement these following actions?

- Explicit commitment to portability implementation

- PHAs portability collaboration/cooperation

- Assignment of specific personnel to process portability paperwork

- Existence of PHAs administrative procedures to facilitate movement of families across jurisdictions

- Voucher recipients are provided with assistance and suggestions to improve relocation

- Mobility of Section 8 Voucher recipients across PHAs jurisdictions affects administrative costs

- PHA and caseworkers' positive attitude towards portability of the program

- PHA and caseworkers have experience with portability 
- Financial and technical support by HUD in portability matters

- PHA practices absorption (of families that has exercised portability)

- Presentation of portability to recipients as a greater opportunity when moving to a new jurisdiction

- Additional procedures when implementing portability

- Briefing requirement

- Recipients may require porters to make a scheduled appointment with a portability clerk

- Recertification of recipients (recipients need to be recertified before they can use their vouchers in the county)

\section{Structural Factors}

- What would you think is the main obstacle for the Section 8 HCV Program's complete success in your area?

(Market causes, budgeting causes, family preferences, landlords' racial and ethnic discrimination, "discretionary administrative practices")

\section{SECTION C. PERCEIVED IMPACT ON POLICY OUTCOMES}

\section{Neighborhood Quality \& Unit Quality}

1. How do you think your actions help to improve Section $8 \mathrm{HCV}$ program's recipients' access to quality housing and neighborhood?

2. Which actions help the most to this aim?

3. Please provide examples if possible.

\section{Race and Poverty desegregation}

1. How do you think your actions help to improve Section $8 \mathrm{HCV}$ program's recipients' access to non-racially segregated and non-poverty concentrated neighborhoods?

2. Which actions help the most to this aim?

3. Please provide examples if possible. 


\title{
Appendix B
}

\section{INFORMATIONAL LETTER}

\section{PUBLIC SERVICE VALUES AND DISPARATE OUTCOMES: THE CASE OF SECTION 8 HOUSING CHOICE VOUCHER (HCV) PROGRAM}

\author{
To Whom It May Concern
}

Hello, my name is Melissa Gomez Hernandez. I am a Ph.D. Candidate in Public Administration at Florida International University. You have been chosen at random to be in a research study about Public Service Values and Policy Outcomes. The purpose of this study is to understand how public administrators' values and attitudes influence policy outcomes. If you agree, you will be one of 40 people in this research study. Participation in this study will take about one and a half to two hours of your time. Your consent to meet with me will involve the following: $\quad$ 1. Contact me, Melissa Gomez Hernandez, at 786448-6513 or mgome255@ fiu.edu to schedule an appointment for an interview at a time and place of your convenience. 2. During the interview, answer questions about public administrators' attitudes toward the implementation process of Section 8 Housing Choice Voucher Program. There are no foreseeable risks to you for participating in this study. A foreseeable benefit to you for participating in the study may be the resulting provision of insights to public organizations interested in the improvement of their policy outputs and outcomes. There is no cost or payment to you. If you have questions while being interviewed, you may ask and always have the option of terminating the interview. Your answers are confidential. Your identifying information (name, surname, and email) along with other records of this study will be kept private and will be protected to the fullest extent provided by law. Any resulting publication may not include any information that 
will make it possible to identify you as a participant. Researcher records will be stored securely, and only the researcher will have access to the records. If you have questions you may contact my dissertation advisor Professor Mohamad Alkadry by phone at 305348-4338 or by email at malkadry@ fiu.edu. If you would like to talk to someone about your rights of being a subject in this research study or about ethical issues with this research study, you may contact the FIU Office of Research Integrity by phone at 305-348-2494 or by email at ori@fiu.edu. Your participation in this research is voluntary, and you will not be penalized or lose benefits if you refuse to participate or decide to stop. You may keep a copy of this form for your records. 
VITA

\section{MELISSA GOMEZ HERNANDEZ}

2004

2010

2013

2017

2018

2018
B.A. in Political Science, Universidad del Cauca - Popayán (Colombia)

M.A. in Political Studies, Universidad Nacional de Colombia - Bogota (Colombia)

Fulbright - Colciencias Doctoral Scholarship

APPAM Equity \& Inclusion Student Fellowship, November 2nd to 4th, 2017

PAT-Net Fellows Program award, May 31th - June 3th, 2018

Ph.D. in Public Affairs, Department of Public Administration, Florida International University, Miami, FL

\section{PUBLICATIONS AND PRESENTATIONS}

Gomez Hernandez, M. (2018). Latin American Women in Public Service: Progress, But Not yet Equality. Book Chapter. In: Governing In a Global World: Women in Public Service. D'Agostino, Maria J. and Marilyn Marks Rubin Eds. New York: Rutledge

Gomez, M. (2012). Transphobic Violence in Bogotá. First edition. In: Serie Documentos para la Paz. Segunda Edición: Víctimas: miradas para la construcción de paz. Observatorio de Construcción de Paz Universidad Jorge Tadeo Lozano. Universidad Jorge Tadeo Lozano, Facultad de Relaciones Internacionales y Ciencias Jurídicas y Políticas/FOS COLOMBIA. ISBN 978-958-725-093-0.

Gomez, M. (2011). The Values Crisis Discourse as a Dispositive for Social Control regarding Gender, Sexual Diversity and Sexual and Reproductive Rights. In: "Comunicación, Sociedad y Crisis: Escenarios e Itinerarios Transicionales." Prólogo de Sergio Eduardo Visacovsky. ISBN 978-958-8657-05-9. INPAHU Fundación Universitaria, Facultad de Comunicación, Información y Lenguaje. Bogotá D.C. 2011

Gomez, M. (2010). Tabloids and Discrimination: Newspaper El Espacio’s Approach to Transgender Women's Body. In: Diálogo Académico: Comunicación, Medios y Sociedad Política en Colombia. Freddy Leonardo Reyes Albarracín. Compilador. ISBN 978-9588657-03-5. INPAHU Fundación Universitaria, Facultad de Comunicación, información y lenguaje. http://issuu.com/la39/docs/di_logo_acad_mico_versi_n_digital_ 
Gomez Hernandez, M. "The Toll of Environmental and organizational Factors on Policy Performance and Local Officials' Response to the Challenge." ASPA-2018 annual conference, Denver, CO. March $9^{\text {th }}, 2018$

Gomez Hernandez, M. "Dead on Arrival: Analyzing the Environmental Toll on Policy Performance: A Case Study." Southeastern Conference for Public Administration SECoPA- Hollywood, Florida. October $6^{\text {th }}, 2017$.

Gomez Hernandez, M. "When Navigating from Theory to Practice Turns Complicated: Public Service Values and Policy Outcomes. A Link?" The 30th Annual Meeting of the Public Administration Theory Network - Laramie, Wyoming. June 1 - 4, 2017

Gomez Hernandez, M. "Expertise-Founded Administrative Discretion as a Proxy for Political Neutrality: The Impact on Citizenship". Public Administration Theory Network Annual Conference - 2016 - Important Immeasurables and Public Administration Theory. May 21th 2016. San Antonio TX.

Gomez Hernandez, M. "Political Neutrality and Administrative Discretion as Expertise: Policy making Process, Citizenship and Political Outcomes." ASPA-2016 annual conference, Seattle, WA. March $20^{\text {th }}, 2016$

Gomez Hernandez, M. "Redevelopment in Black Miami: A Tale of Two Citizenships." Urban Affairs Association 45th annual meeting. Miami, Florida. April, 11 ${ }^{\text {th }}, 2015$

Gomez Hernandez, M. "Narrowed Citizenships, Vulnerability and Gentrification Policies in Developing and Developed Countries: The Comparative Case Studies of Miami's "Northern Wedge" Neighborhoods in the United States, and Barrio Getsemaní at Cartagena, Colombia." Midwest Political Sciences Association-73th annual conference. Chicago, IL. April $17^{\text {th }}, 2015$

Gomez Hernandez, M. "Lessons for Public Administration from Feminism and Critical Theories." (Coauthored with Dr. Mohamad Alkadry). ASPA-2015 annual conference, Chicago, IL. March 9th, 2015

Gomez Hernandez, M. "A Tale of Two Citizenships, or The Political Dimension of Gentrification: The Case of Miami's "Northern Wedge" Neighborhoods." ASPA—2015 annual conference, Chicago, IL. March $7^{\text {th }}, 2015$

Gomez Hernandez, M. "Economic Development, Identity, and Vulnerable Communities: The Gentrification of Barrio Getsemani at Cartagena, Colombia." Public Administration Theory Network annual conference. Miami, FL. May, $16^{\text {th }}, 2014$ 